

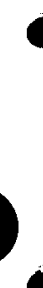

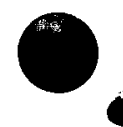

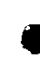

0

0 


\title{
The Hawall Geothermal Project
}

\author{
INITIAL PHASE II PROGRESS REPORT
}

February 1976

\begin{abstract}
SUPPORT FOR PROJECT PROVIDED BY:
Energy Research and Development Administration

National Science Foundation

State of Hawai i.

County of Hawai

Hawaiian Electric Company

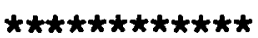

$\begin{array}{ll}\text { Management - Coordination } & \text { John W. Shupe } \\ \text { Geophysical Program } & \text { Augustine S. Furumoto } \\ \text { Engineering Program } & \text { Paul C. Yuen } \\ \begin{array}{l}\text { Environmental- } \\ \text { Socioeconomic Program }\end{array} & \text { Robert M. Kamins } \\ \text { Drilling Program } & \text { Gordon A. Macdonald }\end{array}$

$k t k t k t k t k t k t$

University of Hawaii

Holmes Hall 2402540 Dole Street

Honolulu, Hawai i 96822 
HAWAII GEOTHERMAL PROJECT

INITIAL PHASE II PROGRESS REPORT

TABLE OF CONTENTS

Page

MEMORIAL TO AGATIN TOWNSEND ABBOTT . . . . . . . . . . . i

FOREWORD . . . . . . . . . . . . . . . . . . . $i i$

OVERVIEW OF PHASE I AND PHASE II . . . . . . . . . . . . . . 1

Summary of Phase I Activity .................. 1

Summary of Phase II Activity to Date .......... . 6

MANAGEMENT - COORDINATION ................. 9

Overview of Project Management ............ 9

Director of the Drilling Program ............ 15

Drilling Consultant................. 15

Drilling Subcontract ................ 16

Dedication of HGP Well No. 1 . . . . . . . . . . . 17

Funding for HGP No. 1 and Support Programs . . . . . . . . . 19

Comments on the Drilling Program to Date . . . . . . . 19

GEOPHYSICAL PROGRAM .................. . . 22

Introduction and Summary ............... 22

Publications ................... 25

Progress Reports:

Gravity Profile and the Intrusive Zone . . . . . . . 26

Puna Magnetics ... . . . . . . . . . . . 32

Puna Seismology, May to December 1975 . . . . . . . 36

We11 Temperature Survey, May to December 1975 . . . . 39

Hydrology ................. . . 45

Physical Properties of Rocks . . . . . . . . 50

Geoelectric Surveys . . . . . . . . . . . 63

Geochemical Survey ..... . . . . . . . 70

ENGINEERING PROGRAM . . . . . . . . . . . . . . . 72

Introduction . . . . . . . . . . . . . . . . 72

Jask 3.1 Geothermal Reservoir Engineering . . . . . . . 74

Timetable .................. 74

Progress to Date . . . . . . . . . . . 76

Future Work .................. 100

References .................... 101 
ENGINEERING PROGRAM (CONTINUED)

Task 3.6 Optimal Geothermal Plant Design .......... 103

Timetable ................ 103

Progress to Date . . . . . . . . . . . 104

Future Work .................. 132

References.................. 132

ENVIRONMENTAL-SOCIOECONOMIC REPORT . . . . . . . . . . . 133

Summary ....................... 133

Task 4.1 Environmentai . . . . . . . . . . . . . 133

Task 4.2 Legal and Regulatory . . . . . . . . . . . . 135 Legal Regime for Geothermal Resources and Policy

for the ir Development.......... 135

Regulation of Geothermal Production ......... 136

Obtaining Use of Private Land as Site for

Exploratory Wel1............. . 137

Task 4.4 Economics . . . . . . . . . . . . . 137

DRILLING PROGRAM .................... . . 139

Task 5.0 Management and Support ........... 139

Introduction ............... . . 139

Drilling Management . . . . . . . . . . . . 140

Task 5.1 Drilling: Drilling Program ........... 141

Appendix I: Summary of Driliting Progress ......... . 143

Drilling from December 10-23, 1975 .......... 143

Drilling from January $1-15,1976 . . . . . . . . .144$

Drilling from January 19-February 8,1976 ....... 145

Appendix II: Testing Program .............. 148 
MEMORIAL TO AGATIN TOWNSEND ABBOTT

In late July the Hawaii Geothermal Project suffered a great loss in the unexpected death of Dr. Agatin T. Abbott, who was heading the Exploratory Drilling Program.

Ag Abbott was born in Duluth, Minnesota, on October 13, 1917, and educated at the University of Minnesota, Arizona College of Mines, and the University of Washington (Ph.D., 1953). In 1955 he became chairman of the Department of Geology at the University of Hawai, remaining such until 1965. From 1956 on, he served as a consultant to the Reynolds Mining Co. on Hawailan geology and the occurrence of bauxite in Hawaiian soils. Shortly afterward he became a consultant to the Hawaij Thermal Power Co., and in that capacity selected several sites for test drilling for geothermal energy on the Island of Hawaii, One of the wells (Thermal 2) reached a bottom hole temperature of $102^{\circ} \mathrm{C}$, but the volume of steam was very small.

When the Hawaij Geothermal Project was established in 1972, Ag was put in charge of its geological work. By 1974 several types of studies had indicated areas of geothermal interest, and in February of that year Ag was asked to serve as the Principal Investigator of an exploratory drilling program. Assisted by a committee which he appointed, Ag narrowed the choice to the east rift zone of $\mathrm{Kilauea,} \mathrm{as} \mathrm{the} \mathrm{area} \mathrm{most} \mathrm{likely} \mathrm{to} \mathrm{yield} \mathrm{fluid} \mathrm{hot}$ enough and in large enough volume to be useable for generation of electricity by present conventional methods, and in May 1975 he placed a stake in the ground at the chosen site. However, for a year his health had been deteriorating, and in June he was forced to relinquish (temporarily, we hoped) the headship of the drilling program. He died at Queen's Hospital, Honolulu, on July 31.

$\mathrm{Ag}$ is remembered with affection by his colleagues on the Project, for his capability in organizing and administering the drilling program and coordinating the geological, geophysical, and geochemical investigations, and for his cheerfulness and unfailing patience!

Gordon A. Macdonald

February 12, 1976 
HAWAII GEOTHERMAL PROJECT

INITIAL PHASE II PROGRESS REPORT

\title{
FOREWORD
}

Phase I of the Hawaii Geothermal Project (HGP) consisted of a two-year study on the potential of geothermal energy for the Big Island of Hawaii. It was primarily a geological and geophysical survey program, with supporting activity on the engineering, economic, environmental, legal, and regulatory aspects of geothermal development. One conclusion from Phase I was that an experimental drilling program was essential to verify predictions regarding subsurface conditions. Preliminary results looked sufficiently encouraging to warrant the expenditure of funds (Federal, State, private) to drill the first experimental geothermal well in the Puna area of the Big Island, and Phase II got underway.

HGP Well No. 1 was dedicated in the Hawaijan tradition on November 22, 1975. In the remarks presented at the ceremony by Dr. John M. Teem, who at that time was the top administrator for geothermal energy in ERDA--the Energy Research and Development Administration, he commented favorably on the breadth of participation in the HGP by the University, the utility company, and State, County, and Federal authorities; and was optimistic of the spinoff in technology from this project to the national geothermal effort.

Dr. Teem cautioned that ".... the outcome of this project cannot be predicted with confidence;" but that in any case "..... we see this project as filling an important void in our geothermal planning matrix." Now that we are two months into the drilling program, the attitude continues to be one of continuous optimism.

The bulk of this progress report was prepared by the program directors and their research staffs:

\author{
Geophysical Program--Augustine S. Furumoto \\ Engineering Program--Paul C. Yuen \\ Environmental-Socioeconomic Program--Robert M. Kamins \\ Drilling Program--Gordon A. Macdonald
}

The preparation of this report coincides with a joint meeting of the national and local advisory committees in Hilo, Hawaii, on February 27-28, 1976. Five ERDA officials will be in attendance, and a thorough review of the drilling program and of overall HGP objectives will be conducted. We look forward to this meeting as providing focus and direction to the future development of geothermal energy in Hawaii. 
HAWAII GEOTHERMAL PROJECT

OVERVIEW OF PHASE I AND PHASE II

SUMMARY OF PHASE I ACTIVITY

The Hawaii Geothermal Project (HGP) was organized to focus the resources of the University, the State, and the County of Hawaii on the identification, generation, and utilization of geothermal energy on the Big Island of Hawaii. Figure 1 shows the five volcanoes which form this largest island in the Hawaiian chain. Hawaii is also the youngest of the islands and is still experiencing growth from recent activity of the Mauna Loa and Kilauea volcanoes, so represents the island with the greatest amount of heat at or near the earth's surface. Consequently, the Big Island was selected as the site for initial geothermal exploration.

The research program as developed by the HGP involves an interdisciplinary team of researchers from throughout the University system which conduct scientific investigations on short-range exploratory and applied technology tasks to assist in the early development of any conventional geothermal resource -- steam or hot water -- that may exist, as well as engage in research studies of a more basic nature. The immediate objective or goal of the HGP is to encourage the development of geothermal energy in Hawai $i$ through:

1. Improvement of geophysical survey techniques for locating underground heat sources.

2. Development of efficient, environmentally clean systems for conversion of underground heat resources to useful energy.

3. Completion of socioeconomic and legal studies to assist in land use regulations and resource utilization.

4. Establishment of environmental baselines with which to monitor subsequent geothermal development.

5. Identification of potential geothermal resources, initially on the Big Island, but ultimately for the entire island chain.

A long-range objective of the HGP is to develop techniques, materials, and components for the recovery of useful energy from molten lava. The nature of the basaltic lava flows on the Big Island make this an ideal location for the study of power generation from magma. Although the focus of this study is on Hawaii's geothermal resources, both the short and longrange research programs will contribute significantly to the technology base for the recovery of energy from subsurface heat, no matter where it occurs. 


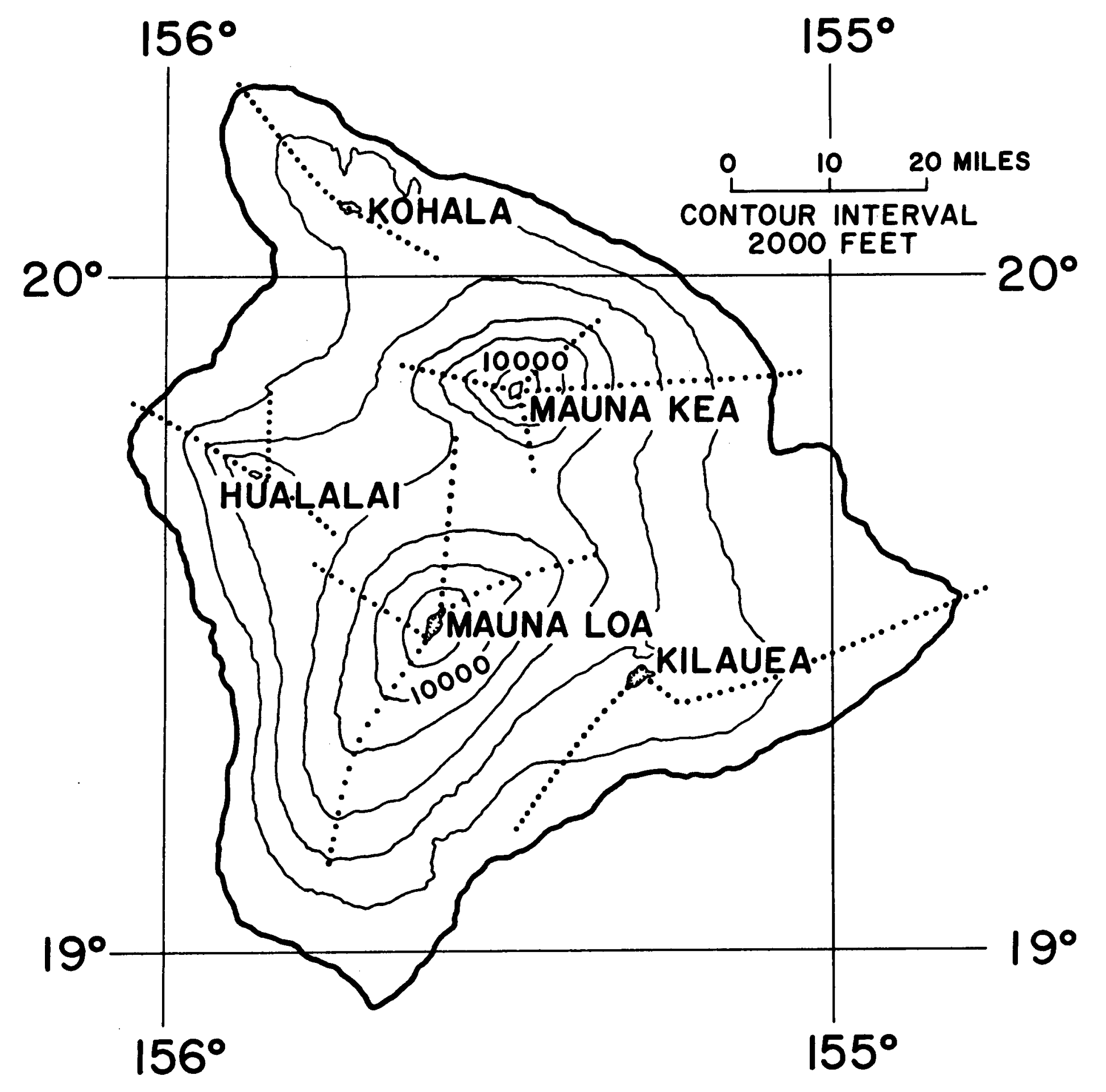

\section{VOLCANOES \& RIFT ZONES ON THE} ISLAND OF HAWAII

Figure 1 
The HGP came into being when the 1972 Hawaij State Legislature allocated $\$ 200,000$ for geothermal research -- $\$ 100,000$ to be administered through the County of Hawaii budget. This action was taken prior to the energy crisis and was a progressive step for a state governing body to take. Total support for the HGP through April 1975 was as follows:

TOTAL PHASE I SUPPORT

State of Hawaii

$\operatorname{FY}(72) \quad \$ 100,000$

County of Hawaii

$\mathrm{FY}(72) \quad 100,000$

National Science Foundation (NSF)

FY(73) $\quad 252,000$

$\mathrm{FY}(74) \quad 217,000$

NSF--Energy Research and Development Administration (ERDA)

FY(75) $\quad 119,000$

Other Public \& Private Funds

$$
\begin{array}{r} 
\\
\text { Total }
\end{array}
$$

Phase I was organized into four separate programs, encompassing the following research tasks:

Geophysical Program -- Augustine S. Furumoto

Photogeologic (Infrared Scanning) Survey

Electromagnetic Survey

Electrical Resistivity Survey

Microearthquake and Microseismic Survey

Geochemical Survey

Thermal Survey of Wells

Engineering Program -- Paul C. Yuen

Reservoir Modeling

Well Test Analysis

Ghyben-Herzberg Lens Analysis

Energy Extraction From High Temperature Brine

Environmental-Socioeconomic Program -- Robert M. Kamins

Regulatory and Legal Aspects

Land Use and Planning

Economic Analysis

Environmental Baseline Studies

Research Drilling Program -- Agatin T. Abbott 
The initial NSF grant of $\$ 252,000$ was made in April 1973; the $\$ 200,000$ of local support was released by the State and County of Hawaii a short time later; and the project got underway in the early summer of 1973. The major emphasis of Phase I was on the Geophysical Program, since the issue of if and where geothermal resources exist is crucial to the project. However, parallel studies were initiated in all supporting programs, so that progress was made in identifying and clarifying the technological, environmental, legal, regulatory, social and economic problems that could impede the development of geothermal power in Hawaii.

A consensus developed in early 1974 -- both on the basis of preliminary geophysical results and from complementary studies conducted on the Big Island over the past several decades -- that an exploratory drilling program was essential to verify the subsurface conditions predicted by the surveys. The decision to proceed with a drilling program was strongly endorsed by both the national and local advisory boards, and assistance was provided by the Hawaii Advisory Committee in obtaining an appropriation of $\$ 500,000$ from the 1974 State Legislature for exploratory geothermal drilling, contingent upon additional federal matching funds.

A Site Selection Committee was established in April 1974, chaired by Dr. Abbott, to develop recommendations for the drilling program and site selections. Initially the drilling program was planned as a series of intermediate and deep holes covering multiple sites. Subsequent negotiations with program managers from NSF, and later with ERDA, limited initial support to one research hole. Therefore, the task for the Site Selection Committee took on even greater importance.

Two additional grants were received from NSF, and these funds were used to continue the geological surveys and support programs, in accordance with the expenditure schedule listed in Table I. In April 1975 the HGP was notified by ERDA that a $\$ 1,064,000$ grant had been approved, of which $\$ 580,000$ was earmarked for the drilling program and $\$ 484,000$ allocated to geophysics, engineering, and environmental-socioeconomics. The $\$ 500,000$ of State funds was then released for the drilling program, and the Hawaitian Electric Company also contributed $\$ 45,000$ to this effort. The location recommended by Dr. Abbott and his advisory committee was established as the site for the initial research drill hole, and plans were set in motion for proceeding with HGP Well No. 1. 
TABLE I

HAWAII GEOTHERMAL PROJECT

PROGRAM PLANNING AND EXPENDITURE SCHEDULE

1.0 Management. .................

1973
.
. Hawa il Advisory Comittee .......... National Liaison Board. .............

2.0 Geophysical Coordination \& Support. ........

2.1 Photogeologic Surveys .............

2.2 Geoelectric Surveys ...............

2.3 Theoretical and Numerical Modelling, Computational Geophysics, Magnetic and Gravity Surveys. . . . .

2.4 Temperature Survey. . . . . . . . . . .

\& 2.5 Seismic Studies...............

2.6 Geochemical Surveys ..............

2.7 Hydrology .................

2.8 Physical Properties of Rocks. .........

3.0 Engineering Coordination and Support. .......

3.1 Geothermal Reservoir Engineering. .........

3.6 Optimal Geothermal Plant Design .........

4.0 Environmental-Socioeconomic Program Support ...

4.1 Environmental Aspects ..............

4.2 Legal and Regulatory Aspects. . . . . . . . .

4.3 Land-Use and Planning Aspects ..........

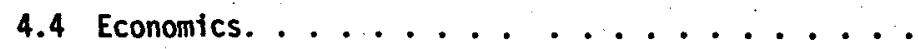

5.0 Exploratory Research Drilling Program .......

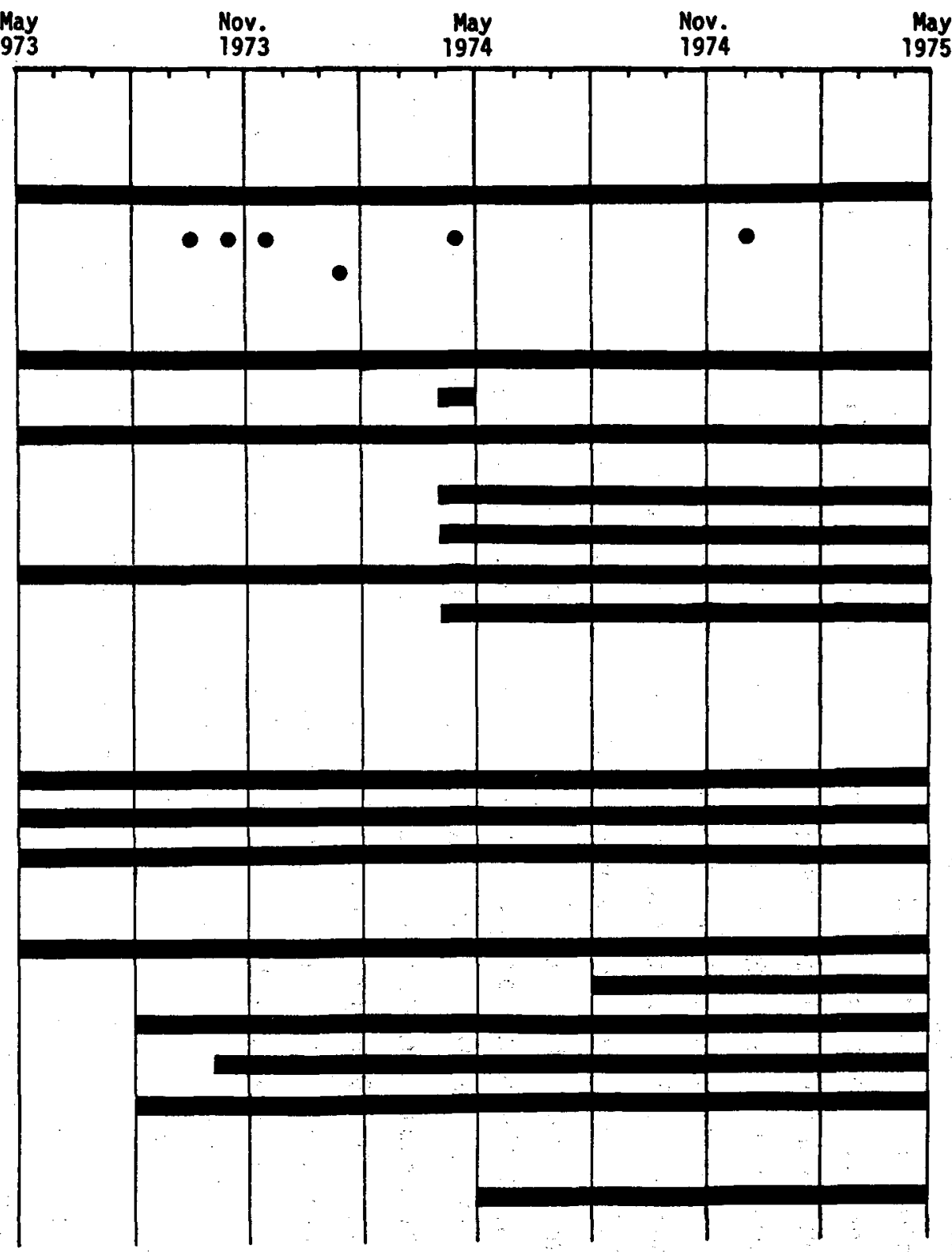

TOTAL PHASE I

ALLOCATIONS

$\$ 63,785$

93,038

23,900

123,424

44,871

27,638

109,822

24,109

66,298

50,790

11,426

9,300

17,561

10,552

*Includes $\$ 100,000$ from State of Hawait and $\$ 100,000$ from County of Hawail. 
SUMMARY OF PHASE II ACTIVITY TO DATE

May 1, 1975, was established rather arbitrarily as the beginning of Phase II. Although the majority of the research tasks of Phase I still continue and much of the geophysical data obtained earlier remained to be fully analyzed and interpreted, May 1 represented both a two-year anniversary date and the transition from NSF to ERDA funding. Therefore, it seemed an appropriate time to initiate Phase II -- the research drilling program.

Total support for Phase II to date is as follows:

Energy Research and Development Administration $\$ 7,064,000$

State of Hawai $i$

500,000

Hawaiian Electric Company

Total

$$
\frac{45,000}{\$ 1,609,000}
$$

Initial allocation of these funds provided: 1) $\$ 979,000$ for the drilling subcontract; 2) $\$ 505,000$ for the support programs -- Geophysical, Engineering, Environmental-Socioeconomic, Drilling; and 3) $\$ 125,000$ for site preparation, the drilling consultant, well-testing, and contingency.

Preliminary scheduling called for drilling to commence in early october of 1975, with completion of the well to a depth of 6000 feet by the end of the year. However, delay was encountered in resolving the drilling subcontract. Although 28 invitations to bid were sent to potential drillers located throughout the mainland United States, Hawaii, Canada, Alaska, and Australia, there was only one proposal submitted for the bid opening on July 1. This single bid came from a Honolulu firm -- Water Resources International, Inc. It was late November before the sole bid precedure was resolved and the subcontract signed. The site location in the Puna area of the Big Island was dedicated November 22 and drilling commenced December 10, 1975.

Because of limited experience within the HGP on drilling for geothermal resources -- particularly after the tragic death of Dr. Agatin Abbott, Director of the Drilling Program -- the consulting firm of KRTA of Auckland, New Zealand, was selected to assist with contract negotiations, develop a drilling plan, and supervise the drilling operation. Dr. Gordon A. Macdonald, Senior Professor of Geology and Geophysics, has served ably as the HGP representative responsible for scientific decisions regarding the drilling and sampling programs. 
Throughout the period of contract negotiations and during the first two months of drilling, parallel activity has continued in all research and support areas. In the Geophysical Program additional gravity, seismic, and electrical surveys have been conducted; water and rock samples have been collected; and analysis and interpretation of data has proceeded. The Engineering Program has expanded its earlier work on mathematical and physical modeling of geothermal reservoirs; continued with the analysis of liquid-dominated geothermal systems; and initiated studies on testing of geothermal wells. An environmental assessment statement of HGP No. 1 was prepared and baselines established for crucial environmental parameters. Economic, legal, and regulatory studies were completed and alternatives identified for the development of geothermal power in Hawaii. The Drilling Program, under the leadership of its new director, Dr. Macdonald, has provided assistance in contract negotiations, preparation of the drilling and testing programs, and scientific input to the drilling operation.

Early stages of the drilling program proceeded slowly. Tough lava flows were encountered close to the surface before much weight could be put on the bit. The initial $97 / 8$-inch drill hole to 400 feet, as well as each of the three passes required to open the hole to 26 inches, were quite time consuming. Difficulty was also encountered in maintaining circulation of drilling mud but, with liberal usage of additives, at least partial circulation was achieved throughout most of the drilling. Cementing of the 20inch surface casing to a depth of 400 feet was successfully accomplished, and drilling beyond that depth has proceeded at a reasonable rate.

Penetration below the surface casing to a depth of 1050 feet was accomplished at a drilling rate in excess of 150 feet per day, with partial circulation over the entire range. At the time of preparation of this progress report, the hole is being enlarged in two additional passes to 20 inches to allow cementing in a 13 3/8-inch anchor casing at 1000 feet.

The remaining drilling program calls for drilling and opening a hole to 2500 feet and cementing in a $95 / 8$-inch production casing. Straight drilling with an $81 / 2$-inch bit will proceed below the production casing to the desired depth of 6000 feet. Cores, temperature measurements, and water samples will be taken at appropriate intervals, and the hole will be logged twice: 1) at 2500 feet, before the production casing is installed; and 2) after drilling is completed. The proposed drilling program calls for 
a 7 5/8-inch slotted liner below the production casing, but this decision will be witheld until the opportunity exists to observe subsurface conditions at that depth -- as well as the budget status. 
THE HAWAII GEOTHERMAL PROJECT

MANAGEMENT - COORDINATION

\section{A. OVERVIEW OF PROJECT MANAGEMENT}

The Hawaij Geothermal Project involves more than forty researchers and support staff from throughout the University of Hawaii system. The two major campuses on Oahu and the Big Island are represented, along with over a dozen research institutes and academic units. Many of the State and County agencies and their staffs are directly involved in the HGP -- along with consultants from the mainland United States and New Zealand, electric utilities, engineering and drilling subcontractors. Because of its potential importance, both for the University and the State, effective coordination among the wide variety of technological, socioeconomic, and political interests at all educational, private, and governmental levels is essential. The Management Program was developed with these diverse interests in mind.

During Phase I of the HGP the Management Program provided the following: (1) coordination of activities among the research programs; (2) administrative services to assist with implementation of the research; and (3) promotional efforts at the University, State, and Federal levels to help assure adequate visibility and support for the HGP. These activities have continued during Phase II, along with the additional responsibility of administering the drilling program -- subcontract negotiations; consul tant selection and coordination; refereeing differences among the consuitant, driller, and the HGP; and monitoring drilling progress.

Figure 2 is the current organizational chart for the HGP. Principal Investigator and Project Director is John W. Shupe, Dean of Engineering at the University of Hawaii. He is aided in coordination of the HGP by Administrative Assistant Diane Sakai. There are four Co-Principal Investigators, each who is responsible for the planning and for the direct technical supervision of his research or service program, and who is assigned a separate budget for carrying out his respective program:

Geophysical Program -- Augustine S. Furumoto, Professor of Geophysics Engineering Program -- Paul C. Yuen, Associate Dean and Professor of Electrical Engineering 
HAWAII GEOTHERMAL PROJECT

ORGANIZATIONAL CHART

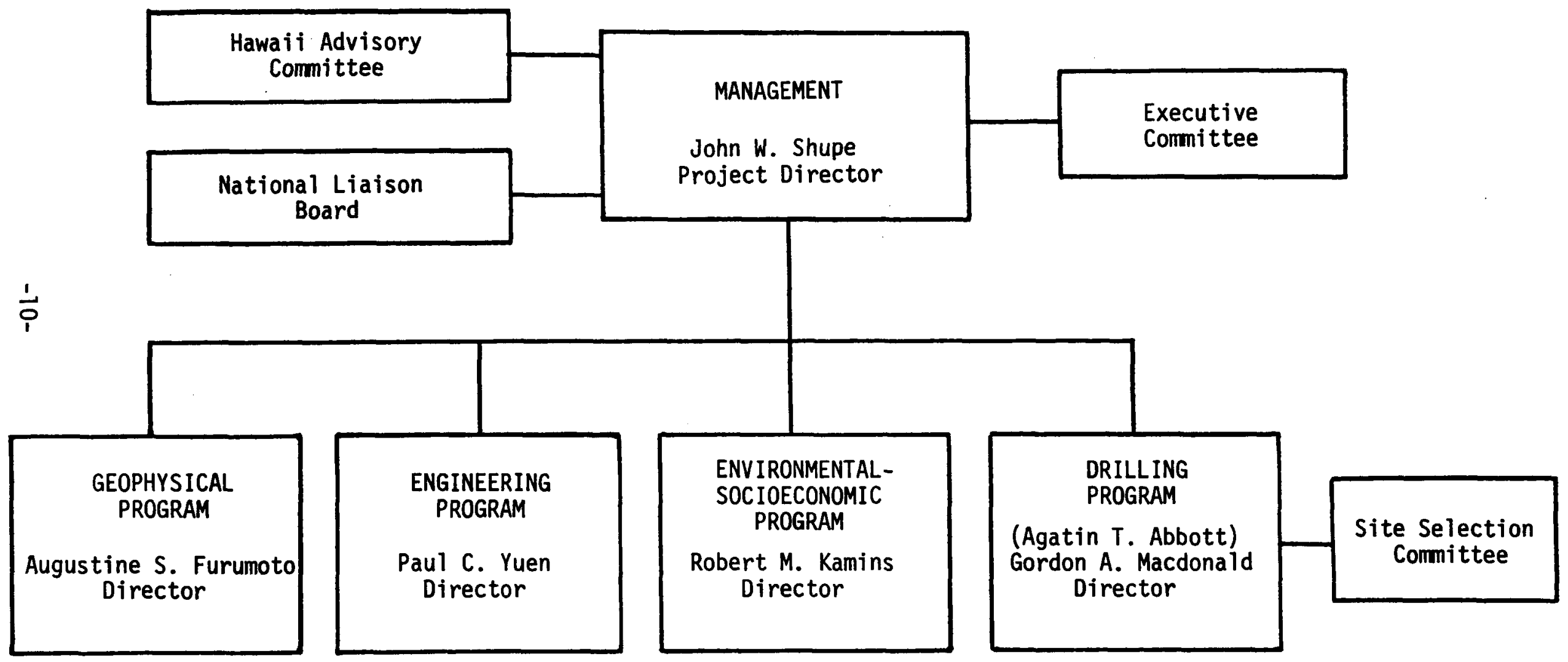

Figure 2 
Environmental-Socioeconomic Program -- Dr. Robert M. Kamins, Professor of Economics

Drilling Program -- Gordon A. Macdonald, Senior Professor of Geology and Geophysics

The HGP Executive Committee consists of the five principal investigators, plus two additional members who assist the Project Director in assuring the necessary visibility and support throughout the academic community, as well as by the governmental and private sectors: a) Dr. John P. Craven, Dean of Marine Programs at the University and Director of Marine Affairs for the State of Hawaii; and b) Dr. George P. Woollard, Director of the Hawai $i$ Institute of Geophysics and a member of the Governor's Science and Technology Advisory Committee. The Executive Committee: (1) provides technical input in establishing overall goals and objectives; (2) reviews and approves the research program developed under the leadership of the principal investigators; (3) maintains liaison essential to project support, both on and off campus; and (4) monitors progress of the project.

To assure that the HGP has both local and national relevance, systematic evaluation and advice are provided to the Executive Committee and the P.I.'s from numerous sources: a) the ERDA Program Manager and staff; b) the National Liaison Board; and c) the Hawaii Advisory Committee. The National Liaison Board (membership list attached) consists of the project leaders of other federal-supported geothermal programs, along with a few of the national leaders in geothermal research and development. The purpose of the Liaison Board is to review program progress, to exchange current information on geothermal science and technology, and to advise on future planning and implementation for the HGP. An informative evaluation session of the Board was held in February 1974, and a joint meeting of the national and the local advisory committees is scheduled for February 27-28, 1976.

The Hawaii Advisory Comittee (membership list attached) was established to provide interaction with key individuals from industry, government, and the scientific community, whose support is essential to the introduction of geothermal power in Hawaii. Serving on this committee are the Directors of the State Office of Environmental Quality Control, the Department of Planning and Economic Development, and the Department of Land and Natural Resources; the president of the major electric utility company; Director of the County of Hawaij Office of Research and Development; a cross-section of business and industrial leaders of the community; and representatives of citizen 
Mr. David N. Anderson, Geothermal Officer State of California Resources Agency Department of Conservation Division of $0 i 1$ and Gas 1416 Ninth Street, Room 1316-35 Sacramento, California 95814

Mr. Ritchie B. Corye 11, Program Manager Advanced Geothermal Energy Research \& Technology National Science Foundation 1800 G. Street, N.W. Washington, D.C. 20550

Dr. George V. Keller, Professor Geophysics Department Colorado School of Mines Golden, Colorado 80401

Dr. Paul Kruger

Professor of Civil Engineering

School of Engineering

Stanford University

Stanford, California 94305

Dr. James T. Kuwada

Rogers Engineering Company, Inc.

111 Pine Street, Sixth Floor

San Francisco, California 94111

Dr. Henry J. Ramey, Jr.

Professor of Petroleum Engineering

School of Earth Sciences

Stanford University

Stanford, California 94305
Dr. Robert W. Rex, President Republic Geothermal, Inc.

11823 East Slauson Avenue, Suite One

Santa Fe Springs, California 90670

Dr. John C. Rowley University of California Los Alamos Scientific Laboratory Post Office Box 1663

Los Alamos, California 87545

Dr. Donald H. Stewart

Battelle Pacific Northwest Laboratories

Post Office Box 999

Richland, Washington

99352

Dr. Louis B. Werner

Assistant Director for Resource Utilization

Division of Geothermal Energy

Energy Research and Development Administration 20 Massachusetts Avenue, N.W. Washington, D.C. 20545

Dr. Donald E. White Geothermal Research Program U.S. Department of the Interior Geological Survey, Branch of Field Geochemistry and Petrology 345 Middlefield Road Menlo Park, California 94025 
Ms. Sophie Ann Aoki

Life of the Land (Environmental Program)

404 Piikoi Street, Suite 209

Honolulu, Hawai i 96814

Mr. Christopher Cobb

Chaiman of the Board

Department of Land and Natural Resources

State of Hawaii

Post Office Box 621

Honolulu, Hawaii 96809

Mrs. Alma Cooper

President

Congress of the Hawaiian People

163 Kaiulani Street

Hilo, Hawaii 96720

Dr. John P. Craven

Dean

Marine Programs

University of Hawaii

Holmes Hall 401

Honolulu, Hawai i 96822

Mr. Robert F. Ellis

President

Chamber of Commerce of Hawai $i$

Dillingham Transportation Building

Honolulu, Hawaii 96813

Mr. Clarence W. Garcia, Director

Department of Research and Development

County of Hawaij

25 Aupuni Street

Hilo, Hawai 96720

Dr. Eugene M. Grabbe

Manager

Hawai i Geothermal Energy Policy Project

State Department of Planning and

Economic Development

Post Office Box 2359

Honolulu, Hawai i 96804

$\mathrm{Mr}$. Robert $\mathrm{H}$. Hughes

Senior Vice President

C. Brewer and Company, Ltd.

Post Office Box 3470

Honolulu, Hawaij 96801
Mr. Hideto Kono, Director

Department of Planning and Economic Development

State of Hawaii

Post Office Box 2359

Honolulu, Hawaif 96804

Dr. Richard Marland, Director

Governor's Office of Environmental Quality Control

550 Halekauwila Street, Third Floor Honolulu, Hawaii 96813

Mr. Herbert T. Matayoshi

Mayor

County of Hawai i

25 Aupuni Street

Hilo, Hawai 96720

Dr. Howard P. McKaughan

Director of Research

University of Hawaii

Spalding $\mathrm{Hall} 360$

Honolulu, Hawaij 96822

Dr. Edwin H. Mookini

Acting Chancellor

University of Hawai - Hilo Campus

1643 Kilauea Avenue

Hilo, Hawaii 96720

Mr. Herbert M. Richards, Jr.

Board of Regents

University of Hawai i

Box 837

Kamuela, Hawaij 96743

Dr. Robert I. Tilling

Scientist-in-Charge

Hawaiian Volcano Observatory

U.S. Geological Survey

Hawai National Park, Hawaij 96718

Mr. Carl H. Williams, President

Hawaiian Electric Company

Post Office Box 2750

Honolulu, Hawaij 96803

Dr. George P. Woollard, Director

Hawaii Institute of Geophysics

University of Hawaii, HIG 137

Honolulu, Hawai 96822 
groups. This committee meets semi-annually and supplements the Executive Committee in providing the necessary visibility for the HGP, both on and off campus, to assure public and private support for geothermal power in Hawai i.

Close liaison has been maintained with all four congressional delegates, who are kept well informed on progress of the HGP. Excellent support, information, and advice are provided by our congressional delegates on any shifts in organizational structure and funding philosophy of federal agencies.

Local interest in the HGP has been high. Encouragement, endorsement, assistance, and/or interaction has taken place with the following organizations, many of whom are represented on the Advisory Committee:

State Departments and Offices

Department of Planning and Economic Development

Department of Land and Natural Resources

Department of the Attorney General

Office of Energy Resources

Office of Science Policy

Office of Marine Affairs

Office of Environmental Quality Control

State Task Force on Energy Policy

County of Hawai i

The Mayor's Office

Department of Research and Development

Hawai i County Council

Electric Utilities

Hawaiian Electric Company (Honolulu)

Hawaii Electric Light Company (Hilo)

Business and Industrial Concerns

Bishop Estate

Campbe 11 Estate

C. Brewer and Company, Ltd.

Pacific Resources, Inc.

Water Resources International

Honolulu Chamber of Commerce

Hilo Chamber of Commerce

Geothermal Exploration and Development Corporation 


\section{B. DIRECTOR OF THE DRILLING PROGRAM}

Dr. Agatin T. Abbott, Director of the Drilling Program, died on July 31, 1975, following a short illness. Dr. Abbott's contribution to the HGP, as well as to the overall understanding of the geology of Hawaij, has been significant. A memorial to Dr. Abbott, prepared by Dr. Gordon Macdonald-Senior Professor of Geology and Geophysics, appears as the first page of this progress report.

Dr. Macdonald agreed to help fill the appreciable void created by Dr. Abbott's untimely death and began to serve immediately as Co-P.I. and Director of the Drilling Program. The HGP is most fortunate to have a scientist of his stature, ability, and interest ready and willing to assume this key role.

Dr. Macdonald took sabbatical leave during the fall semester to provide full-time scientific supervision to the drilling of HGP Well No. 1. Unfortunately, the delay in the starting date did not permit him to remain on the Big Island for the entire drilling operation. Once classes for the Spring semester began on January 19, Dr. Macdonald returned to the Manoa Campus on Oahu. However, Mr. Daniel Palmiter, a doctoral candidate of Dr. Macdonald in geology, remained on the Big Island and is in close and frequent telephone communication with Manoa. In addition, either Dr. Macdonald or Project Director John Shupe visits the drilling site at least once a week.

C. DRILLING CONSULTANT

The firm of Kingston, Reynolds, Thom, \& Allardice, Ltd. (KRTA) of New Zealand was selected to provide direction and supervision to the drilling program. KRTA has had extensive experience with geothermal drilling in New Zealand, the Philippines, and Central America. The firm was first recommended to the HGP by Mr. Ken Brunot, who served at one time as NSF program manager for the HGP and was well aware of the limited geothermal experience of project staff. Extensive investigation by Dr. Shupe at the U.N. Geothermal Conference in San Francisco in May confirmed Mr. Brunot's evaluation, and an agreement was reached with Mr. R. Kingston, Managing Director of KRTA, for his firm to provide geothermal consulting services.

As noted in the KRTA brochure:

"For geothermal projects, by arrangement with the New Zealand Government, KRTA has the support and backing of the Ministry of Works \& Development and the Department of Scientific \& Industrial Research. Where necessary the Ministry of Works makes available 
geothermal engineers and equipment, while the DSIR provides geophysicists, geochemists, geologists and chemical engineers. Many of these specialists, in addition to their extensive experience in New Zealand, have carried out overseas assignments on geothermal projects for United Nations and other clients."

Mr. Kingston made his first two consulting tours, totaling nine working days in Hawaii, in July and September. In addition to conferring with all HGP principals on the drilling and testing programs, he spent a great deal of time in negotiating with WRI on the drilling subcontract and in providing advice on the selection and acquisition of appropriate drilling equipment and supplies. He has made two subsequent trips to Hawaij to consult on problems encountered, first in the final stages of subcontract negotiations and second as drilling got underway.

KRTA's man on the job is Warwick J. Tracey, coming to this project with drilling experience on KRTA projects in New Zealand and the Philippines. In his role as drilling supervisor, he works with Dr. Macdonald in providing guidance and direction to the drilling operation, and assures that the University's interests are best served. In addition, KRTA arranged for the geothermal drilling supervisor for the New Zealand Ministry of Works to spend a week in Hawai i en route to the Philippines to discuss high temperature drilling operations with the drilling contractor. KRTA also has sent one of its technicians to Hawai to train HGP personnel on the use of downhole test equipment and interpretation of data.

\section{DRILLING SUBCONTRACT}

Invitations to bid were sent to 28 potential drillers in the mainland U.S. and throughout the Pacific area in early June, with bid documents to be opened July 1, 1975. The only bid submitted was from Water Resources International (WRI) of Honolulu, the firm which drilled the 4137-foot hole for Dr. George Keller in the Hawaii National Park. The University, after thorough review of the bid and upon the favorable advice of KRTA, recommended that it be approved, so that WRI could begin to mobilize for the Project. Unfortunately, the University Procurement Office and the ERDA Contracts Office experienced difficulty in resolving differences in contract philosophy involving the three bureaucracies--University, State of Hawaii, ERDA-as well as in coming to agreement on what constituted acceptable evaluation of a single bid. 
Following four months of negotiations, including a special trip from New Zealand by Mr. Kingston to meet with federal auditors, approval was obtained for finalizing the subcontract in mid-November. The drilling site was dedicated on November 22, 1975, and drilling commenced December 10.

Both WRI and the HGP took a certain amount of risk in assuming that the subcontract would ultimately be resolved. WRI proceeded with the purchase and mobilization of a new drilling rig, as well as acquisition of many key items of equipment and supplies. Since neither Federal nor State funding could be utilized until the contract was signed, effective use was made of the $\$ 45,000$ from Hawaiian Electric Company for site preparation and other key expenditures. Had these actions been delayed until the subcontract was finalized, the well would not be spudded in yet.

E. DEDICATION OF HGP WELL NO. 1

The culmination of over three years of planning and preparation for an experimental geothermal well was, realized on November 22, 1975, with the dedication and blessing--in the Hawaiian tradition--of HGP Well No. 1. An outline of the impressive dedication program follows:

Presiding, John W. Shupe, HGP Director

REMARKS BY DR. JOHN M. TEEM Energy Research and Development Administration, Washington, D.C.

STATE INTEREST IN GEOTHERMAL ENERGY Hideto Kono State Energy Resources Coordinator

COUNTY INTEREST IN GEOTHERMAL ENERGY Mayor Herbert T. Matayoshi

DEDICATION OF HGP WELL NO. 1 Reverend David Kaapu Haili Church

IN MEMORIAM -- Agatin T. Abbott Dr. Gordon Macdonald

Over seventy people, including many of the business and political leaders of the State and County of Hawaii, attended the ceremony. Dr. Teem.'s remarks (included in their entirety on the following page) were particularly well received by those in attendance. 


\author{
DEDICATION OF THE \\ HAWAII GEOTHERMAL PROJECT WELL NO. 1 \\ NOVEMBER 22, 1975
}

Remarks by Dr. John M. Teem, Assistant Administrator for Solar, Geothermal, and Advanced Energy Systems -- United States Energy Research and Development Administration:

The drilling project we are dedicating today has particular significance, both to the State of Hawaii and to the national Geothermal Development Program. It is for these reasons that I am especially interested in this project and grateful for the opportunity to be present at this dedication.

The State of Hawaii has taken progressive and constructive steps to deal with your energy problems. In your Economic Development Plan and in your State Energy Plan you have recognized the desirability of exploring several alternative approaches, rather than depending on simplistic solutions. I am pleased that geothermal energy is included among the high priority alternatives you are considering. At the same time, I congratulate you for demonstrating the wisdom of pursuing a balanced program that is based on your particular needs and resources, as well as a realistic assessment of potential. Your recent conference on alternative energy sources for the State of Hawai $i$ has established a pattern that other states might fruitfully emulate.

From the perspective of our Federal geothermal development program, this project exemplifies both our hopes and our uncertainties. We are quite confident that geothermal energy offers a fruitful approach to reducing our dependence on costly imported fuels by substituting currently under-utilized domestic resources. In partnership with the States and with industry, ERDA believes the technologies can be developed for widespread exploitation of our indigenous geothermal resources. We are appreciative of the collaboration in this project of the university, the utility company, and State, County, and Federal authorities.

We are also aware that the outcome of this project cannot be predicted with confidence. We in ERDA have had no previous experience in a comparable environment, and therefore we see this project as filling an important void in our geothermal planning matrix. It will help us to understand better the nature of volcanic environments and their potential for geothermal development. Whether we find a hydrothermal reservoir, a magmatic resource or some other form of geothermal energy, or even if the results are negative, we will have improved our understanding of geophysical phenomena and our ability to correlate surface data with our subsurface findings. This information will be useful far beyond the shores of these islands.

These feelings of combined hope and anticipation, within a framework of cooperative endeavor, characterize the geothermal program at today's early stage, and we look forward with you to the advances in technology this project may offer. 
F. FUNDING FOR HGP NO. 1 AND SUPPORT PROGRAMS

Initial distribution of the total $\$ 1,609,151$ funding for Phase II (ERDA - \$1,064,151; State - \$500,000; Hawaiian Electric Company - \$45,000) was made as follows:

\begin{tabular}{lrr} 
Drilling Subcontract & $\$ 979,000$ \\
Research and Support Programs & & \\
Management & $\$ 30,877$ & \\
Geophysics & 237,977 & \\
Engineering & 155,792 & \\
Socioeconomic-Environmental & 59,412 & \\
Drilling Support & 21,093 & 505,151 \\
Consulting \& Drilling Supervision & 40,000 \\
Site Preparation \& Preliminary Expenses & 35,000 \\
We1l Testing \& Contingency & 50,000 \\
\hline
\end{tabular}

A fiscal summary of the drilling subcontract through February 13, 1976, is presented as Table II (attached as the following page). The first column of figures represents the initial estimate of the amount required for each of the work categories to complete the well to $6000 \mathrm{feet}$, including $\$ 100,000$ for contingency. The second column lists the amount encumbered in each category to date. The final column shows the amount left in each budget category, as of February 13, 1976.

G. COMMENTS ON THE DRILLING PROGRAM TO DATE

The drilling subcontract was standard with respect to payment based upon drilling time expended, rather than upon depth of penetration. Water Resources International, Inc. (WRI) estimated a daily drilling rate, averaged over the 6000 feet depth, of 100 feet per day--or 60 days drilling time to complete the wel1. This appeared to be a reasonable estimate in view of the fact that the only other deep well for geothermal exploration completed in a similar geological area in Hawaij had been the 4137-foot well, also drilled by WRI for Dr. George Keller in 1973. A total of 1,022 hours, or approximately 42 days, was required for the total drilling and coring operation for the Keller well.

Although it was recognized that the casing program stipulated by KRTA in its recommended drilling program was more involved and would require both a larger number of hole-opening passes and a greater amount of cementing than the Keller well, it was estimated that this would be balanced by a better 


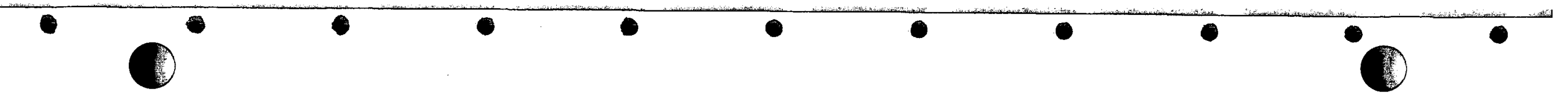

TABLE II - FISCAL SUMMARY OF THE DRILLING SUBCONTRACT

THROUGH FEBRUARY 13, 1976

CONTRACT ESTIMATE INVOICED AMOUNT UNENCUMBERED BALANCE

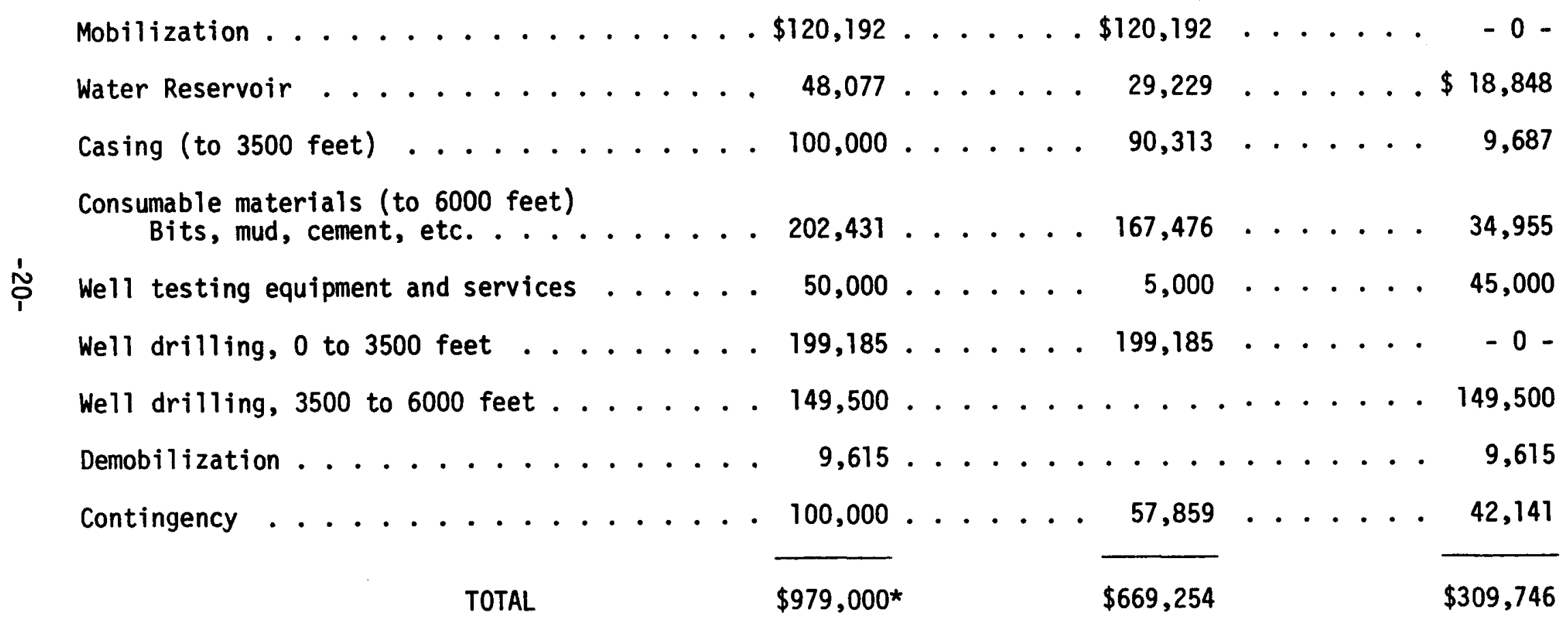


drilling rig and the opportunity to improve the average rate during the bottom 3500 feet, after all hole-opening and cementing operations were completed.

From the very beginning drilling has been difficult. The first day, only two feet of hole was drilled in a very dense rock formed by a fresh basalt lava flow. Both the hardness of the rock and the limited load that could be put on the bit caused a slow rate of penetration in the upper 400 feet. The fact that each opening of the hole to $151 / 2,20$, and 26 inches encountered this dual condition of tough rock and limited weight on the bit, compounded the problem.

Midway through the 20-inch opening pass, after it became quite apparent that the drilling was running far behind schedule, Dr. Shupe called Mr. Kinston to request a review of the necessity of the 20-inch surface pipe and to ask for approval to proceed directly with drilling and cementing in the $133 / 8$-inch anchor casing at 1000 feet. Mr. Kingston, after conferring with both his KRTA staff and that of the Ministry of Works, reported that it was their strong consensus that the 20 -inch casing was essential if there was any likelihood of encountering a geothermal resource. Therefore, the third laborious opening to 26 inches was completed; the hole was reamed; the 20-inch casing, after some difficulty with sticking at 103 feet was overcome, was run in; cementing was successfully completed; and blow-out preventers installed. A total of fourteen working days were required to open the 400 -foot hole from 20 to 26 inches and install the surface casing.

Drilling with the $97 / 8$-inch bit from 400 to 1050 feet progressed rapidly, with the best day's run exceeding 300 feet. There was maximum weight on the bit and no significant thicknessess of hard dense rock encountered. However, the hole-opening passes have gone much slower. Unless additional delays are encountered, by the time of the meeting on February 27-28 with ERDA staff and the HGP advisory committees to review drilling progress, the 1000-foot anchor casing should be installed and drilling should be progressing below that point. 
HAWAII GEOTHERMAL PROJECT

GEOPHYSICAL PROGRAM

A. S. Furumoto

As the geophysical surveys carried out during Phase I of the Hawaii Geothermal Project was far from being satisfactory to give a proper understanding of the thermal and hydrothermal profile of the East Rift of Kilauea, geophysical field surveys were continued during Phase II of the project. Also of importance was further data analysis and interpretation of the surveys that were carried out during Phase I. It should be emphasized here that the field surveys are far from being complete at the time of this report writing as there are several important surveys still to be carried out and as the interpretations of available data have not reached satisfactory conclusions.

The field work carried out during the first half of Phase II were gravity surveys, collection of water samples from Puna wells, collection of rock samples for physical analysis. The details concerning these surveys are mentioned in the report of the individual tasks. Two other surveys, the electrical and seismic surveys were supposed to have been carried out, but because of difficulty in debugging the instruments, the surveys have not gone to the field as yet. The surveys will be carried out during the early part of January 1976.

The analysis of data from surveys of Phase I has also progressed smoothly. The results of further interpretation of the magnetic data are given in the magnetic task report. A few more results from the interpretation of the seismic data are given in the seismic section. The electrical surveys did not concentrate on interpretation as the people involved in the task were busy debugging the instruments.

The gravity surveys gave us a better picture of the subsurface structure of the intrusive zone under the east rift of kilauea. The first attempt at interpretation of the gravity data indicates that the intrusive zone under the Kilauea east rift has a width of $4 \mathrm{~km}$ on the western side of the Puna and then fans out into a width of $6 \mathrm{~km}$ on the eastern side. The zone extends from a depth of $0.9 \mathrm{~km}$ to $1.9 \mathrm{~km}$. The analys is was based on the assumption of $0.6 \mathrm{~g} / \mathrm{cm}^{3}$ density contrast. If lesser density contrast is assumed, the size of the intrusive zone would be larger but at a shallower depth. However, the assumption of $0.6 \mathrm{~g} / \mathrm{cm}^{3}$ 
gave us dimensions of the intrusive zone which agree very well with the topographic features.

The thing to note in the gravity data and its resulting interpretation is that there is a bottom to the intrusive zone. The picture evolving here is that of a conduit through which the lava or magma from the central vent migrates out to the rift zone. The conduit is not a large cavern; it is made up of a series of vertical thin dikes, an inference drawn from our knowledge of dikes exposed by erosion in ancient volcanoes. The dikes are probably at most $5 \mathrm{~m}$ in width. Hence during eruptive activity, magma from the reservoir chamber in the central area migrates rapidly through underground cracks which are no more than $5 \mathrm{~m}$ wide and 1-2 km high to erupt along the rift zone. The viscosity of the magma must be low, about $10^{4}$ cgs.

The analysis of magnetic survey gave us an indication of the thermal structure of the rift zone. It seems that for the most part the rocks in the intrusive zone have temperatures below the Curie Point, which for Hawaiian basaltic rocks varies from about $360^{\circ} \mathrm{C}$ to $400^{\circ} \mathrm{C}$. Only one section in the rift zone was characterized by a magnetic low which may mean that the subsurface rocks in that area may be above Curie Point. That section exists under the resort development known as the Leilani Estates. If a deposit or pocket of hot rock above Curie temperature is sought, then the most probable place will be right in the middle of Leilani Estates.

The hydrology task was able to analyze the water samples from numerous wells in the Puna area. The data show that all of the water samples have had a short life, at most of a few years. The implication of the data is very important. It means that the young water around the selected drill site must have evolved from a rather rapidly convecting unconfined aquifer. It also implies that the hydrothermal behavior near the selected drill site resembles very closely the unconfined aquifer picture as obtained by Keller at the drill site in Kilauea caldera.

The temperature profile of the water column in Geothermal Well 3, as reported previously, showed a hot water layer of only $5 \mathrm{~m}$ thickness. The chemical analysis of water samples showed that the salinity in the hot water layer is much higher than the salinity in the lower colder layer. These facts put together mean that convective motion is proceeding so rapidly that very little mixing takes place. A further inference is that the permeability of the rocks in the region is very high.

The laboratory studies carried out by the physical properties task show that the behavior of electrical properties of fluid filled porous rocks followed 
closely Archie's law as found by many other investigators. Hence we can be certain that the values of temperature arrived at in our previous reports are reliable. An estimate of the temperature of the water in the low resistivity area in Puna has been set at about $140^{\circ} \mathrm{C}$.

During the remainder of the grant period, the geophysical program will mount the following field surveys:

Electrical resistivity surveys to outline the boundaries of low resistivity area;

Seismic refraction surveys to outline definitely the top of the intrusive zone;

Temperature profile on the wells to see whether groundwater was disturbed by the earthquake of Nov. 29, 1975.

On Nov. 29, 1975 an earthquake of magnitude 7.2 rocked the Puna area. The epicenter of the earthquake has been located right about where Kaimu Beach is located. Some of the associated macroscopic phenomena observed have been the subsidence of the sea shore along Puna area and cracks along highways. As subsidence changes the gravity picture in the area, gravity surveys will be redone over the area. Also magnetic survey will be done to detect any subsurface heating. As groundwater certainly changes its character from a large earthquake the temperature in the various wells will also be measured.

At the present writing of this report, the Phase II program is only at its mid-stage. Before the end of the grant period we hope to have a rather complete picture of the subsurface parameters in the Puna area. The disturbance caused by the earthquake of Nov. 29, 1975 is a welcomed phenomena as far as geophysicists are concerned. As we had much data before the earthquake, we can compare data before and after the earthquake to see how a large earthquake disturbs geophysical parameters. This opportunity is something that was unexpected but an unusual one, where definite contributions to basic seismology can be made. 


\section{Publications}

year:

The following articles have seen the light of publication during the past

(1) Douglas P. Klein and J.P. Kauahikaua, 1975. Geoelectric-Geothermal Exploration on Hawaij Island: Preliminary Results. Hawaii Institute of Geophysics Report 75-6.

(2) Augustine S. Furumoto, 1975. A Coordinated Exploration Program for Geothermal Sources on the Is land of Hawaii. Second United Nations Geothermal Energy Symposium, Proceedings. San Francisco.

(3) Augustine S. Furumoto, 1976. Hawaij-to no Jinetsu Chosa (Geothermal Exploration on the Island of Hawaij), Journal of the Japan Geothermal Energy Association. In Press.

(4) McMurtry, G.M. and Fan, Pow-foong, 1974. Geochemistry of a potential geothermal area - Puna Rift zone of the Island of Hawai (Abstr), EOS Trans. Am. Geophy. Un., v. 56, p. 1199.

(5) Druecker, M. and Fan, Pow-foong, 1976. Hydrology and geochemistry of groundwater in Puna, Hawaii. Ground Water (Manuscript submitted).

The following papers were presented at national level meetings:

(1) Wayne Suyenaga and A.S. Furumoto, June 1975. Microearthquake Study of the East Rift Zone of Kilauea, Puna, Hawai.i. Paper presented at the annual meeting of American Geophysical Union, Washington, D.C.

(2) Augustine S. Furumoto, August 1975. "Geothermal Exploration in Hawaii" Invited lecture to Japan Geothermal Energy Association. Tokyo, Japan.

(3) Augustine S. Furumoto, October 1975. "A Systematic Program for Geothermal Exploration on the Island of Hawaij" Invited paper at Geothermal Symposium, Annual International Meeting of the Society of Exploration Geophysicists, Denver, Colorado.

(4) Augustine S. Furumoto, November 1975. "Additional Data on the Seismicity of Hawaij" Annual Meeting of the Eastern Section, Seismological Society of America, St. Louis, Mo. 


\section{Progress Report}

\section{GRAVITY PROFILE AND THE INSTRUSIVE ZONE}

\section{A.S. Furumoto, R. Norris, M. Kam, and C. Fenander}

From June 26th through June 29, 1975 a gravity survey in the Puna district was carried out by four members of the Hawai institute of Geophysics of the University of Hawaij. The instruments used were La Coste Romberg gravity meter and a Worden gravity meter. Over a hundred stations were taken with an average grid spacing of $0.5 \mathrm{~km}$. As there are numerous benchmarks and survey markers along highways the elevations for the gravity survey were determined by using topographic maps.

The gravity data were corrected with the standard methods. Terrain corrections accounted for both topography and ocean mass. The resulting Bouger anomaly map is shown in Figure 1.

A "first cut" attempt at gravity interpretation was done by taking a profile across the gravity map as shown by Lines $A A^{\prime}$ and $B^{\prime} B^{\prime}$ in Figure 1. Using the approximation methods as proposed by Skeels (1963), the subsurface structure of the anomalous body was obtained as shown in Figures 2 and 3 . In the analysis it was assumed that the anomalous body is a horizontal, rectangular prism and that the density contrast of this anomalous body with respect to the neighboring rocks is $0.6 \mathrm{~g} / \mathrm{cm}^{3}$.

Along $B B^{\prime}$ the dike complex is $4 \mathrm{~km}$ wide and $1 \mathrm{~km}$ thick, while at $A A^{\prime}$ it is $6 \mathrm{~km}$ wide and $0.6 \mathrm{~km}$ thick. At both places the top of the dike complex or intrusive zone of the anomalous body is one $\mathrm{km}$ below sea level.

This anomalous body was interpreted as an intrusive zone through which magma from the central magma chamber migrated to the rift zone. The instrusive zone is not a large cavernous conduit but it is made up of a whole series of vertical parallel dikes. Each dike is probably at the most $5 \mathrm{~m}$ in width as seen in ancient volcanoes that have been exposed by erosion. During an eruptive activity the cracks open up in the subsurface and through these cracks highly fluid magma move down into the rift zone to erupt along the various vents. The viscosity of the magma or the lava has been calculated to be about $10^{4}$ CGS.

Even from the "first cut" attempt at analysis we have obtained a good picture of the dike complex or the intrusive zone. We notice that the intrusive zone fans out at about a kilometer or so West of Line $A A^{\prime}$. The reason this happened is that about there the flanks of the Mauna Loa cease. The east rift zone has been formed against the flank of Mauna Loa for a greater part and because of the 
constraints of the flank the intrusive zone in the eastern part of the rift tend to be narrow. Once the constraint of the Mauna Loa flank has been passed, the intrusive zone can fan out and spread into wider area. This has been shown by the $6 \mathrm{~km}$ width of the intrusive zone at Line $A A^{\prime}$.

For a more sophisticated analysis of the gravity data, spatial harmonic analysis of the gravity data has been attempted. Figure 4 shows one attempt at programming the data into what is called the SYMAP form. The resolution of this SYMAP format into its harmonic component is now progressing.

\section{Reference}

Skeels, D.C. (1963). An Approximate Solution of the Problem of Maximum Depth in Gravity Interpretation, Geophysics, Vo1. 28, pp. 724-735. 



\section{Bouguer Anomaly, Profile $A A^{\prime}$}

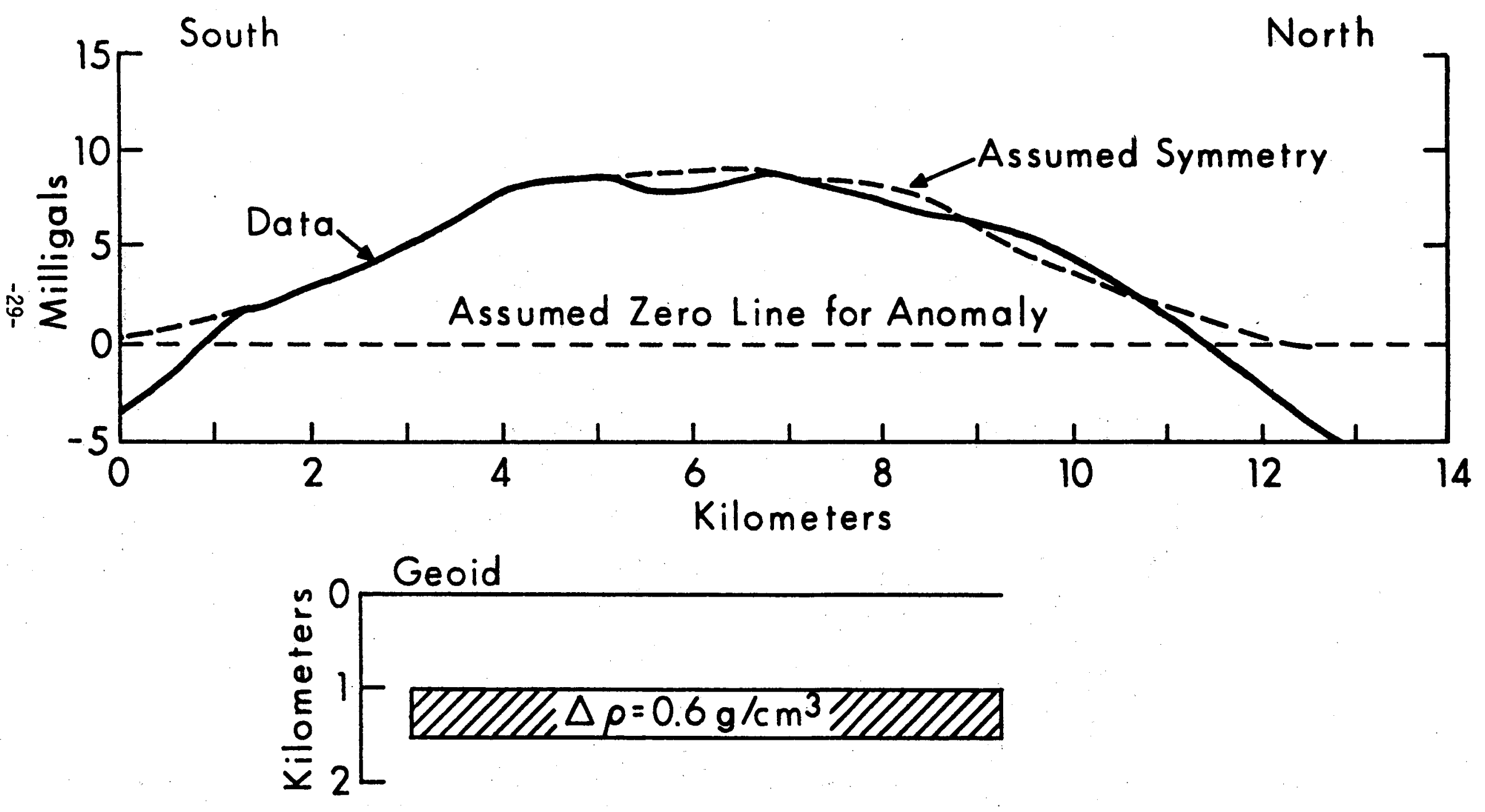




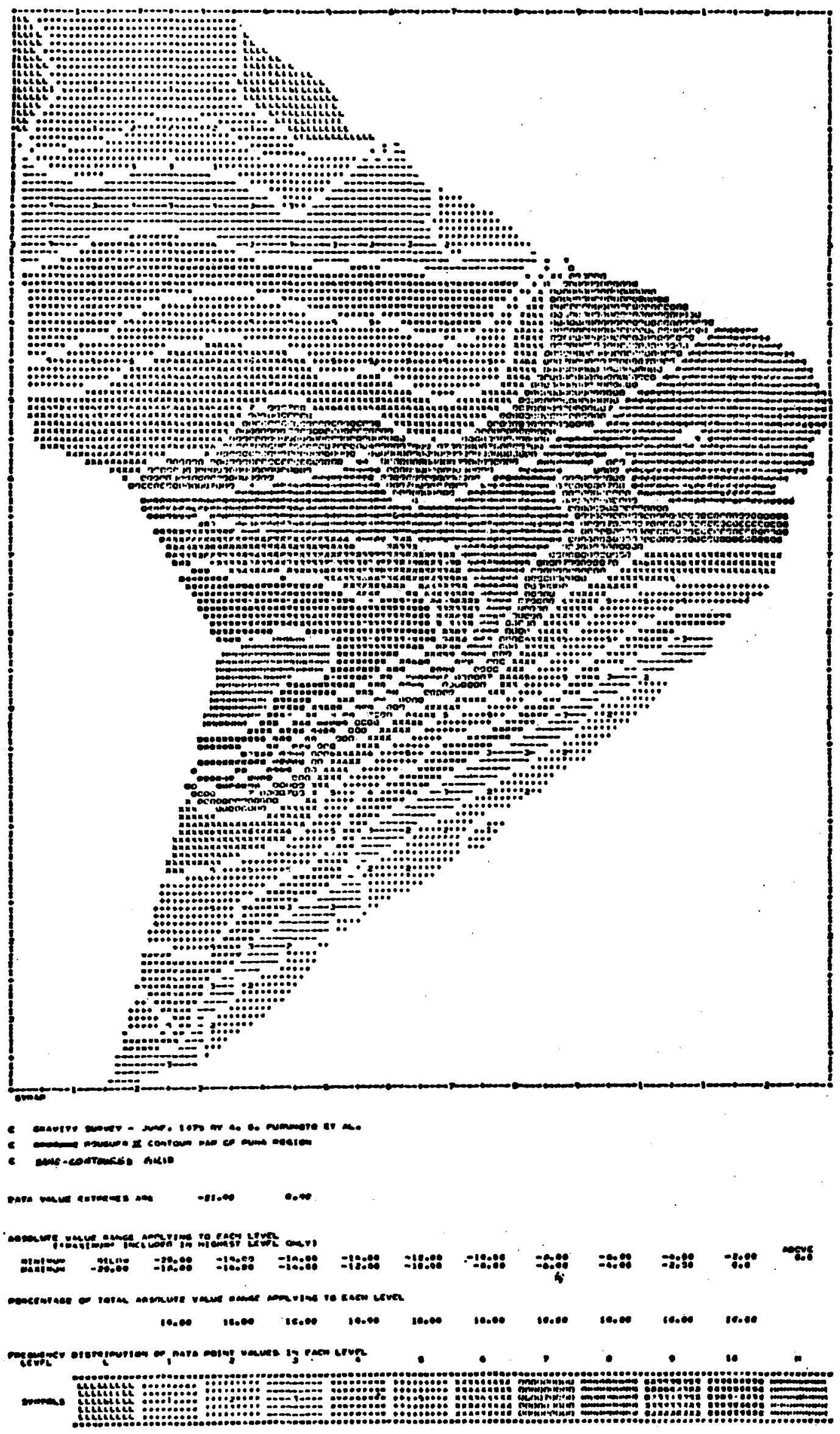

Figure 4. Gravity Data' in SYMAP form 


\section{Progress Report \\ PUNA MAGNETICS}

\section{R. Norris}

The report for Phase I gave a description of the ground survey by total field magnetometer and some preliminary modeling of the subsurface magnetic properties based on the north-south track from Pahoa to Kaimu.

The survey data of over 9000 magnetometer readings, taken at $90 \mathrm{samples} / \mathrm{mile}$, were transformed into 1/10-mile averages to match the resolution of the vehicle's odometer and filter out the shortest wavelength variations. The measurement tracks were digitized from the USGS 1:24000 scale topographic map as a set of points $X(I), Y(I)$ where each point was the end of a straight-line segment. $A$ computer program was written to calculate and punch onto cards the map coordinates of the midpoint of each 1/70-mile segment of track and the heading on that segment. The two data sets: the positions and headings of each 1/10-mile of track, were merged so that the final data set was a deck of cards containing positions and heading-corrected magnetic field values with serial numbers: $X, Y$, $Z$, I on each of 1000 cards. This data was contour-mapped by computer printer using SYMAP5, a mapping program developed at the Harvard Laboratory for Computer Graphics and Spatial Analysis (Fig. 5). Complicated magnetic topography required a nice choice of areal interpolation. It was decided to do localized interpolation within a one-kilometer diameter circle to avoid meaningless extrapolation and to filter for detection of features half a kilometer or greater in size.

Figure 5 does not show any prominent ridge-and-trough feature over the rift zone. It's most extensive feature, which will be called the Leilani Low, is a trough trending west from the Puulena pit crater group. This trough and what may be seen of the ridge south of it has been idealized and modeled in Fig. 6 . Three types of models were applied and the synthesis indicates a body with magnetization contrast of 0.01-0.02 oersted with a depth-to-top of 1000-2000 feet. The other prominent feature, which will be called the Kapoho High, is an intense but very localized high associated with Kapoho Crater. The low half of the dipole was not found. If subsequent measurement were to show a proportionate magnetic low near the south rim, then it could be concluded that there is an anomalously un-magnetic body, and therefore possibly a hot body, though a small one, beneath Kapoho Crater. The Leilani feature cannot be ruled out as an indicator of heat at depth because the magnetic body may well be a network of high-magnetization intrusions above a non-magnetic magma source which is not resolved because of its depth and 
the masking effect of shallow variations. In an attempt to put the shallow effects in perspective and bring out the effect of deeper material an upward continuation of the field was computed for al titudes from 2000 to 10,000 feet. The maps of the upward-continued functions however did not resolve the effect of any deep-seated magnetization contrast beneath the Leilani anomaly. The drill site, about 1-2 miles northeast of the Leilani anomaly (marked by a star in Fig. 1) is in a mixed area of localized shallower, smaller contrasts probably perturbed by the presence of the Puulena group of collapse craters. The complexity here as elsewhere does not lend itself to modeling. 

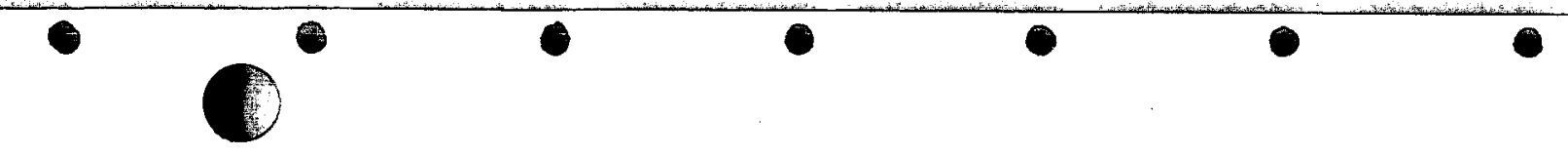

Figure 5. Total magnetic field interpolated within a $1-k m-d i a m e t e r$ circle and contoured.

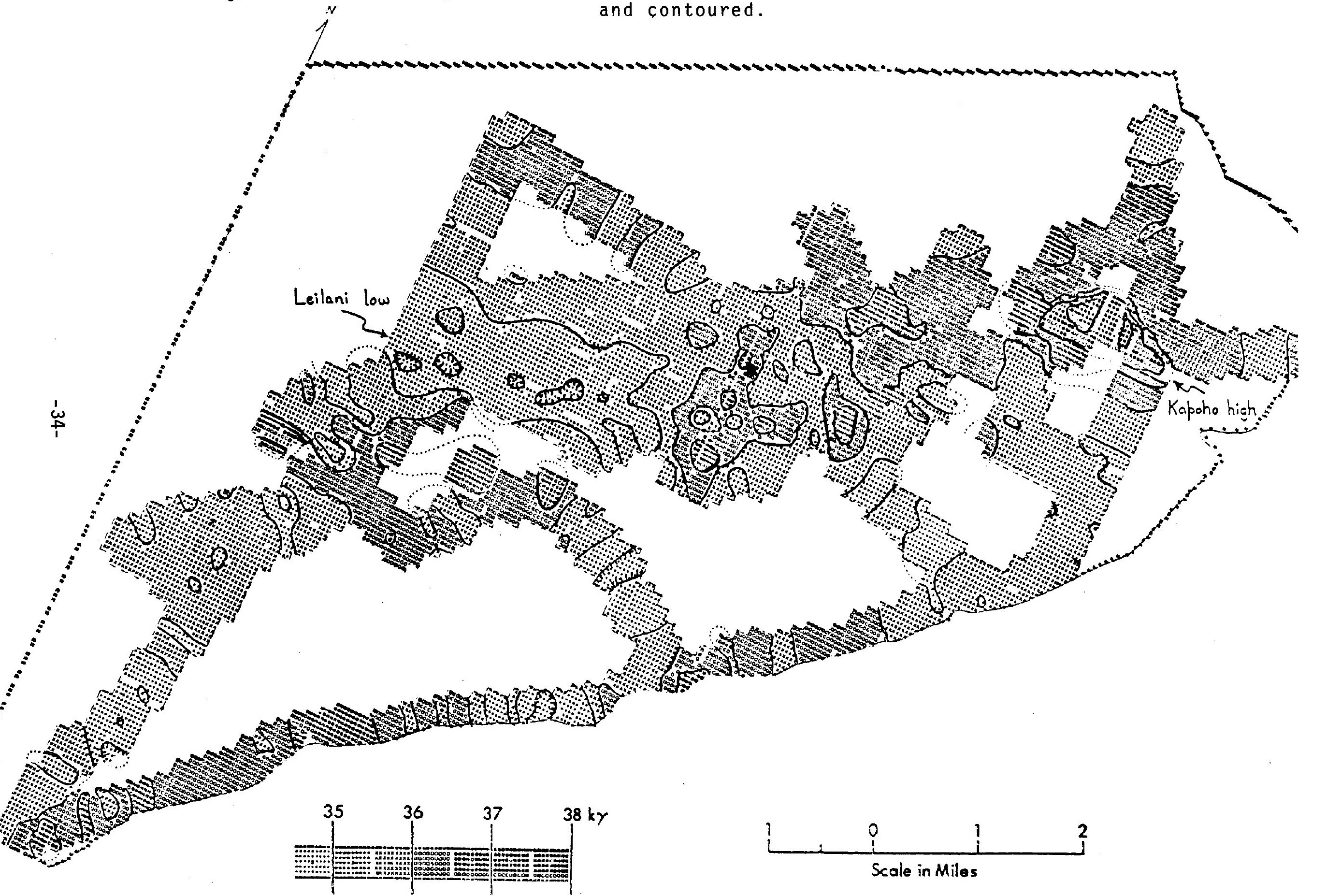


Figure 6. Generalized cross-section of the anomaly west of Puulena pit crater and some models for it.

total magnetic
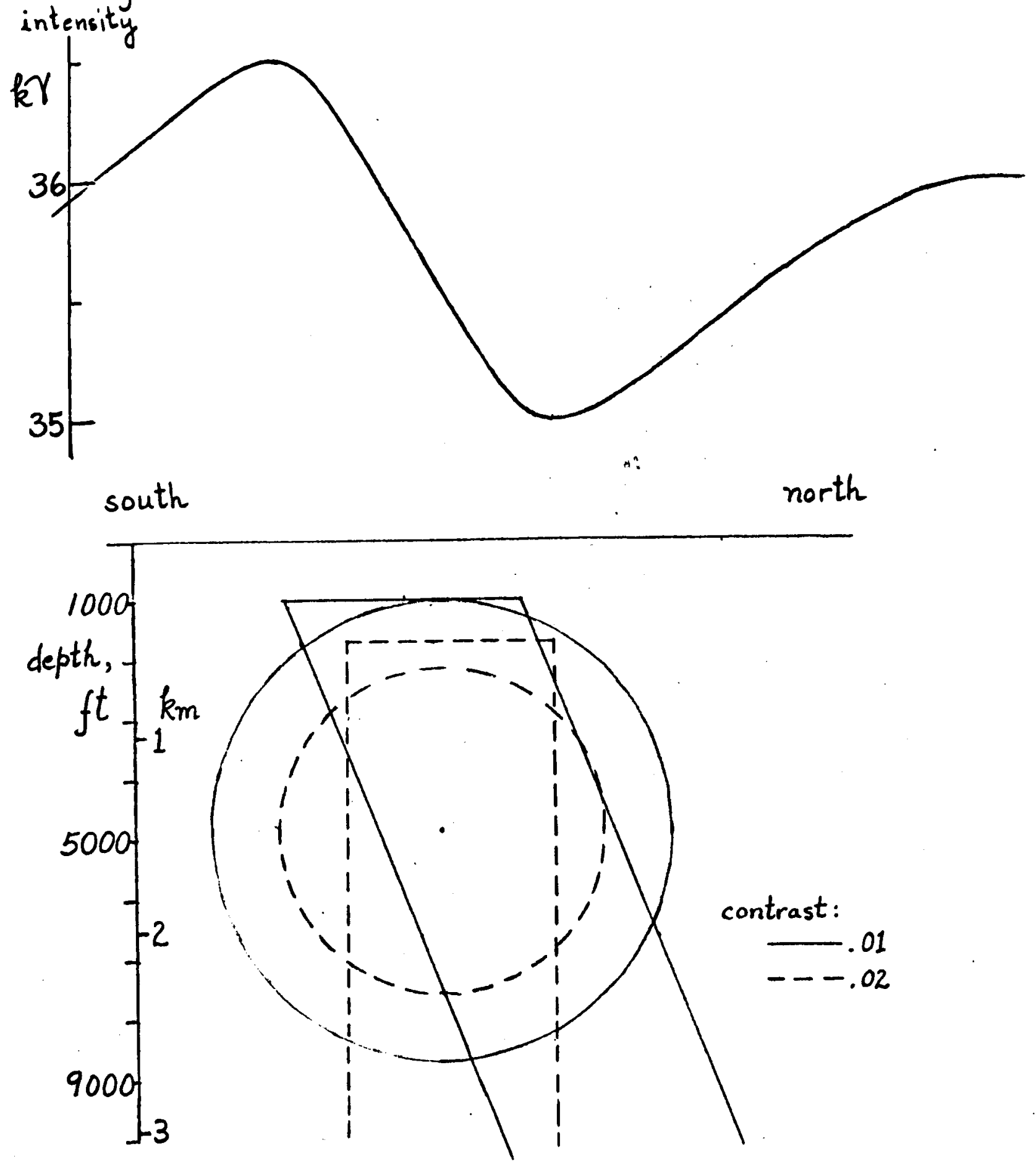

$-35-$ 


\section{Progress Report}

PUNA SEISMOLOGY

May-December 1975

Wayne Suyenaga and Michael Broyles

The early portion of the period was spent analyzing data from the microearthquake survey conducted the previous summer. Most of the results were presented at the American Geophysical Union's Spring Annual Meeting (Suyenaga and Furumoto, 1975) and are much the same as those contained in the Summary Report of Phase 1 of this project. A final report on the microearthquake and seismic noise surveys is in preparation. A revised plot of epicenters is shown on an accompanying figure. It illustrates the main conclusion of the microearthquake study as it applies to the geothermal work which is that no single fault was delineated by the hypocenters. Down to a depth of about five kilometers almost all of the foci were located in a three kilometer wide band vertically beneath the surface expression of the rift zone. It appears that the search for geothermal resources in the east rift zone is complicated by seismic activity from other sources such as the settling of the entire volcanic structure.

The remainder of the effort during the past few months was in preparation for the seismic refraction experiment. From Hill (1969), we have an approximate seismic structure below about three kilometers. Although the travel path used to calculate Hill's Capa Kumukahi SW models spanned the Puna area, the recording system and the blasts were on opposite sides of the rift zone. One of the conclusions of our microearthquake survey and of other studies (Ward and Gregerson, 1073; Ellsworth and Aki, 1975) is that the rift zone is comprised of material of significantly higher velocity than that surrounding it. The resulting heterogeneous travel path might be the cause of the range of models of Cape Kumukahi SW. Since there were no shots closer than $10 \mathrm{~km}$, the shallow structure of Cape Kumukahi SW was extrapolated from a model located further to the southwest. Our seismic refraction work will attempt to determine the shallow structure in Puna, both on and off the rift zone. Of particular interest is the proposed $3.1 \mathrm{~km} / \mathrm{sec}$ layer at about $700 \mathrm{~m}$ depth under the rift zone.

For the refraction work, a twelve channel analog tape recording system is being field tested. An additional recording system is being put together with amplifiers from the microearthquake system. Field tests have been conducted in the Waimanalo area of Oahu, In the meantime, work in Puna has been delayed due to difficulty in obtaining permission to drill and blast in appropriate plots of 
land. The work is now planned for the early part of January. A line over the rift zone will be along Leilani Avenue in Leilani Estates and another line is planned to the south of the rift zone.

\section{References}

Ellsworth, W.L. and K. Aki, High-resolution lateral crust and upper mantle structure of Kilauea volcano, Hawaii, EOS, Trans. Am. Geophys. Un., 56, $394,1975$.

Hill, D.P., Crustal structure of the island of Hawaii from seismic refraction measurements, Bul1. Seism. Soc., Am., 59, 101-130, 1969.

Suyenaga, W. and A. Furumoto, Microearthquake study of the East Rift Zone of Kilauea, Puna, Hawai i, EOS, Trans. Am. Geophys. Un., 56, 397, 1975.

Ward, P.L. and S. Gregerson, Comparison of earthquake locations determined with data from a network of stations and small tripartite arrays on Kilauea volcano, Hawai i, Bull. Seism. Soc. Am., 63, 679-711, 1973. 


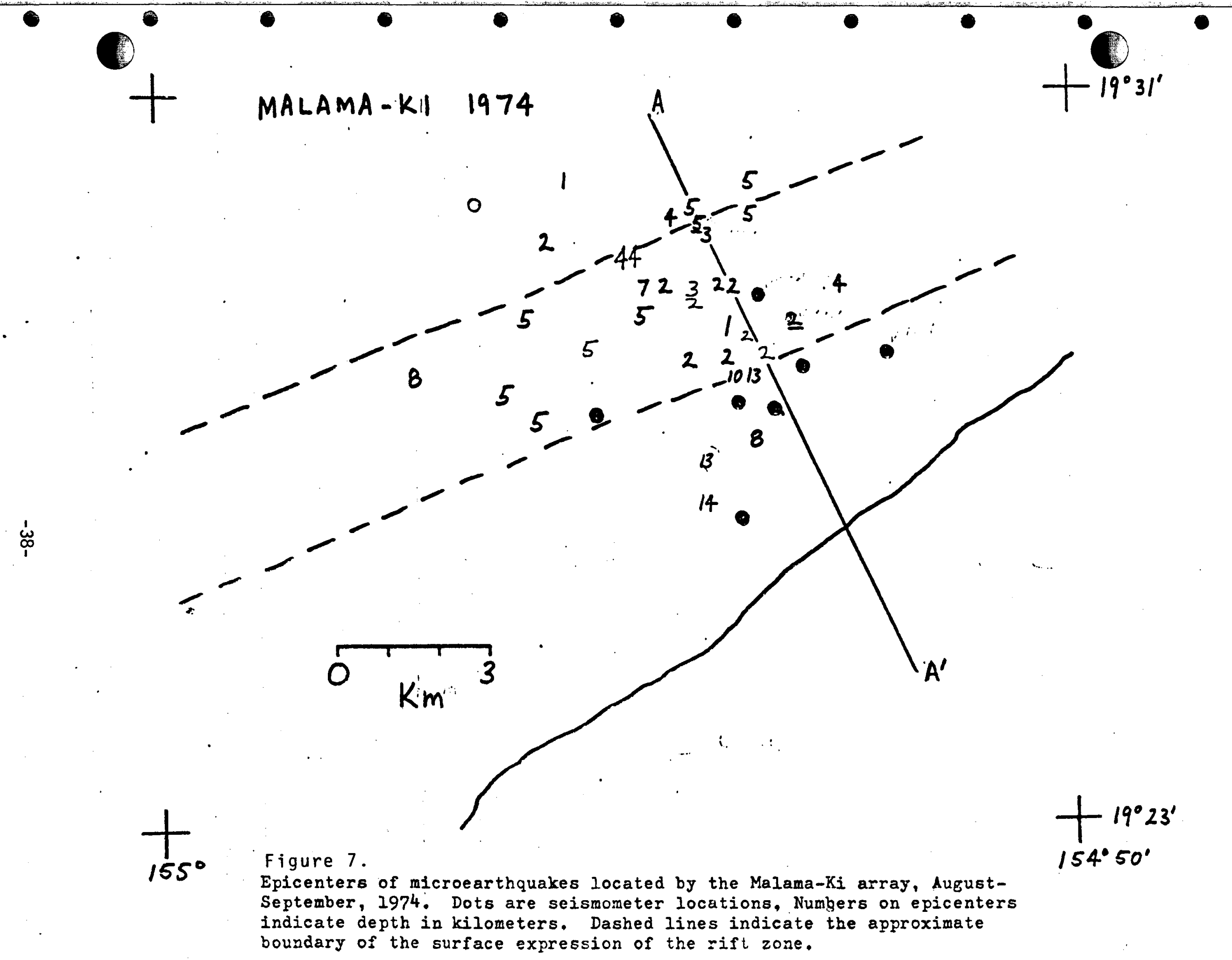


Progress Report

WELL TEMPERATURE SURVEY

May-December 1975

David Epp and John Halunen

Temperature versus depth profiles have been obtained for 21 wells on the island of Hawaii (Table 1). This constitutes all of the wells that we could find that we felt would give reliable temperature values. Three of the wells were drilled on the Puna rift in 1961 for geothermal exploration purposes. The others are wells or test holes drilled for water. The wells we measured are either dry holes, contain brackish water, or are unused for some other reason. Some unused wells still have a pump in place which prevented us from getting our instrument down the hole. Some of the older abandoned wells can no longer be located. Wells that are presently being pumped on a regular basis were not measured because the water column is not in thermal equilibrium with the surrounding countryrock.

The highest temperatures were recorded in the wells on the Puna rift zone (see Table 1 and Fig. 8). With the exception of wells 6048-01 (15) and 6147-01 (16) located in the South Kohala district, the maximum temperature recorded in wells not in the Puna rift area was less than $25^{\circ} \mathrm{C}$. Temperatures in 3389-01 (9-4) and 2102-01 (9-10) are considerably lower than temperatures in wells closer to the rift zone, indicating that the temperature decreases rather rapidly to the north and south of the rift zone.

Temperature measurements were repeated approximately one year after the first measurements in four of the high-temperature wells on the Puna rift. The allison well (2881-01) was not remeasured because a pump had been installed during the past year and we could not get our instrument down the hole. Geothermal No. 2, Geothermal No. 3 and 2783-01 (9-9) show little or no temperature variation during the past year (Figs. 9 and 10). The temperatures in Geothermal No. 2 were measured three times. Previous to the 4 oct. 1974 measurement, the well had been tightly capped, preventing steam from escaping. Thus when the well was opened for the 4 Sept. 1974 measurement, thermal equilibrium was distributed in the upper part of the hole and high temperatures were recorded in the upper $70 \mathrm{~m}$ of the hole. The 4 0ct. 1974 values were obtained after the hole had been open for about 28 hours. A loose cap was installed that allows steam to escape from the well, and it is apparent from the 3 Sept. 1975 measurement that a new isothermal equilibrium has been established in the upper $70 \mathrm{~m}$ of the hole. The small 
temperature changes recorded below $80 \mathrm{~m}$ in Geothermal No. 2 and throughout Geothermal No. 3 may be partly due to measurement error, but probably also indicate small changes in well temperatures over the past year. No variation was observed in well No. 2783-01 (9-9) (Fig. 10).

There appears to have been a significant temperature increase in well No. 3081-01 (9-6) during the past year. It is not known at this time whether this increase is related to some underground movement of magma, a change in groundwater movement, or some unaccounted measurement error. In any case, this we11, and other wells in the Puna area, will be remeasured in the near future to determine if this temperature increase is real and possibly related to the 29 November earthquake that was located south of the Puna area. 
Figure 8. Location of the wells measured in the Puna area.

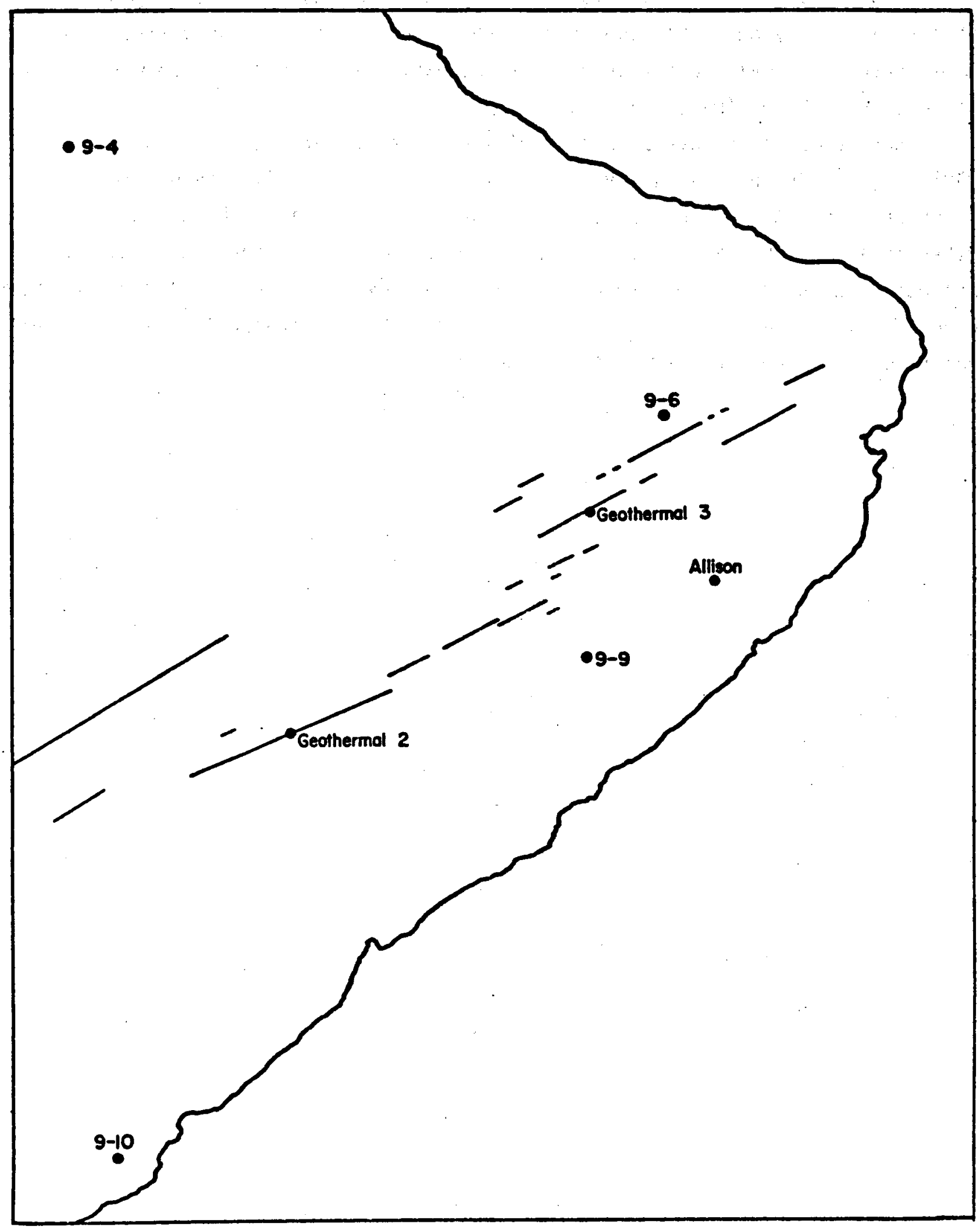




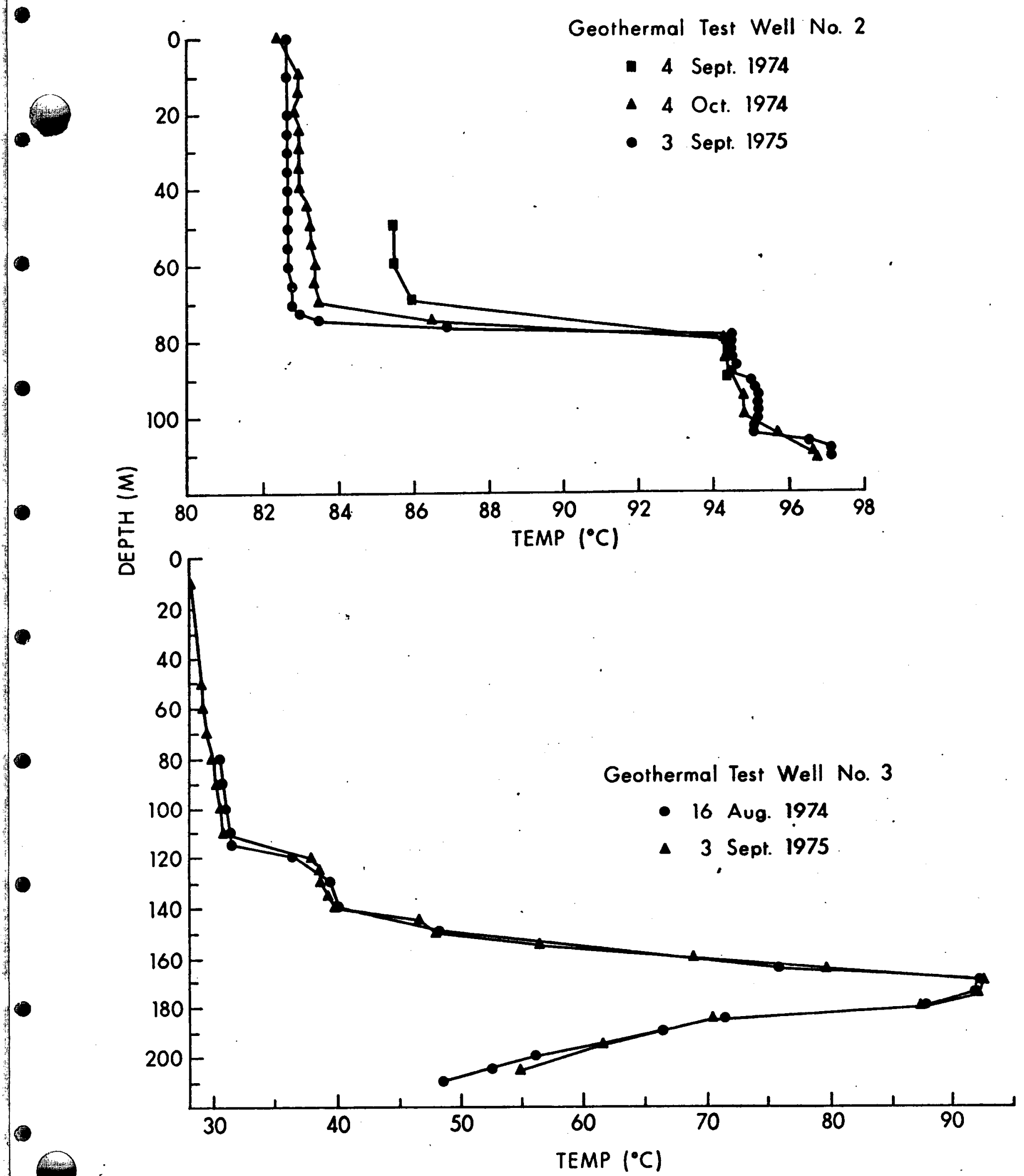

Figure 9. Temperature vs. depth variations in.Geothermal Test Wells Nos. 2 and 3. 


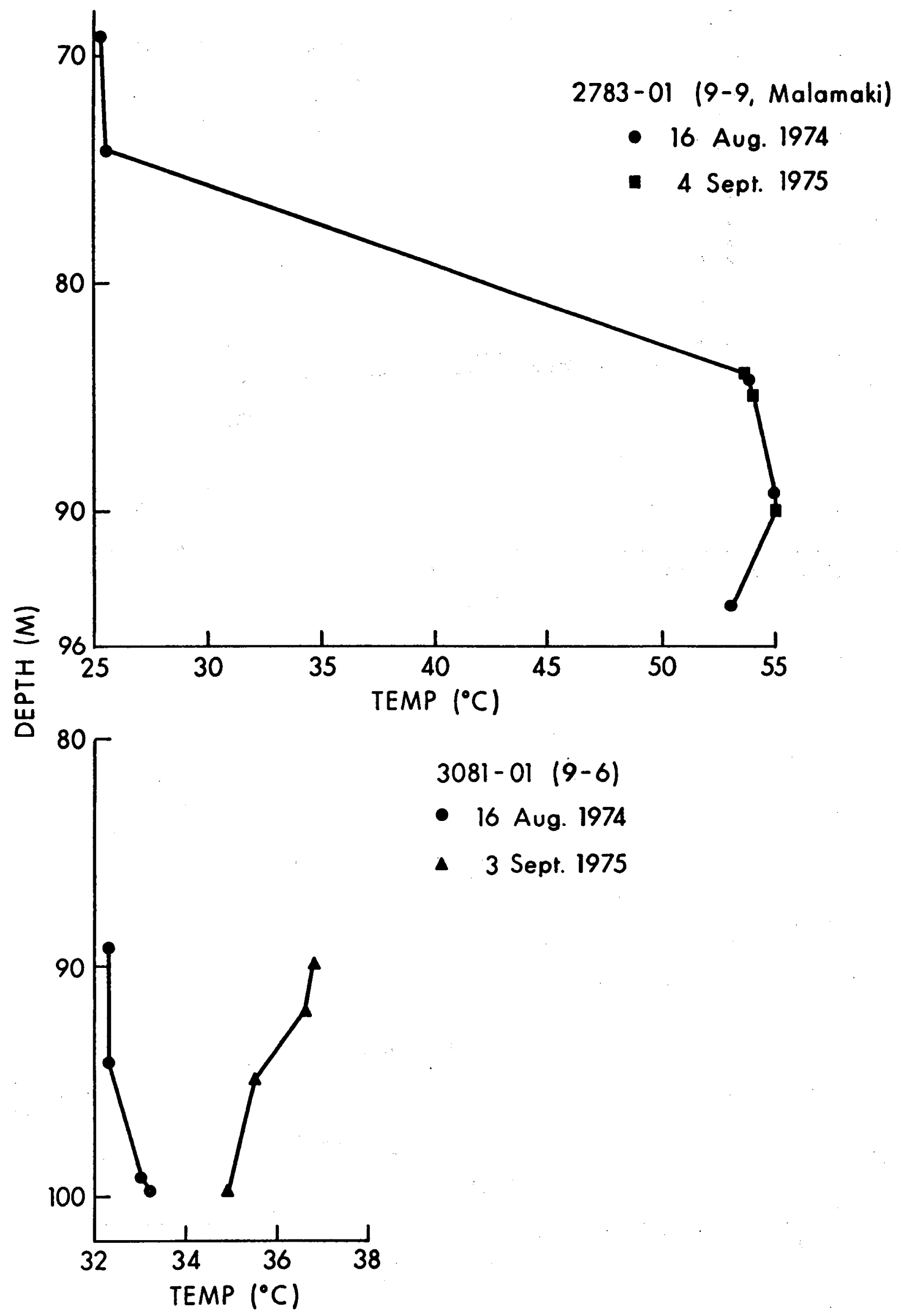

Figure 10. Temperature vs. depth variations in We11s 2783-01 and 3081-01 (9-6). 


\section{Table 1}

We11 No. *

Geothermal Test Well No. 1 Geothermal Test We 11 No. 2

Geothermal Test Wel1 No. 3

7448-01 and 02 ( 2 and 2-2)

$3389-01 \quad(9-4)$

3081-01 (9-6)

3500-01 (9-8)

2782-01 (9-9)

2102-01 (9-10)

2881-01 (A11ison)

$0533-02(10-1)$

1033-01

3758-01 (12)

4858-01 (12-7)

6048-01 (15)

6147-01 (16)

3505-01 (T1)

3207-02 (T3)

3308-01 (T4)

6341-01 (T19)

4532-01 (T20)
Location

Puna Rift

Puna Rift

Puna Rift

N . Kohala

Keaau - Pahoa

Kapoho (Airport)

Keaau - Pahoa

Ma 1 amaki

Puna

Pohoiki (Puna)

$\mathrm{Kau}$

Kau

N. Kona

N. Kona

S. Kohala

S . Kohala

Kurtis town

Mountain View

Mountain View

S. Kohala

saddle
Higest Temp

Measured ( $\left.{ }^{\circ} \mathrm{C}\right)$

68.8

97.1

92.5

23.4

22.7

36.8

22.5

55.0

25.7

38.9

18.0

19.0

20.8

21.9

26.0

36.6

15.6

17.4

18.6

16.6

18.6

* U.S.G.S. numbers with the old U.S.G.S. number in parenthesis 


\section{Progress Report}

HYDROLOGY

R. Buddemeier, P. Kroopnick, and L.S. Lau

The hydrology task officially was initiated only with the beginning of Phase II of the Hawaii Geothermal project. However, the cooperation and assistance of Hawaii County, U.S.G.S., and researchers from ongoing H.G.P. tasks permitted us to begin sampling prior to the formal contract period.

The primary goals of the task are characterization of the hydrology of the Puna District and analysis and interpretation of chemical and isotopic characteristics of geothermal fluids, either naturally occurring at the earth's surface or encountered as a result of drilling.

This progress report presents only data newly obtained by task personnel. A substantial body of data on the chemical and isotopic composition of nongeothermal Hawaijan groundwaters, previous analyses of Puna District waters, and hydrologic data on the area has been assembled and will be used in comparison and interpretation, but for the sake of brevity is not included in this report.

A total of eight major sources of groundwater (wells, shafts and springs) form the nucleus of the water sources studied (see Figure 11). Of these, five show temperatures consistently above ambient. All have been sampled (surface samples) in January and also in July or October. Geothermal No. 3, which is the hottest well and which is the only well showing a distinct thermocline, has also been sampled below the surface layer. Rainwater samples were also collected and analyzed.

Chemical data are presented in Table 2 , and isotope analysis resulted $\left({ }^{3} \mathrm{H}\right.$ and 180 ) are reported in Table 3 . In addition to some analyses still in progress, the $2 \mathrm{H}$ analyses remain to be performed in order to use ${ }^{2} \mathrm{H} /{ }^{18} \mathrm{O}$ ratios to ascertain the elevation of the source rainfall and/or evidence of geothermal alteration.

Although only preliminary interpretations have been made, several observations are of interest. First, the surface layer in Geothermal No. 3 is not only hotter but also more saline than the underlying waters. This implies that the well lies down-gradient from a thermal source which is advecting hot saline water up from depth.

Second, all of the tritium values are within or only very slightly below the range of values for contemporary rainwater (a long and continuing series of rainwater ${ }^{3} \mathrm{H}$ measurements on 0ahu provide comparison data). Even without allowance for the (unknown) tritium activity of the saline water component in the saltier 
water sources, this indicates that the mean residence time of all of these waters does not exceed a few years.

Third, the similarities in the seasonal variations in $\Delta{ }^{18} 0$ between rain and groundwater suggest that recharge to the surface waters may have a time constant of less than a few months. This is true for the hot as well as the normal water sources.

Finally, some logical patterns of water chemistry as a function of temperature may be seen. With the exception of $\mathrm{Allison}$ well, $\mathrm{SiO}_{2}$ content increases as water temperature increases; with the exception of Kalapana well, the $\mathrm{Mg} / \mathrm{Cl}$ ratio of the water decreases as temperature increases. Both observations are consistent with an increased rate of reaction of the hot rock with geothermal fluids at elevated temperatures.

In addition, one water sample was retrieved from the Keller test well on Kilauea. Although small and contaminated with drilling mud, we were able to analyze for $\mathrm{Cl}(62.9 \mathrm{mg} / 1)$ and $\triangle 180(-7.646 \%)$. Both values are consistent with the expected characteristics of higher elevation perched groundwater.

Major future activities will consist of analyses of fluids obtained by down-hole sampling in the test well, and sampling of all the water sources near the test well. After the end of the drilling operation additional samples will be collected to test for the existence of any extended effects of the drilling. All the data will be analyzed and integrated with geophysical data into a general hydrology-oriented model of the geothermal area. 
Table 2. Chemical Data (a)

\begin{tabular}{|c|c|c|c|c|c|c|c|c|c|c|c|c|c|c|c|c|}
\hline USGS No & No. & Name & Date & $\mathrm{T},{ }^{\circ} \mathrm{C}$ & $\mathrm{pH}$ & $\mathrm{Na}$ & $\mathbf{k}^{\prime}$ & $\mathrm{Ca}$ & $\mathrm{Mg}_{\mathbf{g}}$ & C1. & $\mathrm{HCO}_{3}$ & $\mathrm{SO}_{4}$ & $\mathrm{SIO}_{2}$ & N. (b) & $\mathbf{P}$ & Sr \\
\hline \multicolumn{2}{|c|}{ 2986-01 } & $\begin{array}{l}\text { Pahoa Station } \\
\text { (Wel1 9-5) }\end{array}$ & $\begin{array}{l}1-6-75 \\
7-21-75\end{array}$ & 23.3 & $\begin{array}{l}7.30 \\
6.65\end{array}$ & $\begin{array}{l}36.0 \\
19.3\end{array}$ & $\begin{array}{l}2.72 \\
2.7\end{array}$ & $\begin{array}{l}1.58 \\
1.6\end{array}$ & $\begin{array}{l}2.7 \\
1.9\end{array}$ & $\begin{array}{r}13.5 \\
9.8\end{array}$ & $\begin{array}{l}48 \\
44\end{array}$ & $\begin{array}{l}21.1 \\
27.3\end{array}$ & 50.0 & $\begin{array}{l}0.252 \\
0.57\end{array}$ & $\begin{array}{l}0.078 \\
0.129\end{array}$ & und \\
\hline \multicolumn{2}{|c|}{ 2487-01 } & $\begin{array}{l}\text { Kalapana Station } \\
\text { (Wel1 9-7) }\end{array}$ & $\begin{array}{l}1-6-75 \\
7-21-75\end{array}$ & $\begin{array}{l}28.5 \\
20.8\end{array}$ & $\begin{array}{l}7.68 \\
7.05\end{array}$ & $\begin{array}{l}89.6 \\
78.8\end{array}$ & $\begin{array}{l}5.20 \\
5.0\end{array}$ & $\begin{array}{l}5.30 \\
5.9\end{array}$ & $\begin{array}{l}6.6 \\
5.6\end{array}$ & $\begin{array}{c}132.2 \\
120\end{array}$ & $\begin{array}{c}38 \\
36.8\end{array}$ & $\begin{array}{l}37.2 \\
28.6\end{array}$ & 44.5 & $\begin{array}{l}0.070 \\
0.16\end{array}$ & $\begin{array}{l}0.056 \\
0.194\end{array}$ & 0.1 \\
\hline \multicolumn{2}{|c|}{$3080-02$} & $\begin{array}{l}\text { Kapoho Shaft } \\
\text { (We11 9) }\end{array}$ & $\begin{array}{l}1-6-75 \\
7-21-75 \\
10-27-75\end{array}$ & $\begin{array}{l}25.5 \\
22.1\end{array}$ & $\begin{array}{l}7.80 \\
7.10\end{array}$ & $\begin{array}{l}85.8 \\
86.5 \\
92.0\end{array}$ & $\begin{array}{l}6.60 \\
6.2 \\
5.8\end{array}$ & $\begin{array}{r}42.4 \\
.23 .2 \\
32.0\end{array}$ & $\begin{array}{c}37 \\
25.7 \\
27.8\end{array}$ & $\begin{array}{l}16.9(c) \\
95.7 \\
105\end{array}$ & $\begin{array}{l}372 \\
328 \\
330\end{array}$ & $\begin{array}{c}20 \\
22.7 \\
23.0\end{array}$ & 53.6 & $\begin{array}{l}0.378 \\
4.47 \\
2.51\end{array}$ & $\begin{array}{l}0.233 \\
0.268\end{array}$ & $\begin{array}{l}0.2 \\
0.25\end{array}$ \\
\hline \multicolumn{2}{|c|}{$3081-01$} & $\begin{array}{l}\text { Airstrip Well } \\
\text { (Well 9-6) }\end{array}$ & $\begin{array}{l}1-6-75 \\
7-22-75\end{array}$ & $\begin{array}{l}36.8 \\
33.5\end{array}$ & $\begin{array}{l}7.42 \\
7.75\end{array}$ & $\begin{array}{l}238 \\
223\end{array}$ & $\begin{array}{l}13.6 \\
16.8\end{array}$ & $\begin{array}{l}23.0 \\
12.5\end{array}$ & $\begin{array}{c}28 \\
27.2\end{array}$ & $\begin{array}{c}303.5 \\
316\end{array}$ & $\begin{array}{l}48 \\
44\end{array}$ & $\begin{array}{l}204 \\
211\end{array}$ & 71.3 & $\begin{array}{l}0.014 \\
0.39\end{array}$ & $\begin{array}{l}0.040 \\
0.076\end{array}$ & 0.2 \\
\hline \multirow{2}{*}{\multicolumn{2}{|c|}{2881}} & All18on Well & $1-7-75$ & 37.8 & 7.35 & 216 & 10.8 & 13.4 & 15 & 281 & 132 & 69.2 & 24.1 & $>14$ & $<0.002$ & \\
\hline & & $\begin{array}{l}\text { Isaac Hale Park } \\
\text { Spring }\end{array}$ & $\begin{array}{l}1-7-75 \\
10-27-75\end{array}$ & 36.0 & 7.75 & $\begin{array}{l}2020 \\
2140\end{array}$ & $\begin{array}{l}86.0 \\
87.5\end{array}$ & $\begin{array}{l}32.4 \\
98.0 \text { (c) }\end{array}$ & $\begin{array}{l}200 \\
239\end{array}$ & $\begin{array}{l}3534 \\
3660\end{array}$ & $\begin{array}{l}56 \\
61.0\end{array}$ & $\begin{array}{l}507 \\
552\end{array}$ & 81.5 & $\begin{array}{l}1.218 \\
<0.01\end{array}$ & 0.016 & 1.3 \\
\hline \multirow{4}{*}{\multicolumn{2}{|c|}{ 2783-01. }} & $\begin{array}{l}\text { Malama K1 Well } \\
\text { (Well 9-9) }\end{array}$ & $\begin{array}{l}1-7-75 \\
7-22-75\end{array}$ & 52.2 & $\begin{array}{l}7.02 \\
7.45\end{array}$ & $\begin{array}{l}2105 \\
2890\end{array}$ & $\begin{array}{l}109 \\
149\end{array}$ & $\begin{array}{l}66.8 \\
117\end{array}$ & $\begin{array}{l}210 \\
293\end{array}$ & $\begin{array}{l}3811 \\
5120\end{array}$ & $\begin{array}{l}144 \\
128\end{array}$ & $\begin{array}{l}471 \\
598\end{array}$ & 100.7 & $\begin{array}{l}0.280 \\
0.41\end{array}$ & $\begin{array}{l}0.006 \\
0.013\end{array}$ & 2.2 \\
\hline & & Geothermal 3 & $\begin{array}{l}1-7-75 \\
7-21-75\end{array}$ & 93.0 & 6.85 & $\begin{array}{l}2050 \\
2000\end{array}$ & $\begin{array}{l}190 \\
195\end{array}$ & $\begin{array}{l}76.8 \\
81\end{array}$ & $\begin{array}{l}52 \\
59\end{array}$ & $\begin{array}{l}3274 \\
3410\end{array}$ & 30 & $\begin{array}{l}314 \\
335\end{array}$ & 96.6 & $\begin{array}{l}0.003 \\
0.32\end{array}$ & $\begin{array}{l}0.006 \\
0.076\end{array}$ & 1.4 \\
\hline & & $\begin{array}{l}\text { Geothermal } 3 \text { (d) } \\
\text { (Th1ef) }\end{array}$ & $7-21-75$ & 74 & 1.4 & 1740 & 158 & 71 & 62.5 & 2980 & 20 & 317 & & & 0.053 & 1.2 \\
\hline & & $\begin{array}{l}\text { Rain at Kalapana } \\
\text { station }\end{array}$ & $1-6-75$ & & & 4.5 & 0.25 & 0.25 & 0.75 & 7.2 & & $\sim 2.5$ & 0 & 0.024 & $<0.002$ & \\
\hline $\begin{array}{l}\text { (a) } \\
\text { (b) } \\
\text { (c) } \\
\text { (d) }\end{array}$ & \multicolumn{16}{|c|}{$\begin{array}{l}\text { All concentrations are } \mathrm{In} \mathrm{mg/l} \\
\text { January } \mathrm{N} \text { values are } \mathrm{NO}_{2}+\mathrm{NO}_{3} \text {; others are } \mathrm{NO}_{2}+\mathrm{NO}_{3}+\mathrm{NH}_{4} \\
\text { Suspect datum } \\
\text { Th1s aample taken } 50-60^{\prime} \text { below watet surface }\end{array}$} \\
\hline
\end{tabular}


Table 3. Isotopic Data

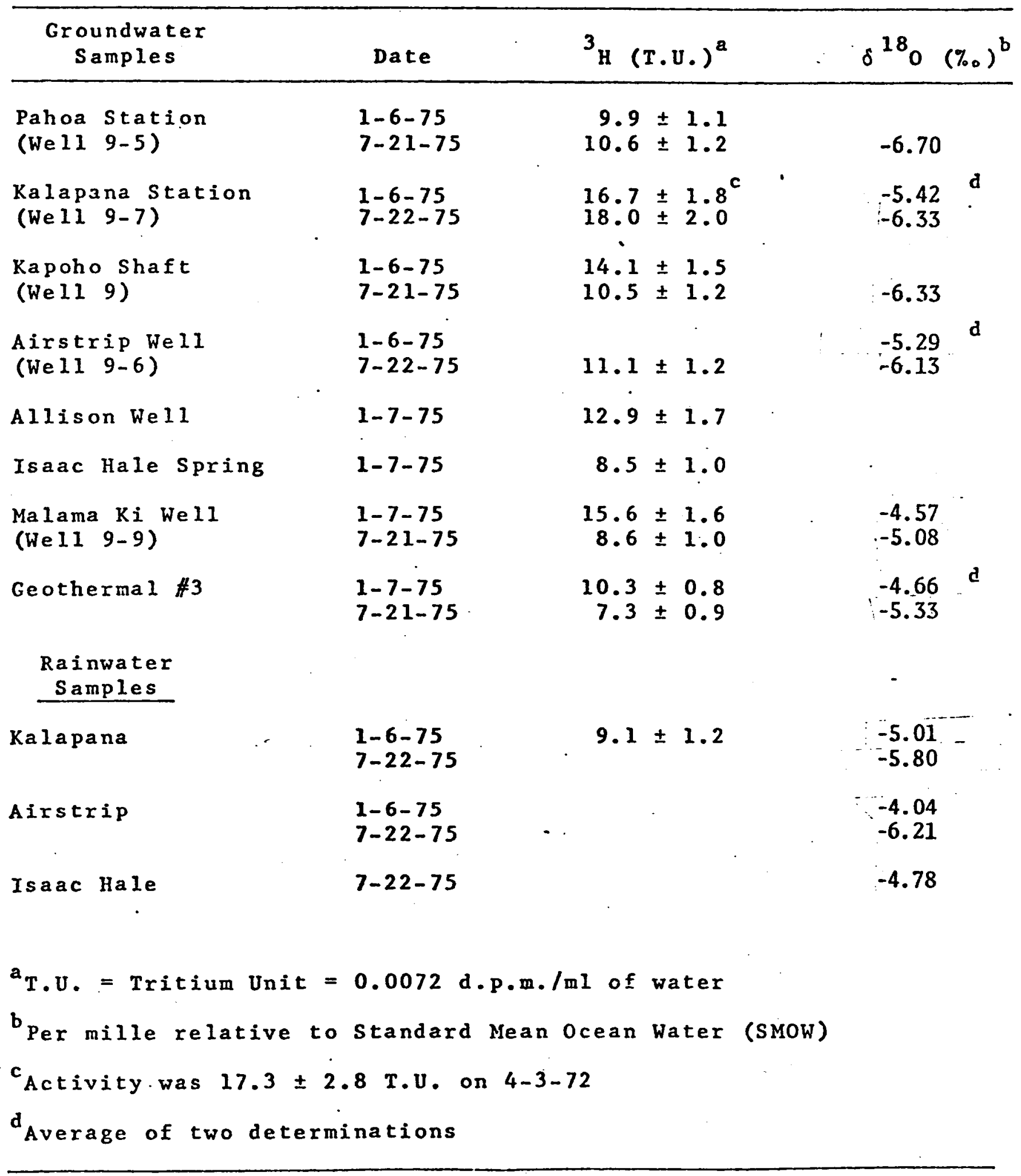




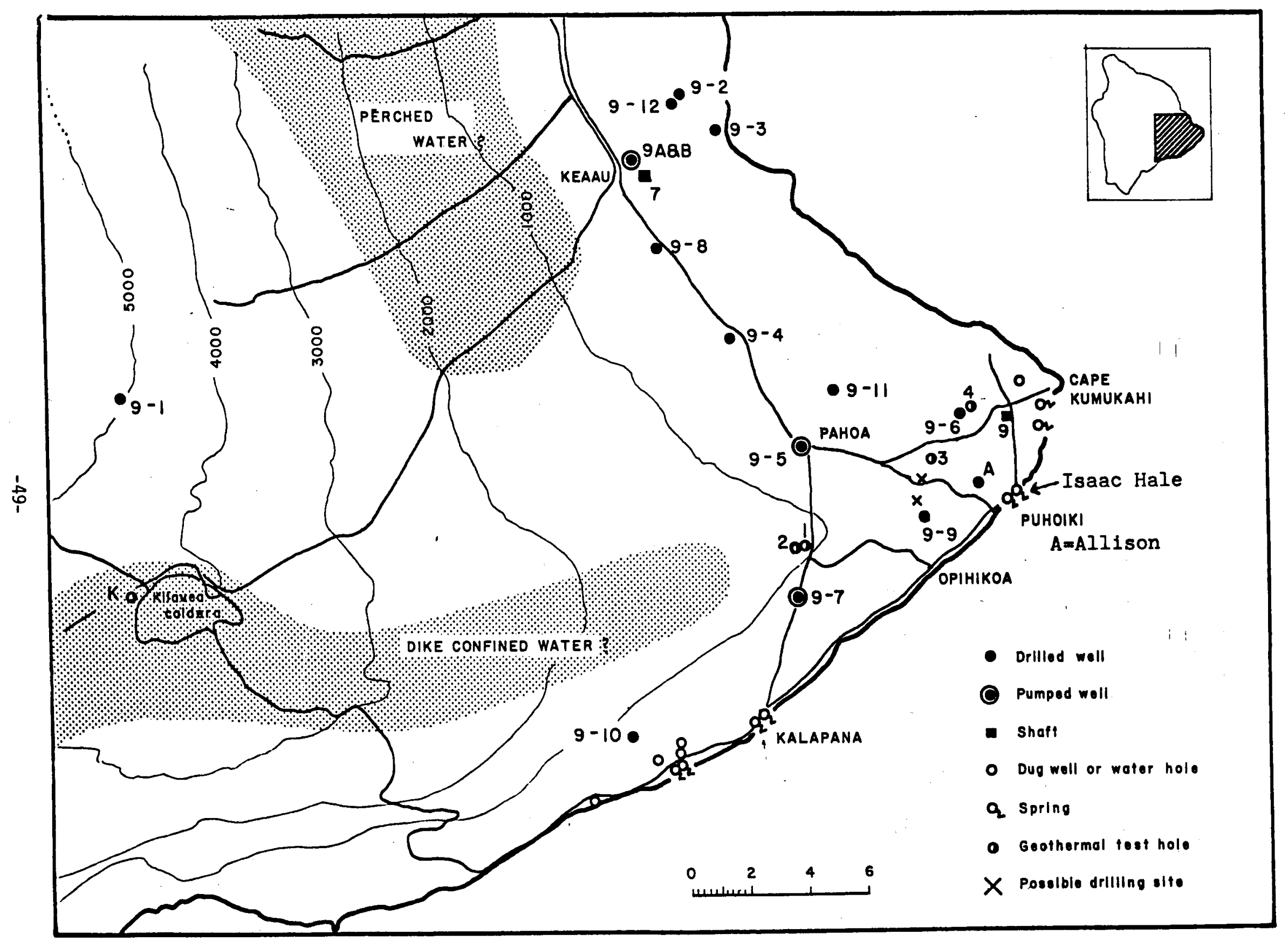

Figure 11. Approximate location of water sources in the puna area, is land of Hawail. 3 


\section{Progress Report \\ PHYSICAL PROPERTIES OF ROCKS \\ M.H. Manghnani, C.S. Rai and T. Hanada}

The physical property measurements on the Hawaiian basaltic rocks, completed and in progress, include density, porosity, thermal diffusivity, electrical resistivity, and compressional $\left(v_{p}\right)$ and shear $\left(V_{s}\right)$ velocities under various pressure and temperature environments. The samples were obtained from two sources: (1) from the core material recovered from the bore hole drilled at the Kilauea Volcano site by the Keller group [Keller, 1974] (test samples were obtained in horizontal and vertical directions from all of the twenty-nine horizons at which the cores were recovered); (2) from Prof. G.A. Macdonald's collection of C-series basalts [Macdonald and Katsura, 1964; Macdonald, 1968; Macdonald and Powers, 1968 ]. The choice of the group (2) samples was made in view of the thorough studies previously conducted on these rocks, namely, the chemical and petrographical analyses by Macdonald and associates, and the elastic properties study by Manghnani and Woollard [1968]. This report discusses the results of the measurements of thermal diffusivity in the temperature range of $300-650^{\circ} \mathrm{K}$, and of electrical resistivity as a function of pressure $(0.1-10 \mathrm{kbar})$, temperature $\left(1130^{\circ}-1725^{\circ} \mathrm{K}\right)$, and type of saturating fluid.

I. Thermal Diffusivity

Method - Thermal diffusivity $K=k / \rho C_{p}$, where $k$ is the thermal conductivity, $\rho$ is density, and $C_{p}$ the specifie heat at constant pressure per unit mass, was measured for some $30 \mathrm{C}$-series Hawaijan basalts, in the temperature range of $300^{\circ}-630^{\circ} \mathrm{K}$, using the Angstrom method [Kanamori et a l., 1969]. The rock types included tholeiite and tholeiitic olivine, and alkalic and alkalic olivine basalts, trachyte, mugearite, Hawaiite, ankaramite, and basanitoid.

Results and Discussion - At $330^{\circ} \mathrm{K}$, the thermal diffusivity values for a 11 the basalts range from 5.0 to $7.8 \times 10^{-3} \mathrm{~cm}^{2} / \mathrm{sec}$. For given rock type, $K$ decreases with increase in porosity. For the three tholeiitic basalts with porosity values of $8.8,9.0$ and $11.9 \%$, the measured $K$ values at $330^{\circ} \mathrm{K}$ are $6.75,6.25$ and $5.3 \times 10^{-3} \mathrm{~cm}^{2} / \mathrm{sec}$, respectively; this range of values is narrowed at high temperatures. Temperature dependence of thermal diffusivity is shown in Fig. 12 .

In the temperature range of this study, the heat is transported by phonos, and $K$ should be clearly related to elastic wave properties of solid. An analysis of the temperature dependence of $K$ shows that $K$ is inversely proportional to $T$ 
and that each $K$ vs $T$ curve consists of two straight lines having different slopes, representing the temperature dependence of $K$ below and above the $\theta_{D}$. Theoretically, the temperature at which a change in the slope occurs, is the Debye temperature $\theta_{D}$ of solid. For basalts, $\theta_{D}$ values thus determined range from $275^{\circ}$ to $510^{\circ} \mathrm{K}$, the median value being $450^{\circ} \mathrm{K}$. $\theta_{\mathrm{D}}$ can also be determined from elastic data. We therefore measured compressional $\left(v_{p}\right)$ and shear $\left(v_{s}\right)$ velocities in these basalts and computed $\theta_{D}$. In $80 \%$ of the cases, the agreement between $\theta_{D}$ calculated from the thermal diffusivity measurements and elastic measurements is within $\pm 12 \%$, the elastic $\theta_{D}$ values are higher, in general:

We are presently investigating the thermal diffusivity-thermal conductivityvelocity relationships in basalts.

\section{Electrical Resistivity Measurements}

Methods - Cylindrical samples (about $2.54 \mathrm{~cm}$ in diameter and 2.5 to $3.5 \mathrm{~cm}$ long) were used in this study. The sample ends were polished flat and parallel and were coated with a conducting paint.

Each sample was first dried at $100^{\circ} \mathrm{C}$ for 12 hours. On cooling, its weight and compressional wave velocity, $V_{p}$, measurements were made. The sample was then evacuated at 30 microns of mercury for about 12 hours, and then dropped in solution for saturation for 24 hours. Following this, weight and $v_{p}$ were again determined. Dry bulk density and effective porosity were calculated from known formulae.

Ambient electrical resistivity was measured at 50, 200, 500, 1000 and $2000 \mathrm{~Hz}$ with General Radio capacitance bridge (Model 1615-A), using three different saturation solutions: (a) tap water $(\rho=24.4 \Omega-m)$, (b) 1 part seawater and 3 parts distilled water $(\rho=0.66 \Omega-m)$, and $(c) 1$ part seawater and 1 part distilled water $(\rho=0.35 \Omega-m)$. In some cases where the resistivity was too low, Princeton Applied Research lock-in amplifier (Model HR-8) was employed instead.

For measurements under hydrostatic pressure, the electrode-sample assembly used by Brace et al. [1965] was employed. In such an assembly pore pressure is near zero. At least an interval of 20 minutes was allowed between each increment of pressure and measurement.

High-temperature conductivity measurements were made, using the loop method [Waff et. al., in press]. The sample was first heated beyond the melting temperature and then its conductivity measured with decreasing and increasing temperatures. The rate of cooling/heating was $100^{\circ}-150^{\circ} \mathrm{C}$ per hour. Inert atmosphere was maintained by flowing either argon or nitrogen gases through the furnace. 


\section{Results and Discussion -}

(a) Electrical resistivity at ambient conditions.

At ambient pressure and temperature conditions, A.C. resistivity $(\rho)$ values measured show frequency dependence for all the three saturating solutions (Fig. 13). Resistivity decreases with increase in frequency. The variation of resistivity in the frequency range of $50-2,000 \mathrm{~Hz}$ is about $13-20 \%$ for most of the samples, and appears to depend on the porosity of rock, and salinity of the saturating solution. The frequency dependence seems to decrease with increases in salinity of the solution, and porosity of the rock.

Figures 14, 15, and 16 are the plots of porosity versus formation factor for three different salinity solutions. Formation factor is defined as the ratio of resistivity of the saturated rock to the resistivity of the saturating solution.

Formation factor $f$ and fractional porosity $\phi$ are related through the well-known Archie's relation:

$$
f=A \phi^{-m}
$$

where $A$ and $m$ are the empirical constants.

For tap water saturation, the data show scatter and fall below the Keller's (1973) relationship $f=3.5 \phi^{-1.8}$ (see Fig. 3). However, the data for seawaterdistilled water $1: 1$ and $1: 3$ solutions fall well on the lines $f=4.50 \phi^{-1.61}$ and $f=7.94 \phi^{-1.36}$, respectively (Figs. 15 and 16 ), and are only slightly different from Keller's relationship.

Basalts, in general, are very resistive rocks. In basalt saturated with tap water there is surface conduction and as such its resistance is lowered. As expected, this effect will increase with decrease in porosity (see Fig. 14). Data for low porosity rocks fall more below the two lines for the $1: 1$ and $1: 3$ saturating fluids.

Resistivity of basalts is mostly governed by porosity and type of saturating fluid and does not appear to be dependent on composition, though alkaline olivine basalts, in general, have lower resistivity than the other basalts of comparable porosity. It is also noted that oxidized basalts show low resistivity for a given porosity (see Figs. 14-16).

(b) Electrical resistivity measurements at high pressure.

Figures 17 and 18 show the variation of resistivity with pressure to 3.5 or 10 kbar. The resistivity increases with pressure, by as much as two orders of magnitude for the low porosity rocks. For rocks of $>8 \%$ porosity, the resistivity increases rapidly between 1 and 200 bars, decreases slightly between 200 and 400 
bars, and then increases uniformly to $2.5 \mathrm{kbar}$. For rocks $<2 \%$ porosity, the resistivity increases with pressure more rapidly than in rocks of higher porosity, and the curves flatten out at much higher pressure. Crystalline rocks of very low porosity $(<0.1 \%)$ show a sharp rise in resistivity to 2 kbar which has been interpreted as being due to closure of cracks (Brace et al., 1970; Brace and Orange, 1968). This sharp rise is mostly absent in the basalts; the only sharp rise is observed in the first 200 bars. A tentative explanation is that the crack porosity in basalts is negligible as compared to the pore porosity.

(c) Electrical resistivity measurements to melting temperatures.

Resistivity measurements have also been carried on an olivine bearing tholeiite up to $1450^{\circ} \mathrm{C}$. Powdered specimens were prepared in two ways. In one case the rock was crushed, and metted in inert gas, and cooled slowly $\left(150^{\circ} \mathrm{C}\right.$ per hour); the solidified basalt was then recrushed to fine powder. In the second case, the sample was crushed and powdered. The powdered samples thus prepared were heated to melting point and resistivity measurements made while cooling down to $500^{\circ} \mathrm{C}$ after which the samples were again heated and measurements made to $1450^{\circ} \mathrm{C}$. Controlled atmosphere was maintained by passing nitrogen or argon gas through the furnace at a constant rate of $400 \mathrm{cc} / \mathrm{min}$ throughout the experiments.

The results are plotted in Fig. 19. At all temperatures below melting, for sample which was not melted before crushing, there is lower conductivity as compared to the sample which was melted before crushing. This difference in conductivity decreases with increasing temperature, and is insignificant beyond $1150^{\circ} \mathrm{C}$. Furthermore, below melting temperature conductivity values are slightly higher in argon than in nitrogen atmosphere, and also during cooling than during heating cycles. The conductivity increases gradually with temperature and show a sharp break at the melting point and increases two order of magnitude in the melting interval. The conductivity values and the melting temperature $\left(\sim 200^{\circ} \mathrm{C}\right)$ are more or less the same. Below the melting temperature, the conductivity of a rock seems to be more affected by the mode of preparing the test sample. Above the melting temperature $\left(>1200^{\circ} \mathrm{C}\right)$ the conductivity increases steeply and more or less linearly with temperature.

Further studies of electrical and elastic properties at melting temperatures are in progress for better understanding of the physical properties of basaltic magmas. 


\section{References}

Brace, W.F., A.S. Orange, and T.R. Nadden, The effect of pressure on the electrical resistivity of water-saturated crystalline rocks, J. Geophys. Res. 70, 1965.

Brace, W.F. and A.S. Orange, Further studies of the effects of pressure on electrical resistivity of rocks, J. Geophys. Res. 73, 1968.

Kanamori, H.H. Mizutani and N. Fujii, Method of thermal diffusivity measurement, J. Phys. Earth 17, 43, 1969.

Keller, G.V., An electrical resistivity survey of the Puna and Kau districts, Hawaii County, Hawaii, unpub1. rep. submitted by Group Seven to Res. Corp., Univ. of Hawai i, July 31 , 1973.

Keller, G.V., Drilling at the summit of Kilauea Volcano, National Science Foundation rep., 1974.

Macdonald, G.A. and T. Katsura, Chemical composition of Hawaiian lavas, J. Petrol. 5, no. 1, 1964 .

Macdonald, G.A., Composition and origin of Hawaijan lavas, Geol. Soc. Amer. Memoir $116,1968$.

Macdonald, G.A. and H.A. Powers, A further contribution to the petrography of Haleakala Volcano, Hawai, Geol. Soc. Amer. Bull., 79, no. 7, 1968.

Manghnani, M.H. and G.P. Woollard, Elastic wave velocities in Hawajian rocks at pressures to ten kilobars, Geophy. Mono. No. 12, 1968.

Waff, H.S., M. Grutzeck and D.R. Weill, unpublished manuscript, 1974. 


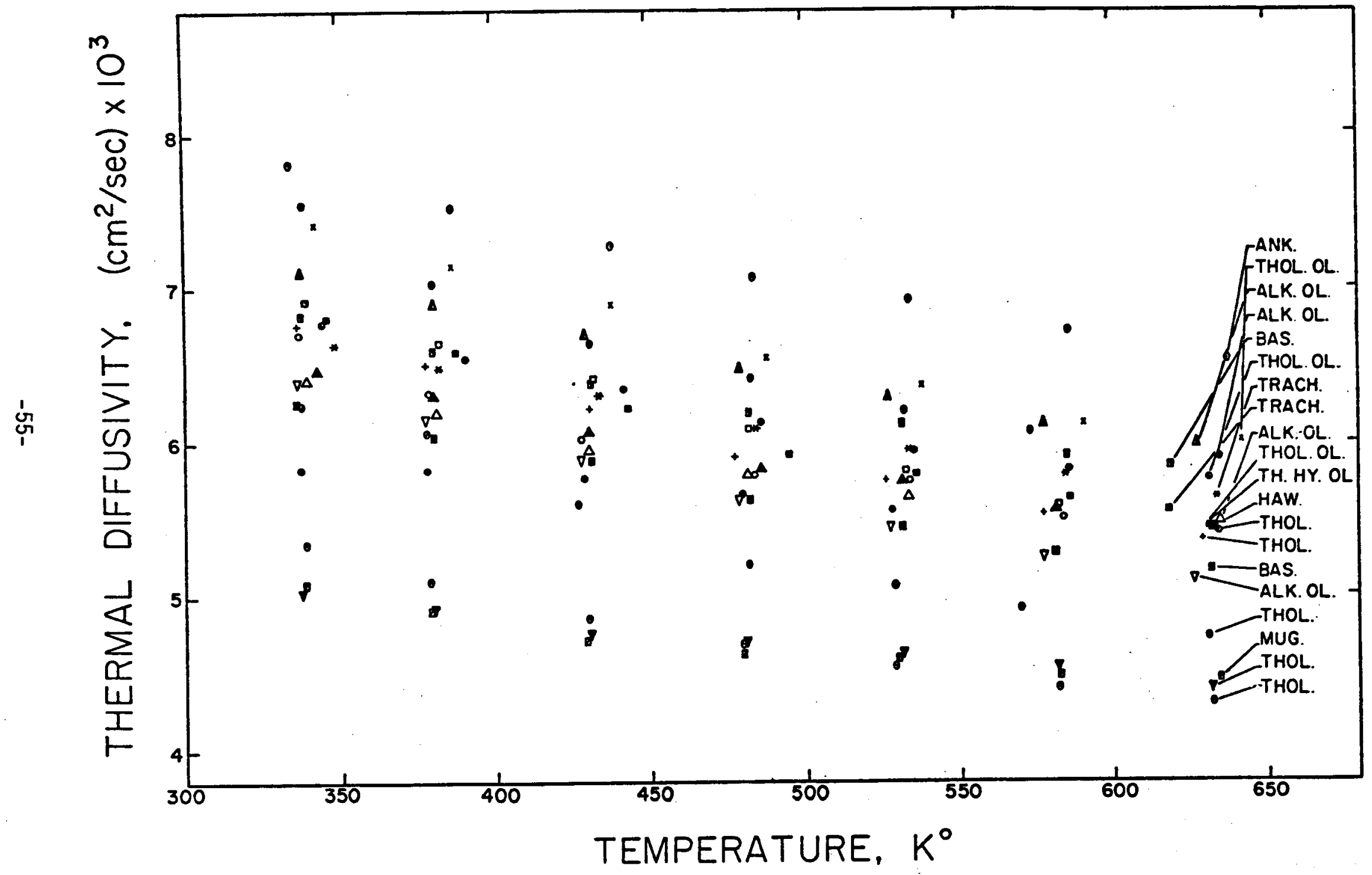

Figure 12. Thermal diffusivity versus temperature for the Hawaiian basalts(ANK.= ankaramite, THOL. OL.= tholeiitic olivine, ALK. OL.= alkalic olivine, BAS.= basanitoid, TRACH.= trachyte, $T H . H Y .0 L .=$ tholeiitic hypersthene olivine, HAly.= Hawaiite, THOL.= tholeite, and MUG.= mugearite). 


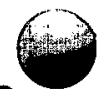

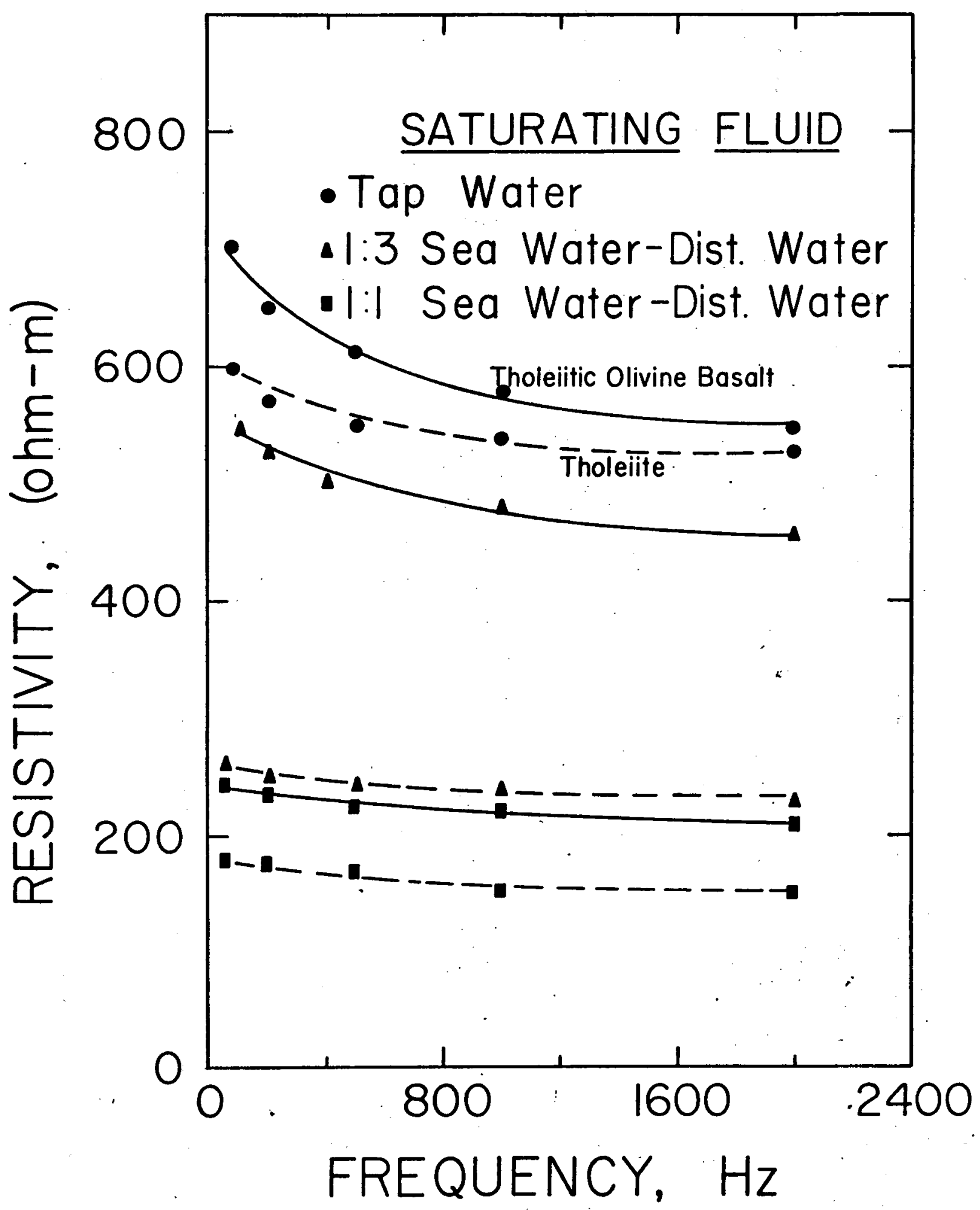

Figure 13. Frequency dependence of electrical resistivity of basalts saturated with different fluids. 


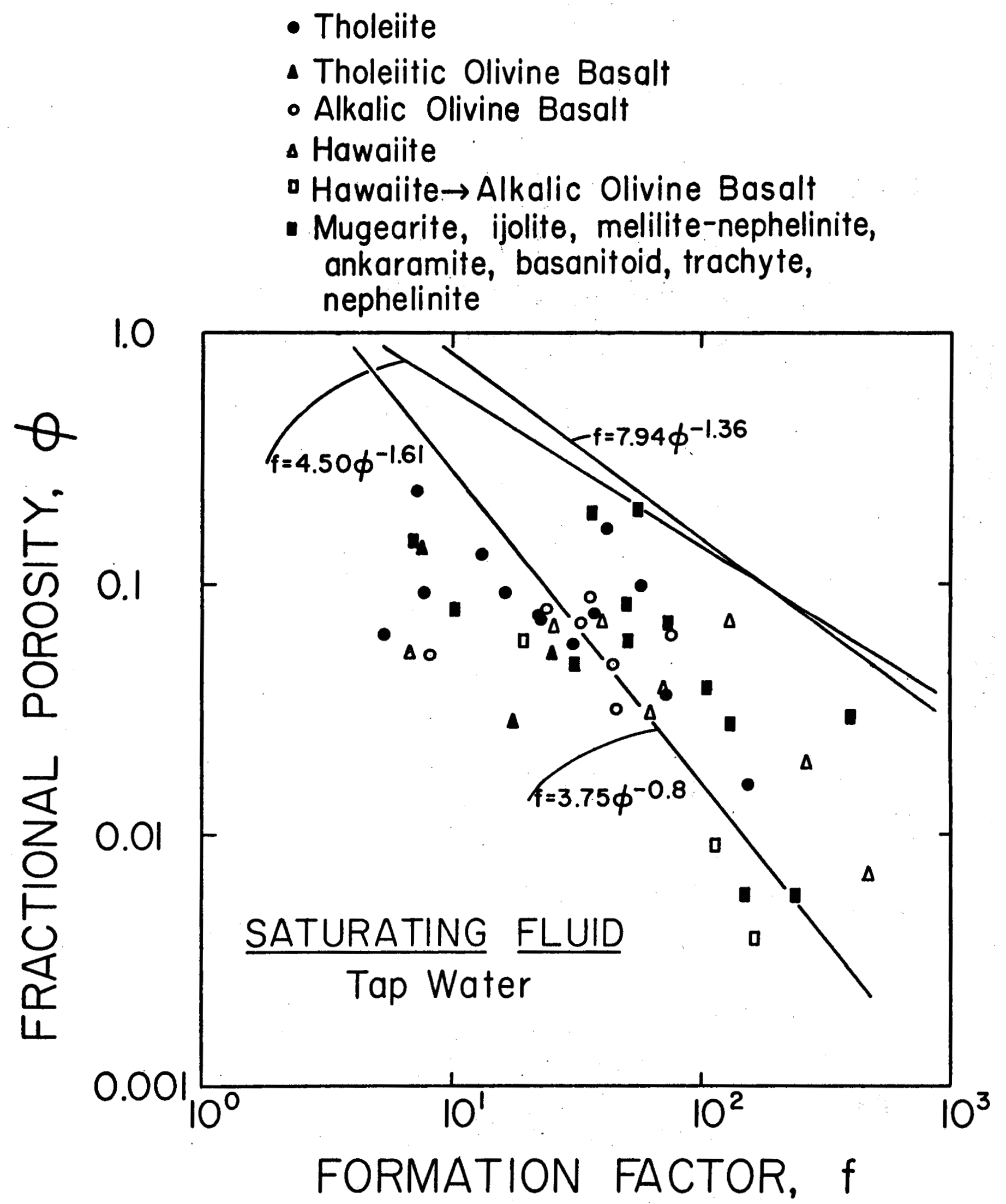

Figure 14. Fractional porosity vs. formation factor of basalts for tap water saturation. The best-fit solution if $f=3.5 \phi=0.8$. Compare this fit wjth that for $1: 1$ seawater- distilled water solution $\left(f=4.50 \phi^{-1.61}\right)$ and that for $1: 3$ solution $\left(f=7.94 \phi^{-1.36}\right)$. A11 measurements made at $500 \mathrm{~Hz}$ frequency. 


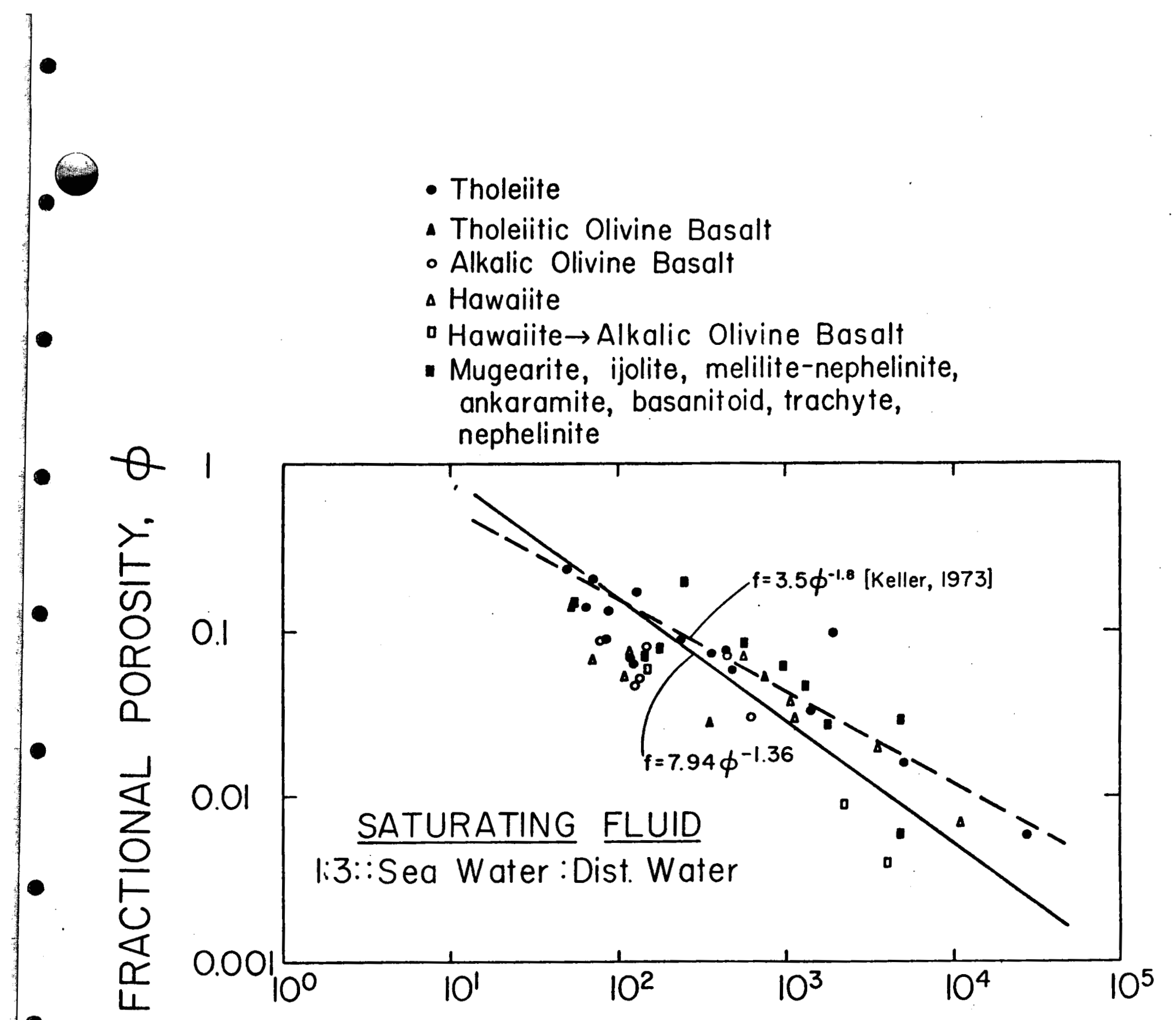

FORMATION FACTOR, $f$

Figure 15. Fractional porosity vs. formation factor for basalts for $1: 3$. seawater-distilled water saturation at $500 \mathrm{~Hz}$ frequency. Best-fit solution is $f=7.94 \phi^{-1.36}$ Compare it with Keller's (1973) solution $f=3.5 \phi^{-1.8}$ 
- Tholeiite

- Tholeiitic Olivine Basalt

- Alkalic Olivine Basalt

$\triangle$ Hawaiite

- Hawaiite $\rightarrow$ Alkalic Olivine Basalt

- Mugearite, ijolite, melilite-nephelinite, ankaramite, basanitoid, trachyte, nephelinite

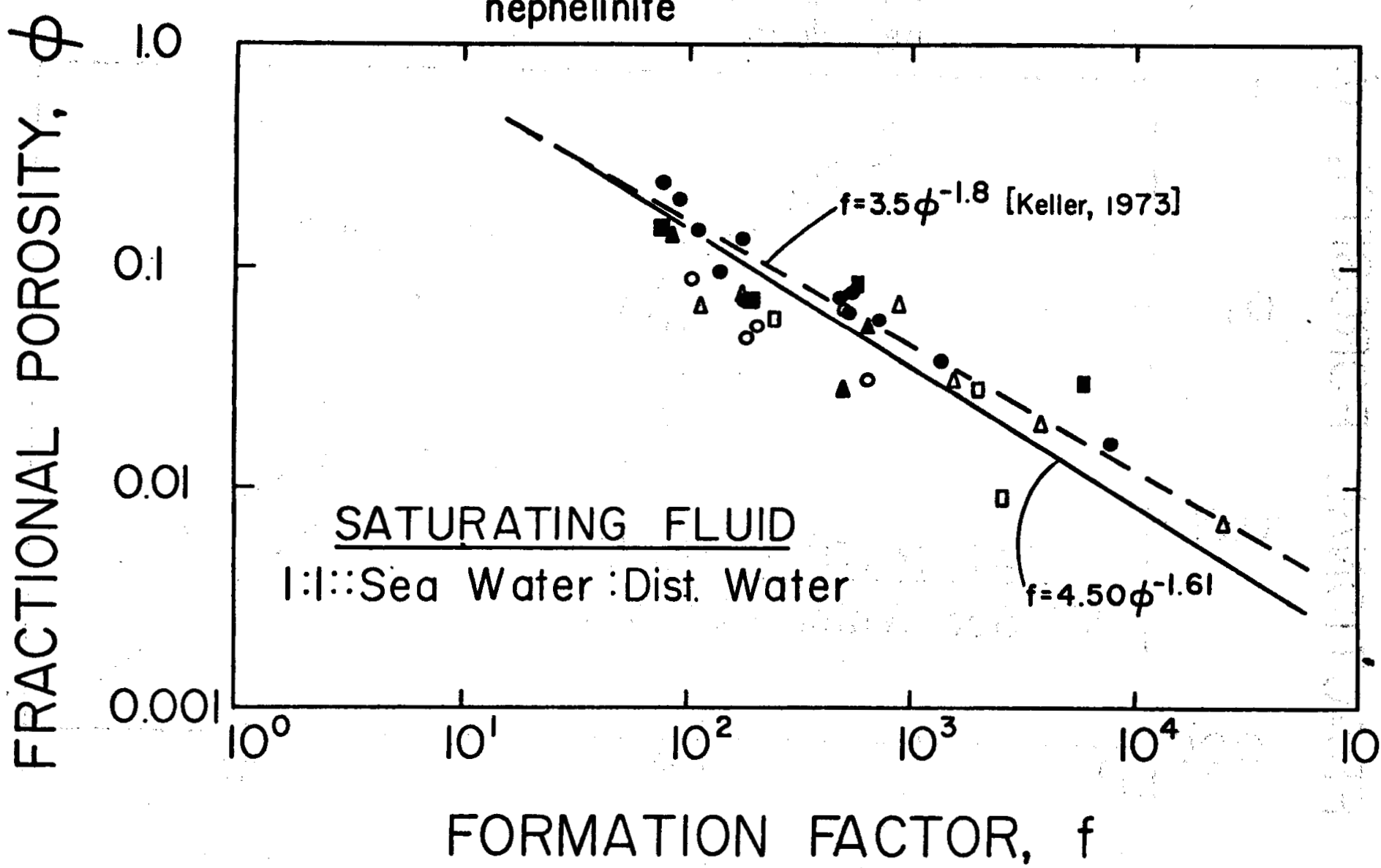

Figure 16. Fractional porosity vs. formation factor for basalts for $1: 1$ seawater-distilled water saturation at $500 \mathrm{~Hz}$ frequency. Best-fit solution js $f=4.50 \phi^{-1.61}$, compared to Keller's (1973) solution $f=3.5 \phi^{-1.8}$. 


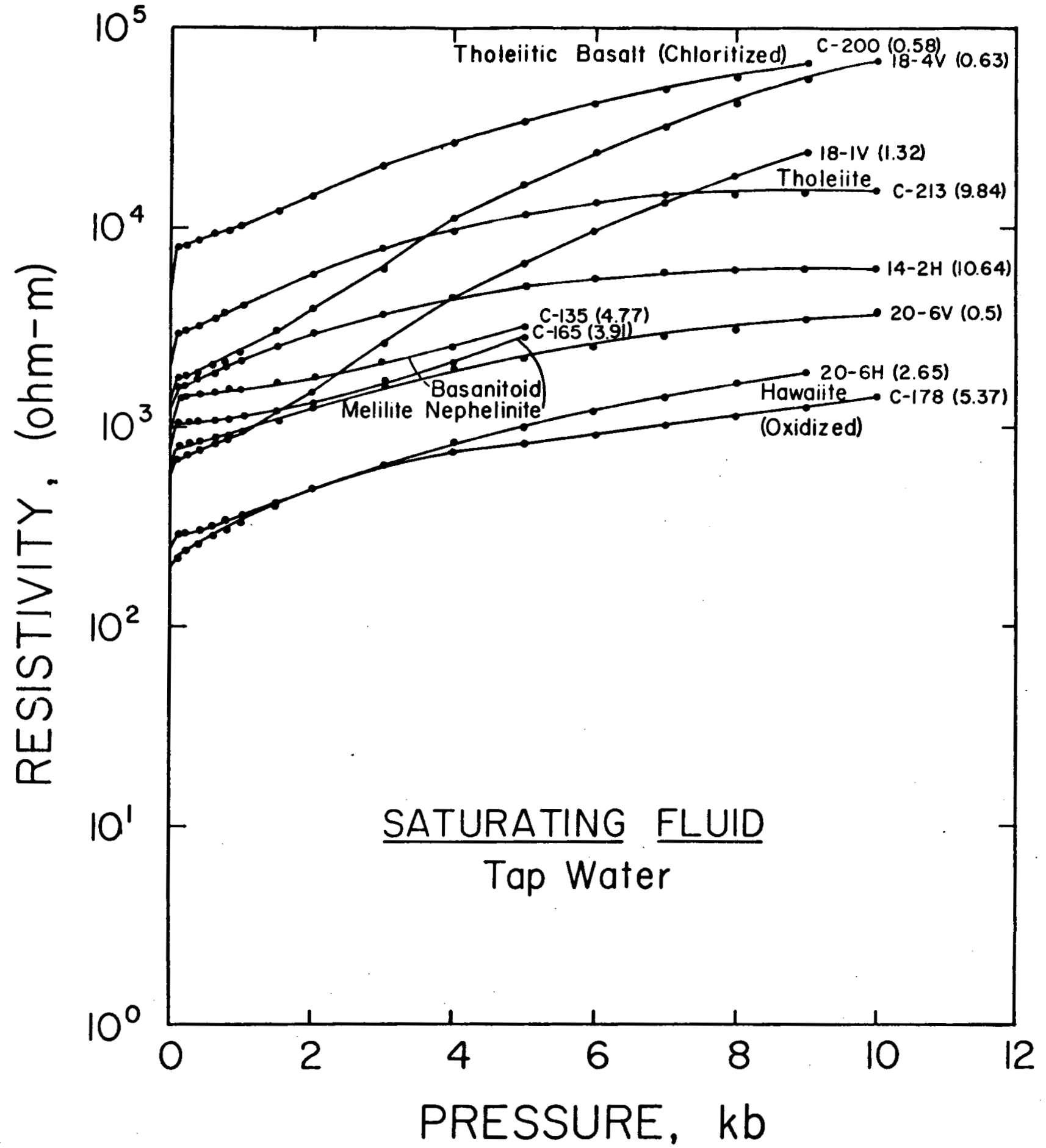

Figure 17. Effect of pressure on resistivity of C-series basalts and those obtained from the Keller drill hole under tap water saturation. Percent porosity is given in parentheses. 

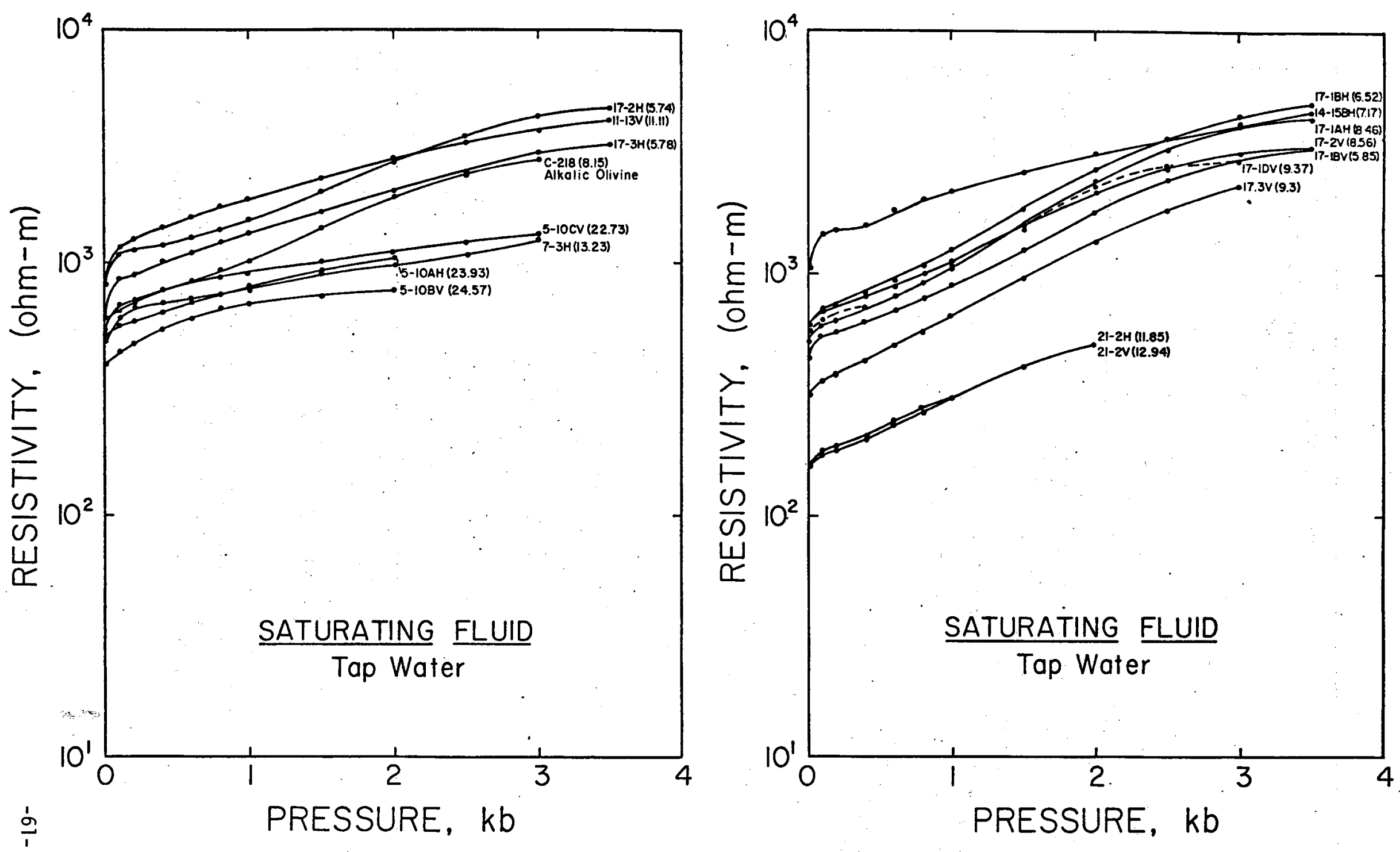

Figure 18. Effect of pressure on resistivity of C-series basalts and those obtained from the Keller drill hole under tap water saturation. Percent porosity is given in parentheses. 


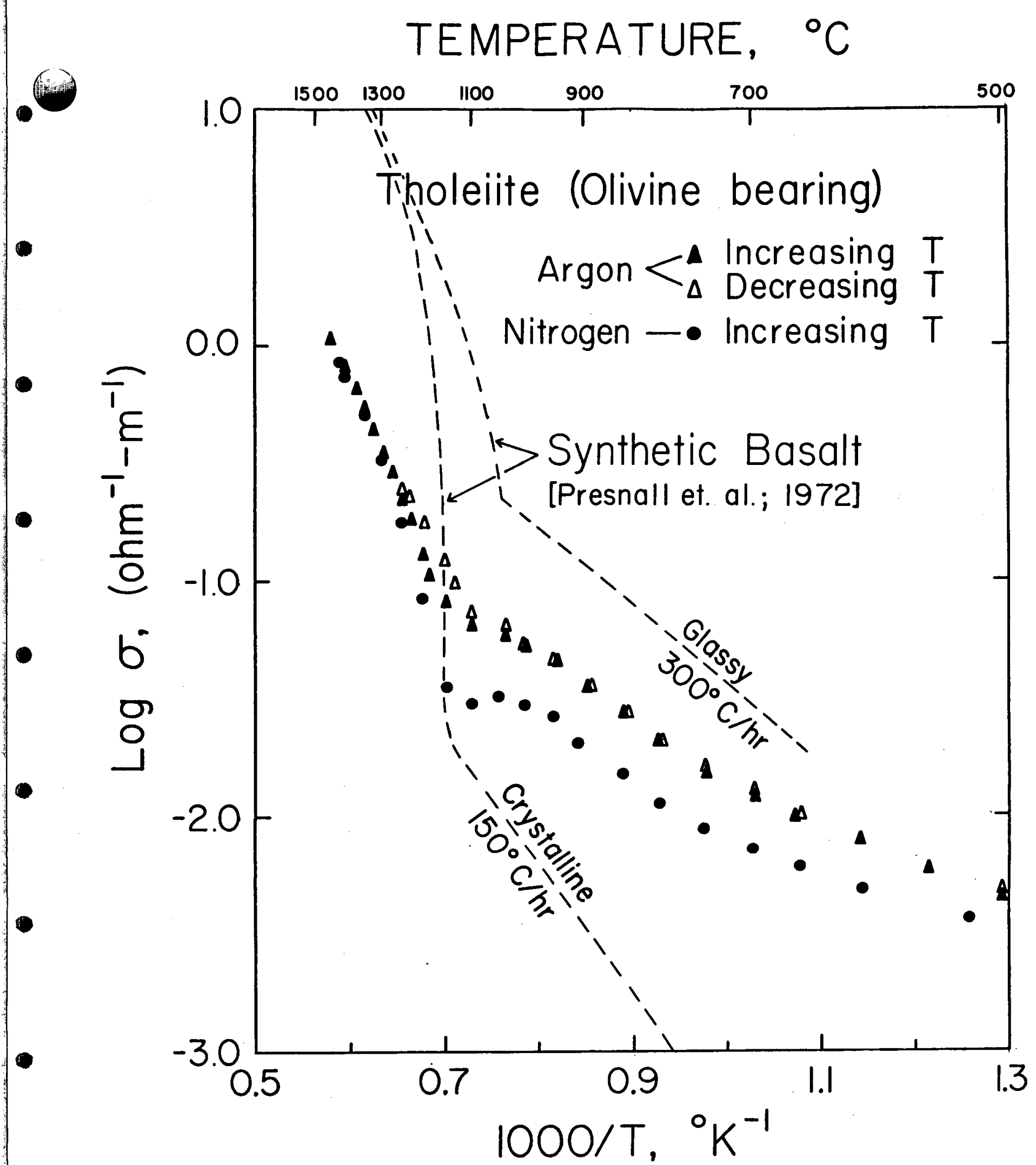

Figure 19. Log conductivity ( $\sigma$ ) vs. 1000/T for a olivine-bearing tholeite. 


\section{Progress Report}

GEOELECTRIC SURVEYS

\section{D.P. Klein, J. Kauahikaua and E.T. Sakoda}

Surveys to locate low-resistivity zones which could indicate concentrations of hot-water have been performed in the areas indicated in Fig. 20. Our primary survey was made using the "time-domain" inductive technique, which because of its large power has the ability to probe deeper than conventional electric survey methods. Several other methods were also employed in order to define the electrical properties in the shallow parts of the rock strata. These secondary surveys are described in Klein and Kauahikaua (1975), and have provided important constraints in the interpretation of the time-domain data.

The main electrical surveys were completed in 1974; the past year has seen fundamental progress toward a more refined interpretation of the data. The first two parts of this report essentially summarize the survey results as reported in the Hawaii Geothermal Project Summary Report for Phase I, May 1975. The last part of this report outlines our recent work on data analysis.

\section{Reconnaissance Surveys}

Time-domain induction soundings were made in the lower regions of the southwest rifts of both Kilauea and Mauna Loa volcanoes (areas 3 and 4, respectively, Fig. 20). Soundings were also made in the saddle area between the Hualalai and Mauna Loa domes (area 5, Fig. 20). Based on apparent resistivity (see Klein and Kauahikaua, 1975) it is fairly certain that none of the above areas contain significant geothermal prospects.

Keller's group (1973) made reconnaissance bipole-dipole galvanic measurements in the region on the northwest coast of Hawaii (area 2, Fig. 20) where water wells show slightly anomalous temperatures of a few degrees $\left({ }^{\circ} \mathrm{C}\right)$ above normal. These latter measurements also did not provide evidence of low resistivities that could be geothermally generated.

Keller's (1973) main reconnaissance effort was in Area 1 (Fig. 20). Here the bipole-dipole survey isolated an anomalous region on the lower part of the rift zone of Kilauea Volcano (the "Puna Anomaly"). Apparent resistivities in this anomaly range from 5 to 20 ohm-meters (ohm-m) which are low enough to be associated with hot-water saturated rock.

Based on the above results, we concluded that the most promising candidate for a geothermal source was the "Puna Anomaly." Subsequent efforts were concentrated in this area. 
Figure 20 Survey Areas on Hawali Island with mean "minimum apparent resistivity" values in ohm-meters $(\Omega-m)$ determined from time domain induction sounding. Small circles show locatian of known well temperatures. These temperatures are normal (about $22^{\circ} \mathrm{C}$ ) everywhere except in Area 2 (about $27^{8} \mathrm{C}$ ) and in the "Puna Anomaly" (range from about 30 to $90^{\circ} \mathrm{C}$ ). The survey methods used are indicated by keyed letters for each area.

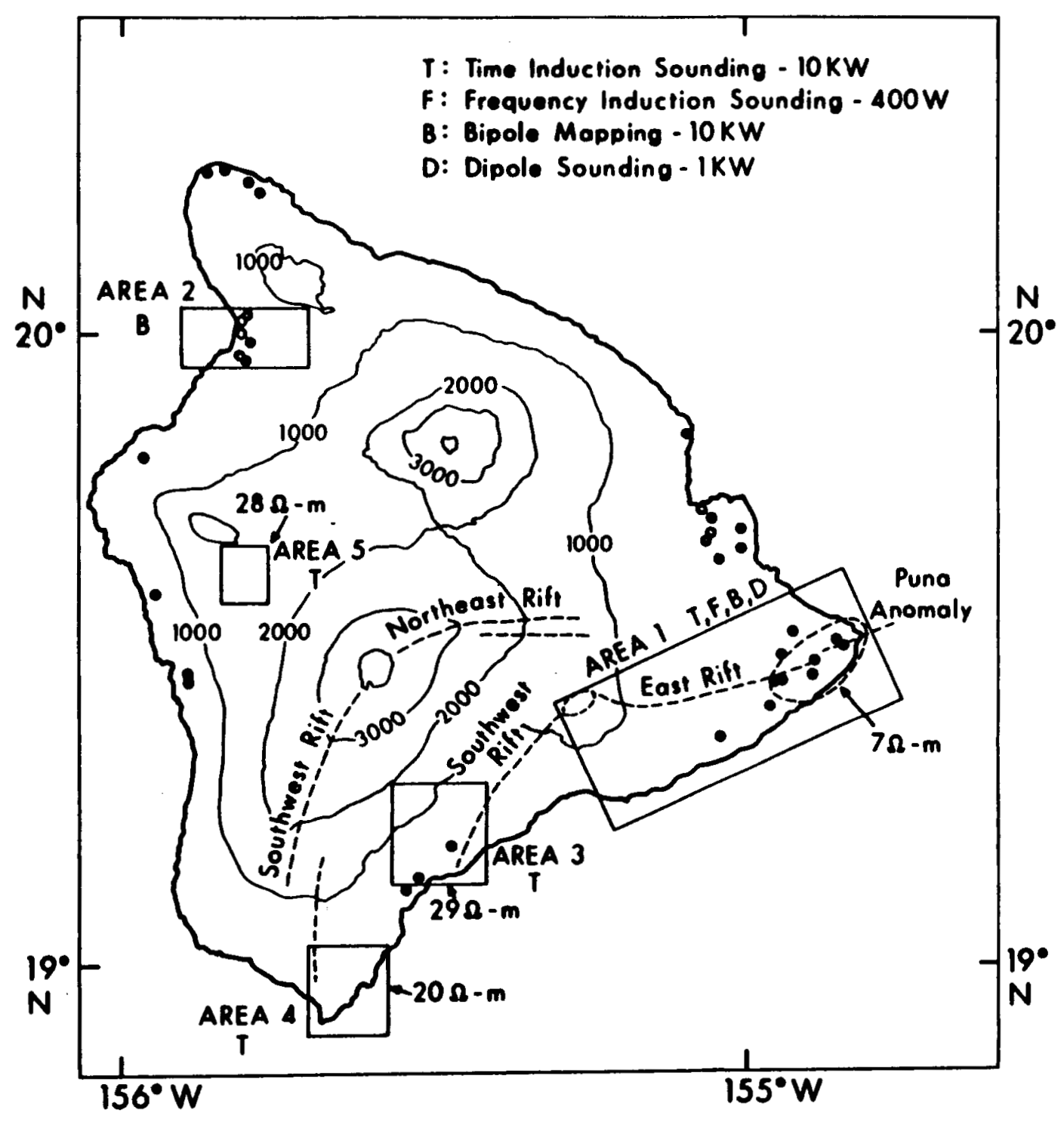


II. Surveys in Puna, A Possible Geothermal Anomaly

The Puna region is shown in Fig. 21. This region is traversed by the east rift of Kilauea Volcano. The "rift" is characterized by numerous thin dikes, several eruptive vents (some as recent as 1962), steam seeps and local areas of warm ground. The low resistivity anomalies are generally along the trend of the most recent eruptive loci. The areas generally around "A" and "B" (Fig. 21) have been considered the most promising for geothermal exploratory drilling.

Thirty-one time-domain induction soundings were obtained in this area by Hawaii Institute of Geophysics (HIG) personnel. The induction resistivity values in Fig. 21 may be considered as an estimate of the average earth resistivity within the zone of induction between the source and receiver; the depth of this zone would be about 500 to 1000 meters. The time-domain inductive apparent resistivity contours in Fig. 21 were controlled by placing the calculated resistivities at a point half-way-between the source and receiver. Such a presentation incorporates the assumption that the region of "average" influence (the sampling region) lies between the source and receiver. The dc contours in Fig. 21 are from a limited bipole-dipole mapping survey by HIG over a particular target of low resistivity.

The above listed data plus C. Zablocki's self-potential map of Puna provided the primary data base for our interpretation of geothermal prospects (see conclusions) in Puna. However, secondary interesting information regarding the nearsurface thermal waters was obtained from several shallow soundings using the loop-loop induction method and the Schlumberger DC method (see Klein and Kauahikaua, 1975).

These data show a very resistive $6000 \mathrm{ohm}-\mathrm{m}$ galvanic resistivity overburden overlying a conductive substratum. The top of the conductive material is generally close to sea level and is considered to be a marker between conductive watersaturated basalts below and dry basalts above.

The inductive resistivity of the second layer ranges from 2 to $10 \mathrm{ohm}-\mathrm{m}$, which is lower than expected for cool-water-saturated rocks and would be more typical of rocks in brackish to saline water having temperatures of $50^{\circ}$ to $100^{\circ} \mathrm{C}$. Well-hole temperature profiles (D. Epp and J. Halunen, personal communication) indicate that, below the rift (i.e., seaward), temperatures are indeed encountered in this range. Commonly however this temperature regime is only a few meters thick and then cools again. 
Figure 21. Time-domain induction sounding stations (circles) and source locations (numbered bars) in Puna. The numbers by the stations indicate the source location. The thin contours relate to the time-domain data (see text). The wider contours are based on bipole-dipole mapping from the unnumbered sources. The drilling site is located at the triangle.

के

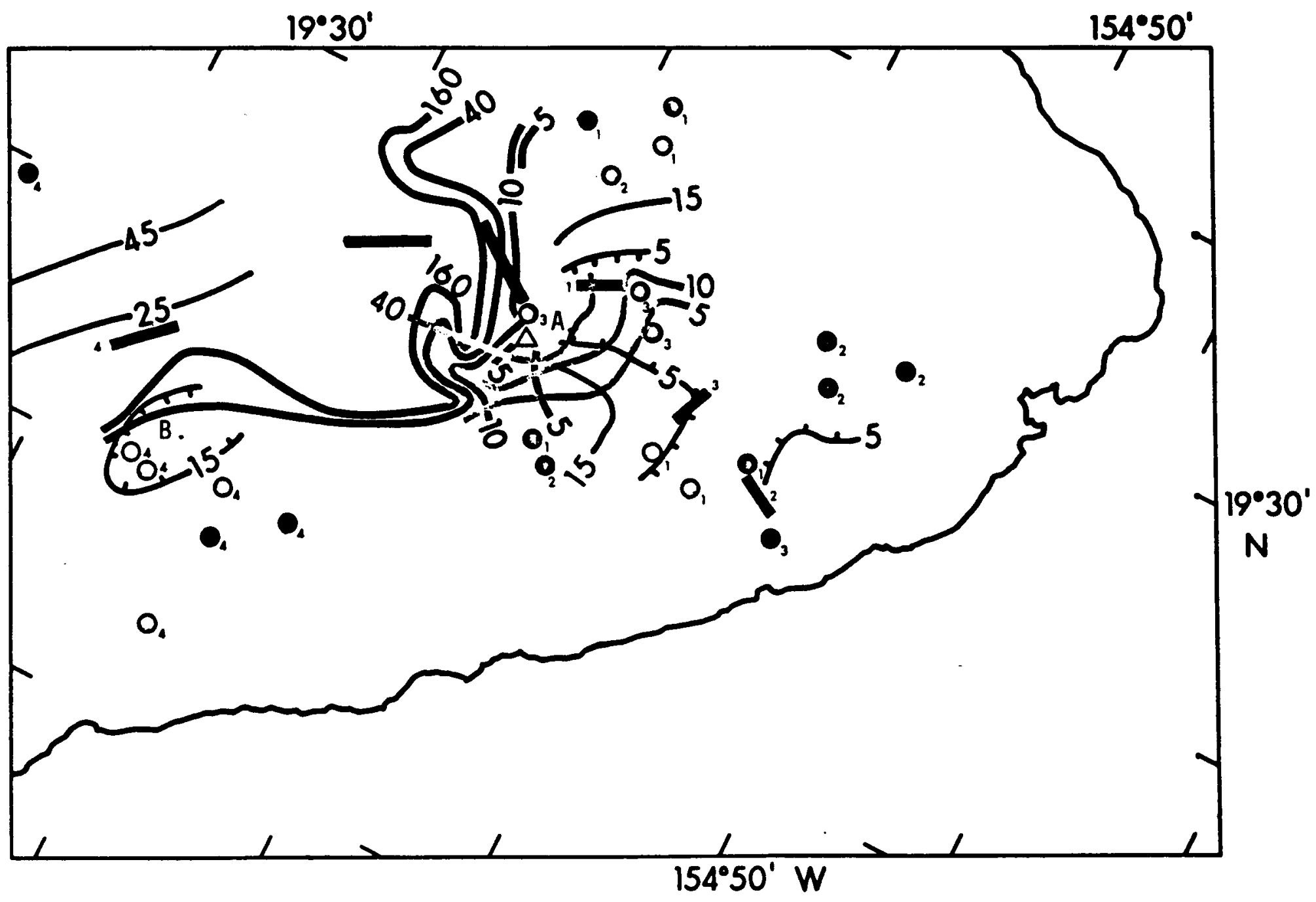




\section{Analysis of Time-Doma in Data}

Theoretically, measuring the time response of the earth to a step current in a grounded wire is the same as measuring the frequency response at all possible frequencies. Unfortunately conventional interpretation of the time response involves a large number of approximations. Therefore, we tried an approach based on standard digital processing techniques, appealing to statistics to determine how much interpretation was allowable.

The basic procedure for obtaining the time response of the earth from field data is:

1. digitize graphical records at 250 samples/sec for up to one second.

2. stack about 10 events per site.

3. obtain estimate of pure error, i.e. error of measurement.

4. deconvolve instrument response from the signal.

The signal that remains should be the earth response. However, due to recording and sampling techniques, the signal we reduced was strongly aliased. The aliasing was only small at frequencies below $35 \mathrm{~Hz}$. Consequently the time response of the earth from our determinations only included frequencies lower than $35 \mathrm{~Hz}$.

Conventional methods, as used by Skokan (1974) and Jackson and Keller (1972), tried to remove the effects of aliasing by using a non-linear filter. The effects of this filter are unreported, although they are expected to be like smoothing.

It would be desirable to do a direct layered-earth-inversion with this data in the time domain. The best-fit parameters for each layer and their uncertainties could be determined by least-squares criterion. Unfortunately, except for a few cases, the time response of a layered earth is not easily obtained in a closed expression. Present methods of calculating particular time responses require the numerical approximation of two Bessel integrals.

In view of the complexity of a full inversion, an interpretation method involving partial inversion was developed. Since the response of a layered earth can be expressed as the response of a homogeneous half-space having the properties of the first layer plus a secondary response due to the layering, removal of the first layer response would greatly enhance interpretation of any layering (Yost, 1952). Fortunately, the response of a homogeneous earth is available in closed form. Davidon's method was used to minimize the sum-of-squares function,

$$
S=\left\{\left\{y_{i}-\left[\beta_{0}+\beta_{1} H\left(\beta_{2}, t_{j}\right)\right]\right\}^{2},\right.
$$

with respect to three parameters, $\beta_{0}, \beta_{1}$ and $\beta_{2} . H\left(\beta_{2}, t\right)$ is the homogeneous half-space response and $y_{j}$ is the observed response at time $t_{i}$. 
Several theoretical sets of secondary responses for two layer models were calculated in an attempt to categorize them. They all consisted of a 2-peaked signal first of a maximum of one sign followed by a maximum of opposite sign. The time of the first maximum was indicative of the depth to the conductor while its magnitude and sign were indicative of the conductivity contrast.

Such an analysis has been completed for the Puna time response data. The error of model fit agreed well with the error or measurement. This implies that most of the time responses were statistically indistinguishable from the response of a homogeneous earth. Significant deviations did occur from the suggested model, but they occurred commonly in the very early part of the signal. This was uncharacteristic of secondary responses as defined above, so it was concluded that the deviations were not due to deeper layering.

The uncertainty of the parameters was disturbingly large, sometimes over $50 \%$ of the parameter value. The third parameter, $\beta_{2}$, was the best determined of the three, and conductivity determination was based on it. Both $\beta_{1}$ and $\beta_{2}$ are function of conductivity. We initially expected to have a strong correlation between them, but no such correlation was indicated by the data.

To estimate the resolveability of deeper layers, we can examine the ratio of total signal magnitude to secondary signal magnitudes and compare this with commonly obtainable signal-to-noise ratios. Most of the Puna records were noisy with $S / N$ ratios (defined as $V_{\max } /$ [standard error]) between 6 and 16, or an average of 11. The conductivity contrast of a layer at a depth of $3 / 8 \times$ separation must be greater than four or less than 0.1 in order to be detected above the noise. The contrast of a layer at a depth of half the separation must be greater than 20 or less than 0.01 to be detected.

Conclusions

The Puna resistivity anomaly can "ambiguously" be interpreted as being of geothermal origin. Highly saline water reaches to the top of water table virtually everywhere seaward of the rift-zone in the Puna region between the areas of " $A$ " and "B" (Fig. 21). This hydrological abnormality implies thermal instabilities in the water table. However, this fact also makes the delineation of hot zones from cool zones difficult when using resistivity data because a resistivity contrast in a low-resistivity overburden is more difficult to detect. We have not been $a b l e$ to prove massive low resistivity layering at depth which would demonstrate a possible economical zone of hot water. We do have indications of lateral changes in resistivity which show a lower resistivity along two portions of the rift zone in Puna. For reasons outlined in the Summary Report of Phase I, 
May 1975, we believe these are due to the heating of near-rift waters by intrusives associated with the rift zone. Our data however gives no positive indications of the depth or the volume of such heating.

\section{References}

Furgerson, R.B. and G.V. Keller, 1974, Computed dipole resistivity effects for an earth model with vertical and lateral contrasts in resistivity. Unpub. report, Colorado School of Mines, ONR Project NR-081-275.

Jackson, D.B. and G.V. Keller, 1972, "An electromagnetic sounding survey of the summit of Kilauea Volcano, Hawaii," JGR, 77:4957-4965.

Jacobsen, J.J., 1969, "Deep Electromagnetic Sounding Technique," D.Sc. thesis, Colorado School of Mines, pp. 19-42.

Kauahikaua, J., D. Klein, and C. Zablocki, 1975, "A horizontal loop induction survey near Kilauea Volcano, Hawaii," in press.

Keller, G.V., 1973, An electrical resistivity survey of the Puna and Kau Districts, Hawaii County, Hawaii. Unpublished report submitted by Group 7 to the Research Corporation of the University of Hawaii, July 31.

Klein, D.P. and J. Kauahikaua, 1975, Geothermal-geoelectric exploration on Hawai $i$ Island, Preliminary Report, Hawaii Institute of Geophysics, HIG 75-6.

Lee, C.Y., 1973, The dipping layer problem in resistivity, Thesis T-1610, Colorado School of Mines.

Macdonald, G.A., 1973, Geological prospects for the development of geothermal energy in Hawaij, Pacific Science 27, p. 209-219.

Silva, L.R., 1969, "Two-7ayer Master Curves for Electromagnetic Sounding," M.Sc. thesis, Colorado School of Mines, pp. 29-117.

Skokan, C.K., 1974, "A Time-domain Electromagnetic Survey of the East Rift Zone, Kilauea Volcano, Hawaii," Thes is T-1700, Colorado School of Mines.

Vanyan, L.L., 1967, Electromagnetic Depth Soundings, Consultants Bureau, New York.

Yost, W.J., 1952, "The interpretation of electromagnetic reflection data in geophysical exploration - Part I, General theory," Geophysics 17:89. 


\section{Progress Report \\ GEOCHEMICAL SURVEY \\ Pow-foong Fan}

Presented here is an analysis of the hydrology and chemistry of the groundwater of the Puna District, based on data from 16 drilled wells, ten test wells, two shafts and four exploratory geothermal wells. Three types of groundwater occur: (1) perched water located north of Mountain View; (2) dike water located along the east rift zone of Kilauea; and (3) basal water occurring throughout most of the district, except where dike water is present. The east rift zone serves as a barrier to groundwater movement, as demonstrated by the difference in basal water table levels on the two sides of the rift zone. Salinity and temperature of the basal groundwater varies greatly north and south of the $r i f t$ zone due to such factors as differences in precipitation, sea-water intrusion, volcanic activity, flow rates, permeability, and discharge.

Basal groundwater type is predominantly sodium chloride. Water samples taken from geothermal test well \#3 showed dissolved silica values two to three times higher than the $49 \mathrm{mg} / \mathrm{l}$ average for the rest of the island. The mixing of waters of different composition at depth proved to be the most difficult problem encountered in estimating deep water temperatures (Druecker and Fan, 1976).

Investigation of the chemical and isotopic composition of groundwaters have proved useful in the exploration of geothermal resources in Hawaii. Of the three major chemical geothermometers applied, the silica method proved to be best for locating the potential geothermal system and evaluating its temperature. The $\mathrm{Na} / \mathrm{K}$ and $\mathrm{Na}-\mathrm{K}-\mathrm{Ca}$ methods were not applicable in Hawai because of the effects of seawater intrusion. The stable isotope, or oxygen-18-deuterium method, also appears to be affected by seawater intrusion, although some indication of a geothermal effect was resolvable. This method gave additional information on the groundwater hydrology (McMurtry and Fan, 1974).

Based on the silica geothermometer, Kilauea and the area near geothermal test hole no. 3 and the Malama-ki well in the Puna district, Hawai i jsland, appear to be the most promising areas for geothermal systems. This conclusion is supported by the electrical resistivity surveys.

The mineralogy of the hydrothermally altered basalts of the Kailua Volcanic Series from Keolu Hills, Oahu, Hawaii, was examined by X-ray diffraction analysis. Vertical and horizontal clay mineral alteration zones were found. In the vertical zones, chlorite-vermiculite occurs more commonly than chlorite, whereas in the 
horizontal zones, chlorite-montmorillonite and chlorite are more common. The zeolites are calcium zeolites which commonly coexist with quartz; laumontite is the dominant zeolite in the study area. The latter's widespread distribution in the Kailua Volcanic Series suggests that low temperatures (approximately $300^{\circ} \mathrm{C}$ ) prevailed during the formation of secondary minerals and indicates that as much as 3,500 feet of weathering has occurred since caldera formation (Fujishima and Fan, 1976). The identification and understanding of different types of Hawaian hydrothermal alteration products are useful background information prior to the drilling project.

\section{References}

Druecker, M. and Fan, Pow-foong. (1976) Hydrology and geochemistry of groundwater in Puna, Hawaii. Ground Water (manuscript submitted).

Fujishima, K.Y. and Fan, P.F. (1976) Hydrothermal mineralogy of Keolu Hills, Oahu, Hawaii. Contribution to Mineral and Petrology (manuscript submitted).

McMurtry, G.M. and Fan, P.F. (1974). Geochemistry of a potential geothermal area -- Puna Rift zone of the island of Hawaii, (Abstr.), EOS Trans. Am. Geophy. Un., Vo1. 56, p. 1199. 


\section{HAWAII GEOTHERMAL PROJECT \\ ENGINEERING PROGRAM \\ Paul C. Yuen}

The principal objectives of the Engineering Program are 1) to use mathematical models to obtain basic information about geothermal reservoirs and their characteristics during discharge through a well (Task 3.1), and 2) to plan and design an environmentally-acceptable, research-oriented geothermal power plant suitable for liquid-dominated geothermal reservoirs (Task 3.6). Research during the past period has been devoted primarily to the theoretical and physical modelling of geothermal reservoirs, preparation for the engineering testing of wells to be drilled on the island of Hawaii, and system studies of methods of converting the heat energy in a liquiddominated geothermal reservoir to electrical energy. Quarterly progress reports, technical memorandums and technical reports written during Phase I are listed in the Surmary Report for Phase I, May 1975. Since that time, results of the research effort have been reported in the following reports and presentations:

1. Hawaij Geothermal Project Engineering Program Progress Report, January 1, 1975 to August 31, 1975.

2. "Numerical Solutions for Steady Free Convection in Island Geothermal Reservoirs," Technical Report No. 8, by P. Cheng, K.C. Yeung and K.H. Lau, August 1975. Presented at 1975 International Seminar on Future Energy Production--Heat and Mass Transfer Problems, Dubrovnik, Yugoslavia, August 1975.

3. "The Effect of Steady Withdrawal of Fluid in Confined Geothermal Reservoirs," Technical Report No. 9, by P. Cheng and K.H. Lau, May 1975. Presented at the Second United Nations Symposium on the Development and Use of Geothermal Resources, San Francisco, California, May 20-29, 1975.

4. "Similarity Solutions for Free Convection About a Dike," Technical Report No. 10, by P. Cheng and W.J. Minkowycz, October 28, 1975.

5. "Free Convection About a Vertical Cylinder Embedded in a Porous Medium, "Technical Report No. 11, by W.J. Minkowycz and P. Cheng, November 5, 1975.

6. "Numerical and Analytical Studies on Heat and Mass Transfer in Volcanic Island Geothermal Reservoirs," presented at NSF Workshop on Geothermal Reservoir Engineering and Well Stimulation, Stanford University, Stanford, California, December 15-17, 1975. 
7. "Buoyancy Induced Flows in a Porous Medium Adjacent to Impermeable Horizontal Surfaces," Technical Report No. 12, by $P$. Cheng and I-Dee Chang, in preparation.

In January 1976 four members of the Engineering Program, Drs. Bill Chen, Ping Cheng, Patrick Takahashi, and Paul Yuen, spent three days on Hawaii in a training session to learn geothermal well-testing techniques. The session was conducted by Mr. L. O. Hunter of KRTA, New Zealand, and consisted of pressure and temperature measurement methods for downhole well testing under high pressure, high-temperature reservoir conditions. Test equipment used was manufactured by the Kuster Company of California. The engineers learned proper equipment setup, test methods, and maintenance procedures for the equipment. Actual testing was performed in the field using the research well drilled near Kilauea by Dr. George Keller of the Colorado School of Mines.

The training program was conducted to enable engineering researchers to become familiar with well testing equipment and procedures prior to the completion of the well currently being drilled in Puna. Further testfamiliarization runs are planned using a hot water well also in the Puna district as well as the well being drilled. The latter tests will be run after penetration of the water table during the off periods in the drilling schedule.

Summaries of the research results for each task follow: 
A. Timetable

1. Numerical Modelling of Geothermal Reservoirs

Investigators: P. Cheng, K. H. Lau, and L. S. Lau

May 31, 1975

1. Complete numerical solutions for heat transfer and fluid flow characteristics in an axisymetric geothermal reservoir

2. Complete numerical solution of steady state pumping in a confined geothermal reservoir

August 15, 1975

1. Complete numerical solution of steady reinjection in a confined geothermal reservoir

2. Formulate problem of transient responses in geothermal reservoirs with pumping and reinjection

December 31, 1975

1. Complete numerical solution of steady state pumping and reinjection in unconfined geothermal reservoirs

2. Complete finite element solution of free convection in a two-dimensional geothermal reservoir with irregular geometry ( 1 inear model)

3. Initiate numerical solution of the effects of geothermal heating on Ghyben-Herzberg lens

4. Complete analytical studies of free convection about vertical and horizontal surfaces

May 31, 1976

1. Complete numerical solution of the effects of geothermal heating on Ghyben-Herzberg lens

2. Complete numerical solution of transient pumping and reinjection in liquid-dominated geothermal reservoirs 
2. Well Test Analysis and Physical Modelling

Investigators: B. Chen, L. S. Lau, and P. Takahashi

Apri1, 1975

1. Complete literature survey

2. Develop well test and analys is methodology

3. Initiate computer program to combine type curve matching and mass/energy balance

June, 1975

1. Initiate physical model tests

August, 1975

1. Interact with drilling manager on logging, coring, drill stem testing and wellhead completion hardware and techniques

2. Complete manuscript--"Update on the State-of-the-Art in Geothermal Reservoir Engineering

November, 1975

1. Order well measurement equipment from Kuster

2. Integrate WASP (Water and Steam Properties) subroutine into predictive model

December, 1975

1. Complete preliminary unpressurized physical model tests

January, 1976

1. Complete training session for geothermal well test

2. Initiate pressurized model test runs

March, 1976

1. Complete preliminary pressurized physical model tests

2. Complete computer program capable of predicting geothermal reservoir performance

June, 1976

1. Initiate series of drawdown, buildup and water injection tests after well completed

2. Predict well performance

3. Analyze data of model studies and design final pressurized physical model 


\section{TASK 3.1 GEOTHERMAL RESERVOIR ENGINEERING}

B. Progress to Date

Research work in the areas of numerical modelling, physical modelling, and well analysis are continuing. A surmary of work done during Phase I of the grant is reported in Reference [1]:*

1. Numerical Modelling of Geothermal Reservoirs

During the past twelve months, the following four problems have been investigated.

a. Effects of Steady Withdrawal of Fluids in Confined Geothermal Island Aquifers

Consider an island aquifer confined by caprock on the top, heated by an impermeable surface at the bottom, and recharged continuously from the ocean (see Fig. 3.1-1). It is of interest to investigate the effects of the location of a production well drilled to the confined aquifer, and of the withdrawal rate on heat transfer and fluid flow characteristics in the aquifer.

The formulation of the problem is given in Reference [2] where the governing non-linear partial differential equations are expressed in terms of dimensionless dependent variables $\theta$ and $P$ and independent variables $R$ (or $X$ ) and $Z$. The parameters for the present problem are the modified Rayleigh number, $\mathrm{Ra}$, the aspect ratio, $L$, and the dimensionless withdrawal rate, $Q$, which is given by $Q=Q * / h \alpha$ for a cylindrical reservoir and $Q=Q^{\star} / \alpha$ for a rectangular reservoir where $Q^{*}, h, \alpha$ are respectively the dimensional withdrawal rate, the height of the reservoir, and the equivalent thermal diffusivity.

Numerical solutions were obtained for $R a=500$ and $L=4$ for the following cases:

1) A cylindrical reservoir with a sink at $(0,0.4)$ and with a withdrawal rate of $-25 \leq 0<0$. The prescribed temperatures are $\theta_{a}=\theta_{S}=0$ and $\theta_{L}=\exp -(2 R)^{2}$.

2) A two-dimensional rectangular reservoir with a sink at $(0,0.4)$ and with a withdrawal rate of $-75 \leq Q<0$. The prescribed temperatures are $\theta_{a}=\theta_{s}=0$ and $\theta_{1}=\exp \left[-(2 x)^{2}\right]$.

*Task 3.1 References are 1isted on pages 101 and 102. 


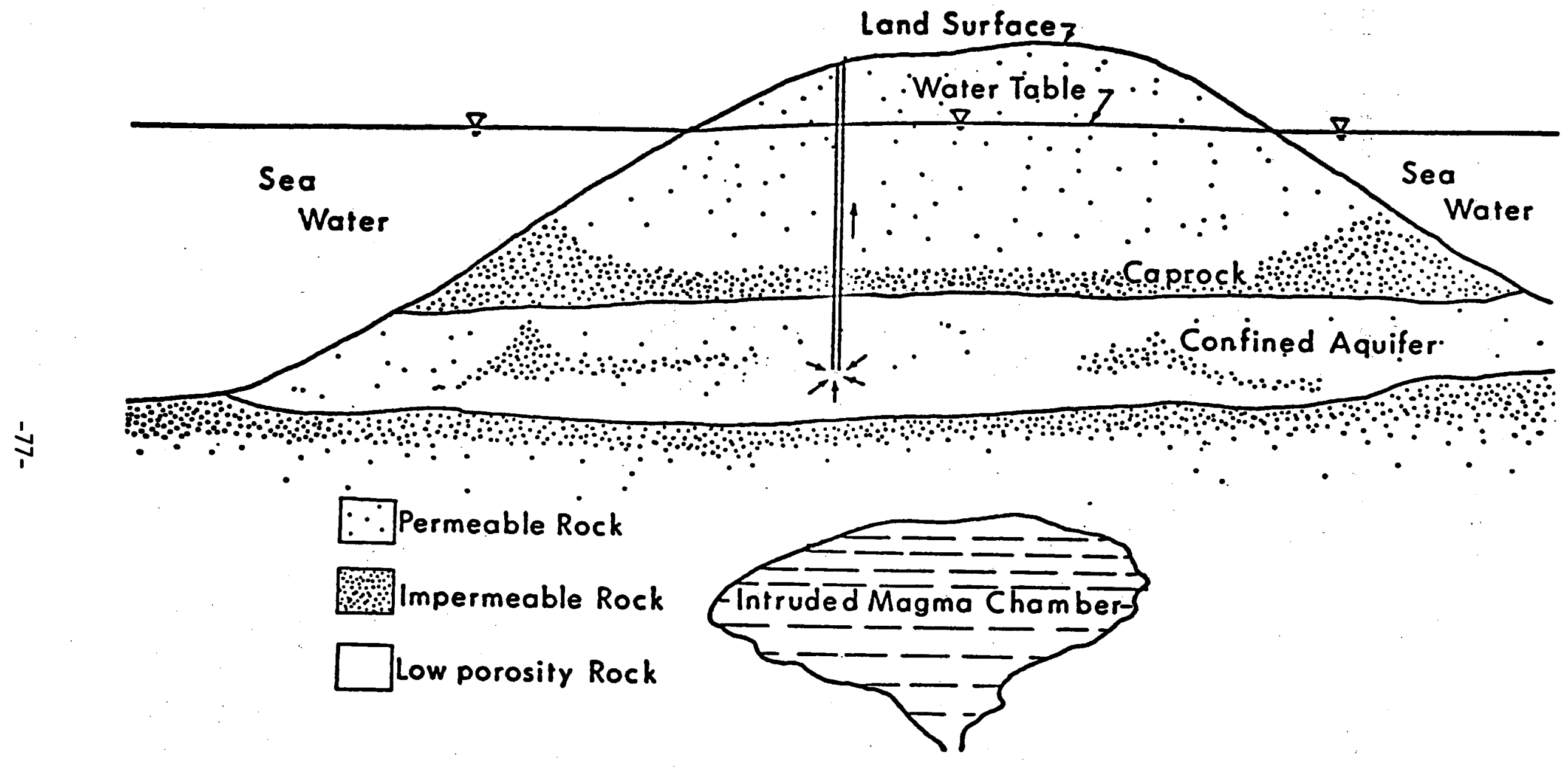

Figure 3.1-1 Withdrawal of Fluids from a Geothermal Reservoir 
3) A two-dimensional rectangular reservoir with an off-center sink at $(0.4,0.4)$. The prescribed temperatures and the magnitude of sink strength are the same as those of Case 2.

4) A two-dimensional rectangular reservoir with two sinks of equal strength at $( \pm 0.4,0.4)$. The prescribed temperatures and the magnitude of sink strength are the same as those of Case 2.

Figure 3.1-2 shows the isotherms in an axisymetric geothermal reservoir for withdrawal rates of $Q=0,-2$, and -25 . It is noted that the isotherms begin to show some signs of contraction when the magnitude of the dimensionless withdrawal rate is increased. At $Q=-25$, the isotherm for $\theta=0.2$ is almost collapsed although the shape for $\theta=0.8$ is hardly changed.

Figure 3.1-3 shows the isotherms in a rectangular geothermal reservoir with a line sink at $(0,0.4)$ for $Q=0,-25$, and -75 . As in Fig. 3.1-2, the isotherms begin to contract as the withdrawal rate is increased. It should be emphasized that the definitions of the sink strengths for a point sink and a line sink are different and therefore their relative magnitudes cannot be compared.

The unsymmetric isotherms shown in Fig. 3.1-4 are due to off-center withdrawal of fluids in a rectangular reservoir. A comparison of Figs. 3.1-3 and 3.1-4 shows that the rate of collapse of isotherms is faster for the off-center withdrawal of fluids.

Figure 3.1-5 shows the effect of withdrawal rates on the isotherms in a rectangular geothermal reservoir with two sinks of equal strength, located symmetrically with respect to the heat source. Whereas the isotherms in Figs. $3.1-3$ and 3.1-4 are almost collapsed at $Q=-75$, the isotherms in Fig. 3.1-5 do not collapse at twice the withdrawal rate. On the contrary, the extent of isotherms for $\theta=0.5$ and $\theta=0.8$ seems to increase as the withdrawal rates are increased.

A detailed discussion of the problem is given in Reference [2], which was presented at the Second U.N. Symposium in Genthermal Resources, San Francisco, California, May 20-29, 1975.

b. Effects of Steady Reinjection of Fluids in Confined Geothermal Is land Aquifers

The residual water from a geothermal power plant is usually disposed of through deep reinjection wells. It will be of interest to study the effects of reinjection rate, the location of the reinjection well, and the 

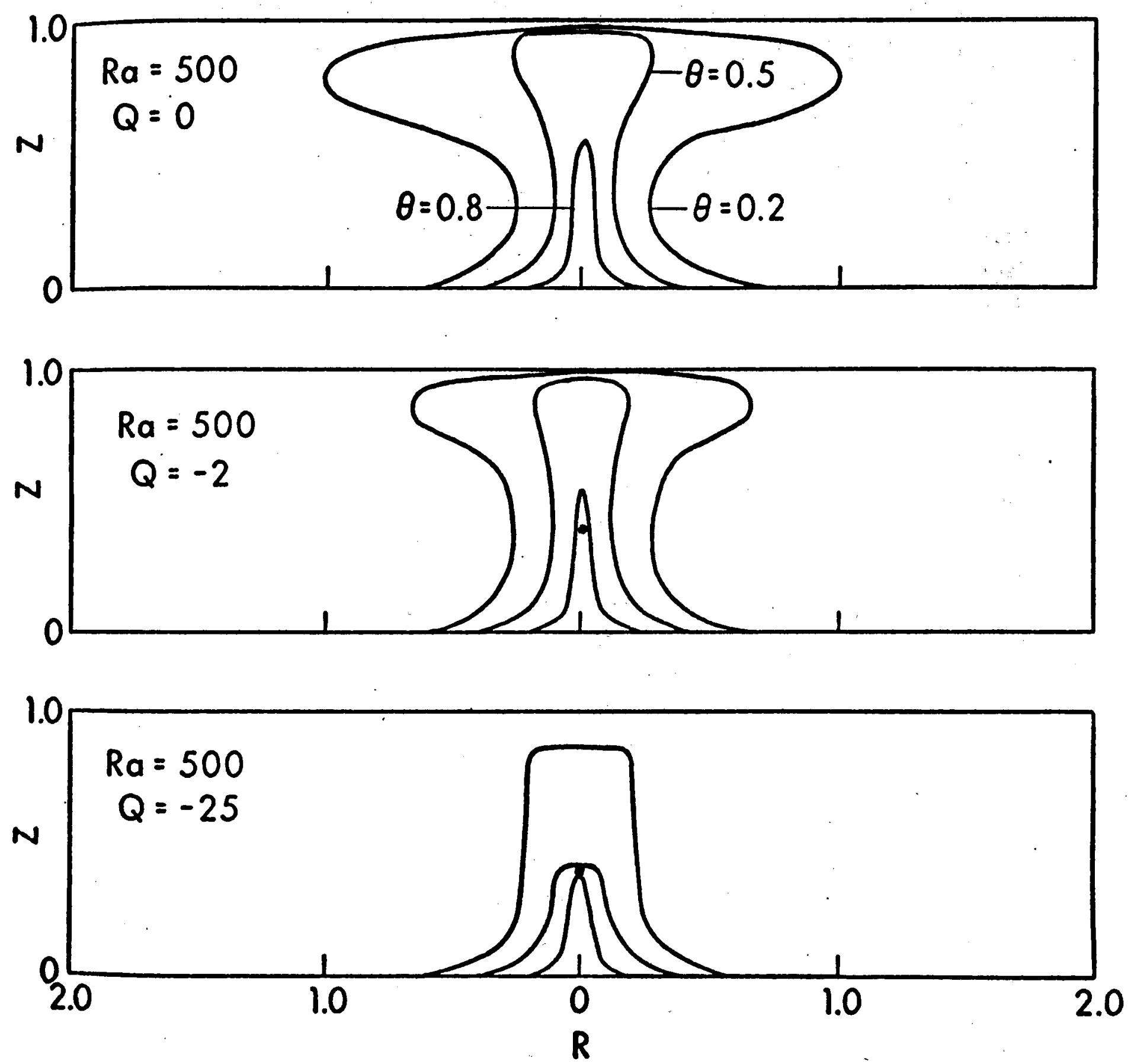

Figure 3.1-2 The Effect of Withdrawal Rates on Isotherms IN AN AXISYMMETRIC GEOTHERMAL RESERVOIR 

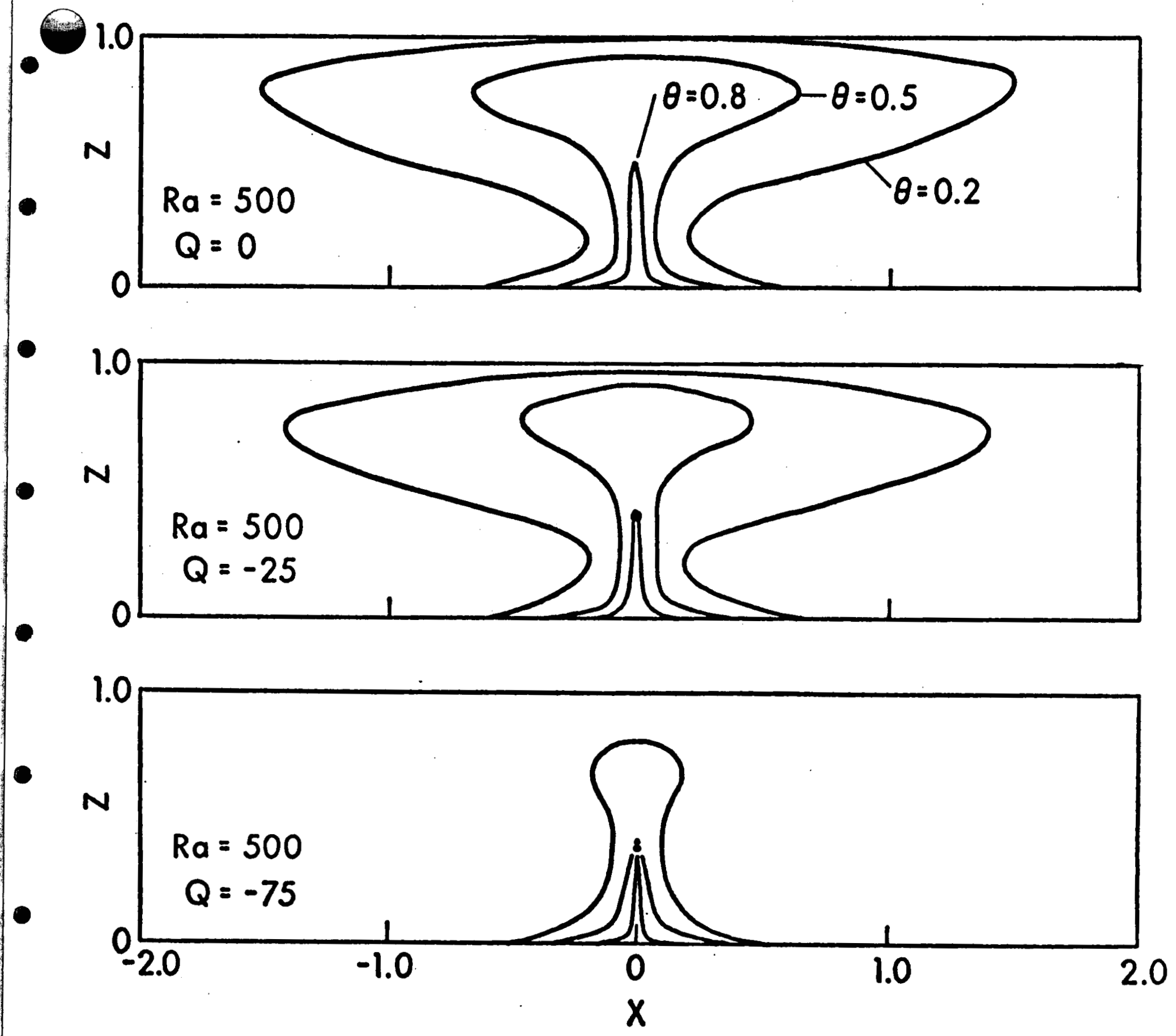

Figure 3.1-3 The Effect of Withdrawal Rates on the Isotherms in a Rectangular Geothermal Reservoir

0 

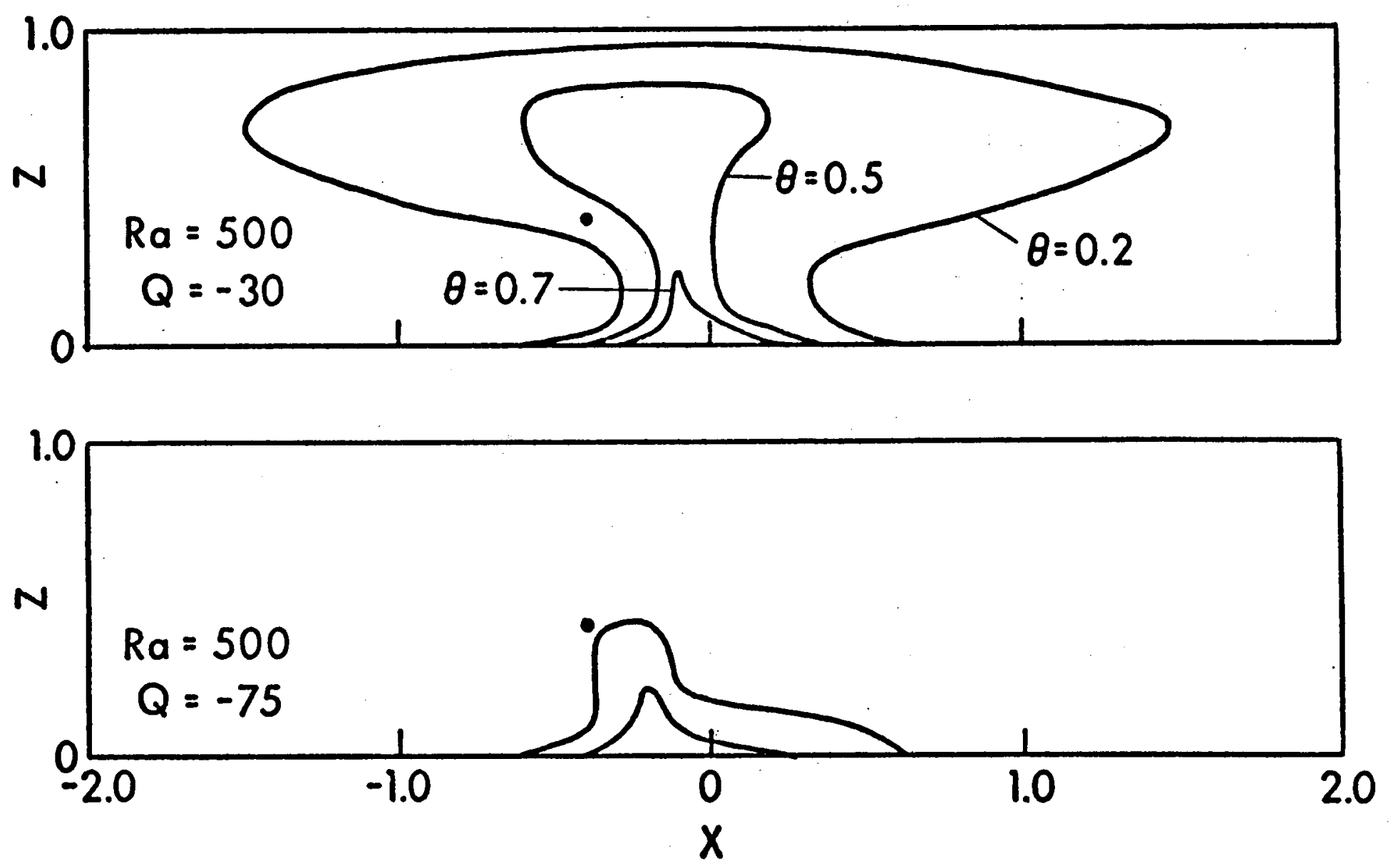

Figure 3.1-4 Isotherms in a Rectangular Geothermal RESERVOIR WITH OFF-CENTER WITHDRAWAL OF Fluids at Different Withdrawal Rates 

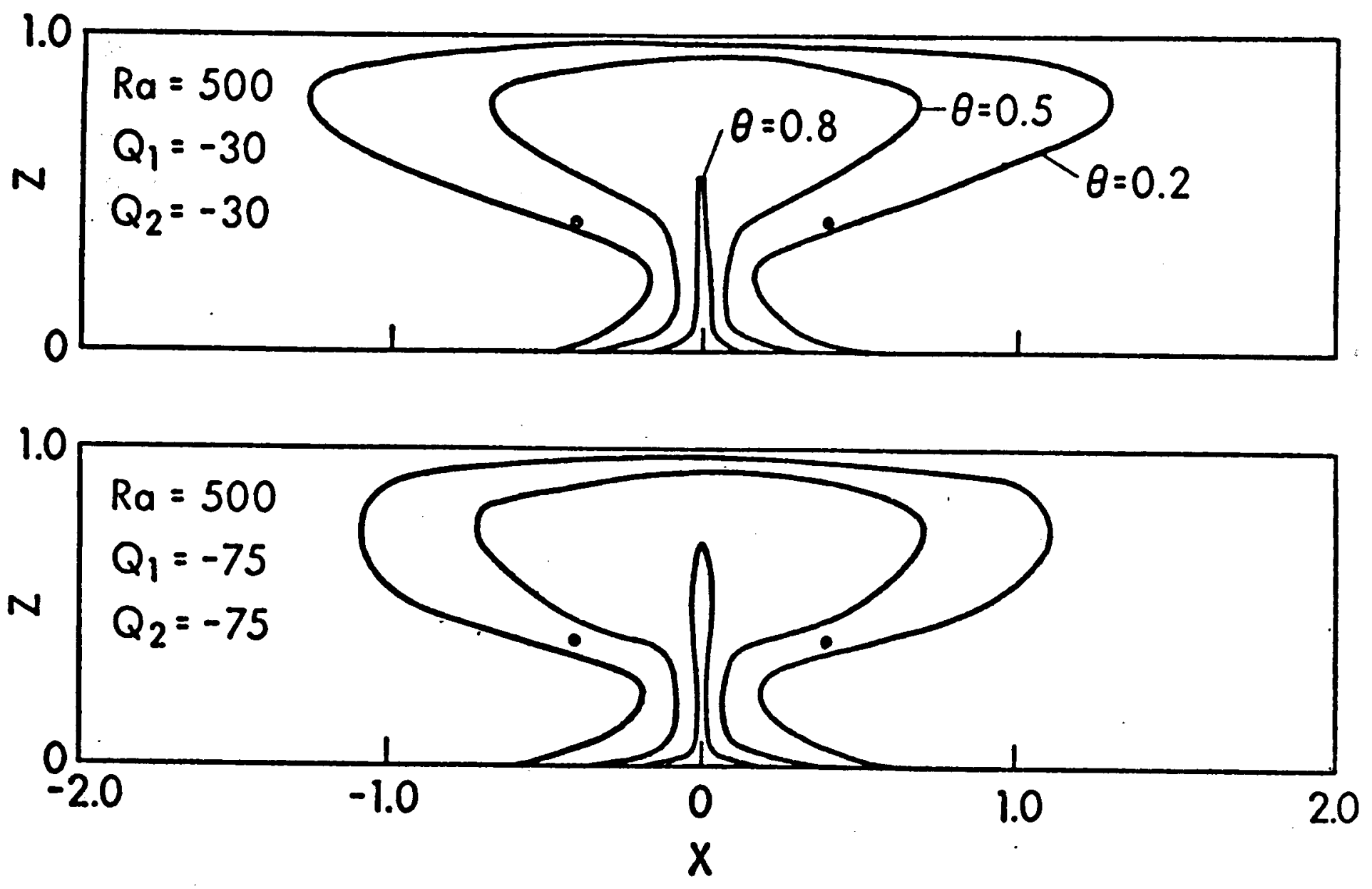

Figure 3.1-5 Isotherms in a Rectangular Geothermal Reservoir With Two Sinks of Equal Strength 
temperature of the reinjected fluid on the heat transfer and fluid flow characteristics in the aquifer.

Figure 3.1-6 shows the effect of reinjection rate on the isotherms in a cylindrical aquifer with $R a=300$. The reinjection well is located at $R=0$ and $Z=0.5$ where the normalized temperature is equal to 0.76 at zero injection rate. If the temperature of the injected fluid is at 0.4 , which is cooler than the corresponding temperature at zero injection rate, a negative buoyancy force is generated which forces the injected fluid to move downward. Thus a portion of the aquifer near the injected well is cooled down. The extent that the aquifer is cooled down depends on the reinjection rate and the temperature of the injected fluid. A detailed discussion of the problem will be reported at a later time. c. Finite Element Analysis of Free Convection in Unconfined Geothermal Reservoirs

Finite element solutions, taking into account the irregular geometry of the boundaries, have been obtained for free convection in unconfined geothermal reservoirs. Since the perturbation equations given in Reference [3] are used, the formulation is only applicable to reservoirs with low Rayleigh number. A report covering this work is currently under preparation.

d. Analytical Studies on Heat and Mass Transfer in Liquid-Dominated Geothermal Reservoirs

From the numerical solutions for free convection in geothermal reservoirs [2], it is observed that boundary layer behavior is pronounced for flow near the heating surface and in the thermal plume at large Rayleigh numbers. Thus the boundary layer approximations analogous to the classical viscous flow theory can be applied. With these approximations, analytical solutions have been obtained for the following problems.

1) Steady Free Convection About Vertical Intruded Bodies. Within the framework of boundary layer approximations, similarity solutions have teen obtained for free convection about a vertical hot dike with surface temperature a power function of distance from the origin; i.e., $T_{w}=T_{\infty}+A x^{\lambda}$ where $T_{w}$ and $T_{\infty}$ are the wall temperature of the surrounding fluid away from the dike. For the special case of an isothermal dike $(\lambda=0)$ with a height $L$ and a width $S$, the 

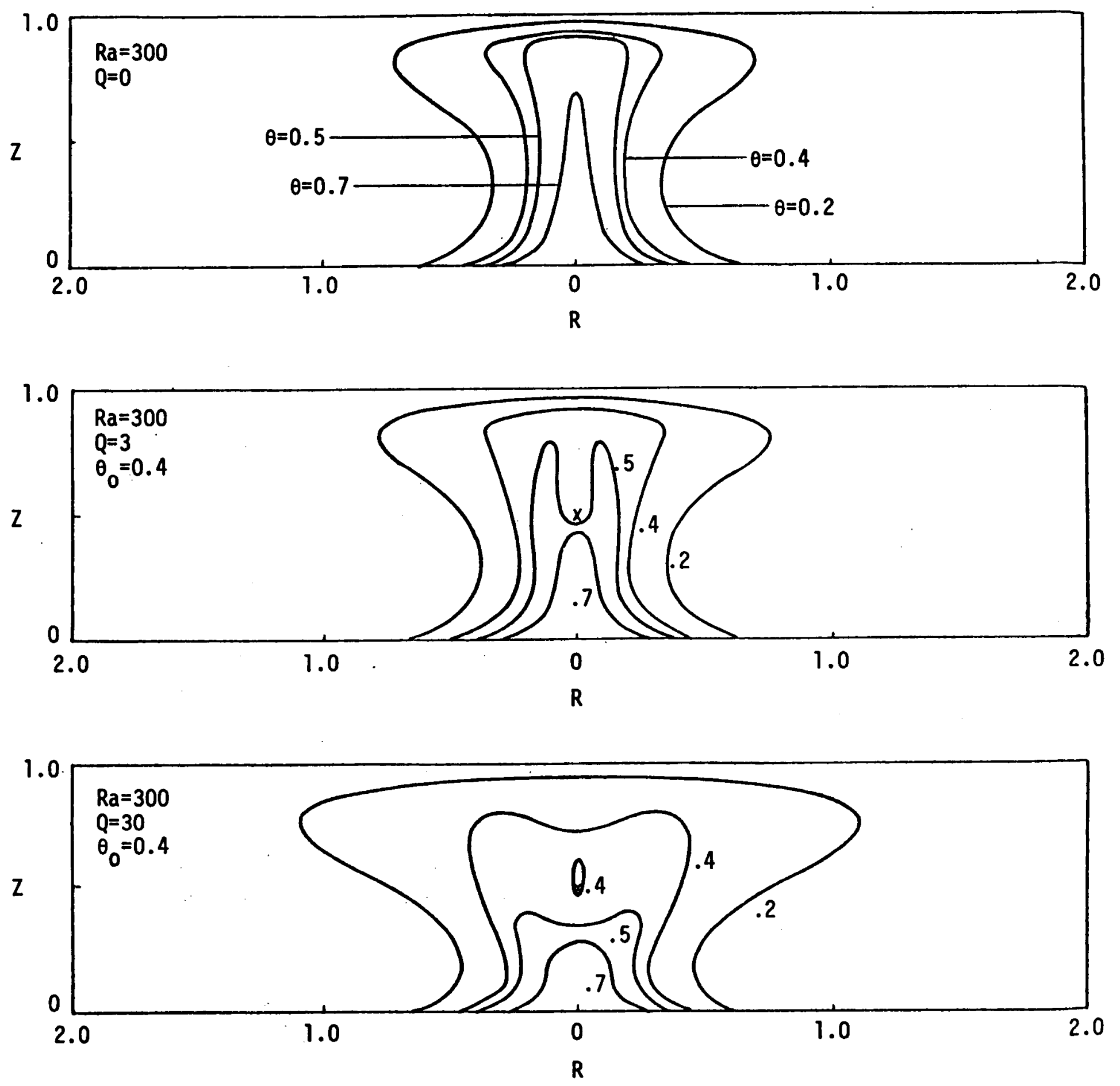

Figure 3.1-6 The Effect of Reinjection Rates on Isotherms in an Axisymmetric Geothermal Reservoir 
local boundary layer thickness $\delta(x)$, and the total surface heat transfer rate $Q$ are given by Cheng \& Minkowycz [4]

$$
\begin{gathered}
\delta(x)=6.3\left[\frac{\mu \alpha x}{\rho_{\infty} g \beta K\left(T_{w}-T_{\infty}\right)}\right]^{1 / 2}, \\
Q=0.88 S k\left(T_{w}-T_{\infty}\right)^{3 / 2}\left[\frac{\rho_{\infty} K \beta g L}{\mu \alpha}\right]^{1 / 2},
\end{gathered}
$$

where $\rho_{\infty}, \mu$, and $\beta$ are the density, viscosity, and the thermal expansion coefficient of the fluid, $K$ is the permeability of the saturated porous medium, $\alpha=k /(\rho C)_{f}$ is the equivalent thermal diffusivity, where $k$ denotes the thermal conductivity of the saturated rock and $(\rho C)_{f}$ the product of the density and specific heat of the fluid.

Approximate analytical solutions for free convection about a vertical cylindrical intrusive have been obtained by Minkowycz \& Cheng [5]. It is found that the ratio of total heat transfer rate for a cylinder to that for a flat plate depends only on the dimensionless parameter $\xi_{L}$ where $\xi_{L} \equiv \frac{2}{r_{0}}\left[\frac{\mu \alpha L}{K \rho_{\infty} \beta g\left(T_{W}-T_{\infty}\right)}\right]^{1 / 2}$ with $r_{0}$ denoting the radius of the cylinder. The ratio varies between 1 to 3 when $\xi_{L}$ varies between 0 and 10 .

2) Buoyancy Induced Flows Adjacent to Heated Impermeable Horizontal Surfaces. Similarity solutions for free convection above a heated horizontal impermeable surface with a power law variation of wall temperature have been obtained by Cheng \& Chang [6]. The local thermal boundary layer thickness $\delta_{T}(x)$ and the total surface heat transfer rate for a horizontal heating surface with a length $L$ and a width $S$ are

$$
\delta_{T}(x)=c_{1}\left[\frac{\mu \alpha x}{\rho_{\infty} g \beta K\left(T_{W}-T_{\infty}\right)}\right]^{2 / 3},
$$


and

$$
Q=C_{2} S K\left(T_{w}-T_{\infty}\right)^{4 / 3}\left[\frac{\rho_{\infty} K \beta L^{3}}{\mu \alpha}\right]^{1 / 3},
$$

where the values of $C_{1}$ and $C_{2}$ depend on the values of $\lambda$ and are tabulated in Table 3.1-1.

Table 3.1-1 VALUES OF $C_{1}$ AND $C_{2}$ FOR EQS. (3) \& (4)

\begin{tabular}{|c|c|c|}
\hline$\lambda$ & $c_{1}$ & $c_{2}$ \\
\hline 0.5 & 4.9 & 1.23 \\
1.0 & 4.4 & 1.32 \\
1.5 & 4.0 & 1.45 \\
2.0 & 3.6 & 1.57 \\
\hline
\end{tabular}

To gain some feeling of the order of magnitude of various physical quantities given by Eqs. (1-4), computations were carried out for a heating surface of $1 \mathrm{~km}$ by $1 \mathrm{~km}$ at a temperature of $300^{\circ} \mathrm{C}$ embedded in an aquifer at $15^{\circ} \mathrm{C}$. The physical properties used for the computations are $\beta=3.2 \times 10^{-4} / \mathrm{C}, \rho_{\infty}=0.92 \times 10^{6} \mathrm{~g} / \mathrm{m}^{3}$, $C=1 \mathrm{cal} / \mathrm{g}-{ }^{\circ} \mathrm{C}, \mu=0.18 \mathrm{~g} / \mathrm{sec}-\mathrm{m}, k=0.58 \mathrm{cal} / \mathrm{sec}-{ }^{\circ} \mathrm{C}-\mathrm{m}$, and $k=10^{-12} \mathrm{~m}^{2}$. With these values, the boundary layer thickness along a dike increases from zero at the origin to $70 \mathrm{~m}$ at $1 \mathrm{~km}$; the tota 1 heat transfer rate is $75 \mathrm{MW}$. For a horizontal heating surface of the same size, the boundary layer thickness increases from zero at the origin to $200 \mathrm{~m}$ at $1 \mathrm{~km}$ with a total heat transfer rate equal to $20 \mathrm{MW}$. 


\section{Well Test Analysis and Physical Modelling}

Discussion of previous work can be found in prior reports to the National Science Foundation and in-house publications [7]. A summary is available in the July 1975 issue of the American Society of Civil Engineering Journal of the Power Division [8]. A more recent update can be found in the October issue of Geothermal Energy [9]. The following is an overview of the research involved:

- An Assessment of Techniques of Testing Geothermal Wells [12]

- Types of geothermal reservoirs

- Downhole well test measurement techniques

- Reservoir analysis during drilling

- Analysis of well flow characteristics

- Results of international survey on geothermal reservoir engineering

- Cost of downhole geothermal we11 testing equipment

- Well Test Analysis

- Historical work and relation of geothermal to petroleum reservoir engineering

- Materials/Energy equations

- Pressure buildup and formation average pressure

- Water/Steam properties

- Sensitivity analysis

- Computer analysis

- Details on computer program capable of predicting well performance given pressure, temperature, and flowrate over time data

- Physical Modelling of Geothermal Reservoirs

- Previous laboratory work

- Dimensional analysis and the Rayleigh number

a. Well Measurement

Letters of quotation were sent out during the summer of ' 75 requesting well hardware and measurement bids. A summary of the responses can be found in the HGP Engineering Program report of January 1, 1975 to August $31,1975$.

The well testing program will be conducted in the following manner:

1) Purchase Kuster downhole instruments. Arrange for a training session to be held in January of 1976 at the Keller Hole on the Big Island. Mr. L. O. Hunter of New Zealand will be the instructor. 
2) At regular intervals during the drilling phase of the program, use Kuster equipment to obtain downhole temperature and pressure data for the purpose of

a) increasing competence at well measurement

b) becoming familiar with well and environs

c) cross-checking the Kuster mechanical measurement data with the Schlumberger electronic measurement data

3) Seek advice from R. Kingston on wellhead plumbing design. If purchase of equipment is necessary, the cost will be about $\$ 70,000$, with the separator being a major part of this expense. A second alternative would be to work out an arrangement with Rogers International for a service contract. The cost would be in the area of $\$ 100,000$.

4) Conduct well tests with the aid of L. 0 . Hunter of KRTA. (It is assumed that the wellhead plumbing, as mentioned in " 3 ", will include a means of determining flowrates. Furthermore, it is expected that a downhole water sampler will be borrowed from KTRA). 5) Reservoir performance will be predicted within the Hawaij Geothermal Project with the initial assistance of Dr. H. Ramey. It should be mentioned again that an assessment of the long term productivity characteristics of the entire geothermal field can only be accomplished after data have been obtained from several wells. However, the results of a one-month stabilization and two-month well test program should be invaluable for helping determine the next course of action.

The well measurement program should occur in the following sequence: 1) Evaluate Preliminary Formation Potential. After each drill stem test, data will be analyzed to determine whether or not to complete the well. These tests will also be used to decide whether the well needs to be drilled further to a greater depth. Furthermore, such tests will also provide important information, as for example, chemical content of the formation fluid, theoretical and actual productivity indexes (PI), reservoir pressure and temperature, and the amount of wellbore damage $[10,11]$. Factors which will be used to decide whether a particular well should be completed are reservoir temperature, reservoir pressure, salt content of the fluid, and the productivity indexes (PI). 
Normally, the actual PI $[7,11]$ is lower than the theoretical PI. A high actual PI shown by a given well will be one of the deciding factors in favor of completing that well. In all probability, the well should be abandoned if the theoretical PI is low; but if the theoretical PI is high, chances for stimulating the well are still good (either by removal of the skin surrounding the well bore or by further penetration of the productive zone) [10].

Another important criterion is the fluid condition. It is widely accepted that conventional steam turbine technology constrains the reservoir temperature of a producible geothermal well to be above $180^{\circ} \mathrm{C}$. Furthermore, the salt content of the geothermal fluid will be a deciding factor as to the method of drawing the fluid. For example, extremely high solids content fluids will more likely be pumped under pressure.

2) Select Well Completion Methods and Surface Plumbing Facilities. If the drill stem tests show favorable reservoir conditions, then the well should be completed for further testing. Various methods, such as perforated casing, slotted liner, commercial well screen and gravel packing will be considered. One or a combination of the above will be chosen. Specific methods will be decided after properties of the borehole are thoroughly evaluated. It should be noted that the steam wells in the Geysers are not completed at all $[12,13]$.

There is strong reason to believe, from geophysical data, that the geothermal wellhead fluid will be a mixture of steam and water (two-phase or flashed-flow). For the ensuing discussion, the above fluid condition has been assumed. In the event of superheated fluid condition, equipment requirements will be simplified.

Surface plumbing facilities will include wellhead valve assembly, separator (for flashed-flow fluids) and silencer. The recommended separator, which has been successfully employed at Wairakei, is the centrifugal cyclone separator $[14,15]$. This type of separator claims an efficiency of 99.9 percent. The current state-of-the-art of flow measurement does not allow one to obtain accurate information on two-phase flow. Therefore, a separator is needed to separate the liquid from the steam. Then, separate flow meters and calorimeters will be used to obtain enthalpy and flowrates. 
3) Initiate Drawdown and Buildup Tests. These tests are basically downhole pressure measurements. A series of alternate drawdown and buildup tests should be conducted to gain information on permeability thickness, porosity thickness, skin effect, wellbore storage, formation average pressure and productivity indexes.

It is suspected that the downhole reservoir pressure will be no greater than the equivalent hydrostatic pressure in Hawaii's geothermal reservoir. Therefore, the well may be started by injecting compressed gas (air, nitrogen or carbon dioxide) to induce the hot liquid up to the surface. It is also probable that due to economic reasons, one cannot completely shut down the well; thus, two-rate buildup tests must be performed.

Conventionally, after well completion, a resting period of about one month is used to enable underground conditions to stabilize. If hands-on experience at well testing is not acquired prior to well completion, it is imperative that on-site training be accomplished or a completed measurement specialist be imported for initial tests. New Zealand officials have indicated that arrangements can be made to obtain such training.

There are potential hazards associated with well testing. For example, noxious gases could concentrate in the drilling cellar, high noise levels will occur at the discharge, and high temperature/ pressure fluids may cause bodily harm. Therefore, safety policies need to be established and maintained.

4) Initiate Temperature Measurements. Temperature measurements vs. the drilled hole depth can reveal information such as conductive and convective zones, high or low permeability zones, etc. A temperature measurement conducted right after a well is shut can also reveal whether any local aquifer inflow exists.

The instruments that have been successfully used at various geothermal sites are the "geothermograph" $[14,16]$, thermistor, and the Amerada-Kuster RPG Temperature Gage. The particular selection of the instrument will depend on the reservoir condition and results of the equipment survey.

5) Estimate Wellbore Heat Losses. By simultaneously measuring the downhole and wellhead conditions, one can estimate the wellbore heat 
losses. In the future, then, downhole reservoir conditions can be approximated by wellhead measurements, which are easier and more economical to run.

Success at planning and conducting well measurement tests increases with hands-on experience. Initial tests will require the supervision of a seasoned instrumentation engineer.

b. Well Analysis

The well analysis phase is in the process of final development and will take the form of a computer program capable of predicting well performance given pressure, temperature and flowrate over time, plus certain geological parameters such as permeability, porosity, etc. The code will be effective for any combination of fluid properties: compressed hot water, saturated hot water, two-phase fluid (steam plus water over the full spectrum of steam quality), steam, and superheated steam. Future research will consider the presence of non-condensable gases and dissolved solids (primarily chlorides, silicates, carbonates and sulfates up to $35 \%$ by weight).

The software effort of developing a computer program for predicting the future performance of a geothermal reservoir using the mass-energy balance equations is nearing completion. The conditions under investigation range from $300^{\circ} \mathrm{F}$ to $600^{\circ} \mathrm{F}$, and 67 to 1544 psia. WASP, a NASA-developed code on water and steam properties, was purchased and modified for use in the program. Thus far, preliminary sensitivity investigations have been begun by varying initial mass and steam quality with changing temperatures. Other parameters will also be checked.

The program will be tested using part of the New Zealand data. After all states have been covered, a sensitivity check on different parameters of the mass-energy balance equation will be made.

Details on the theory behind the computer program can be found in Reference [7]. Using the pressure measurements obtained from the series of drawdown and buildup tests, one will be able to get information on effective permeability thickness, effective porosity thickness, wellbore skin effect, wellbore storage coefficient, formation average pressure and productivity indexes. These can be achieved by applying the type 
curve analyses and standard pressure buildup analyses $[7,11,17]$. Depending on the length of the production of the well, one may get data points on the formation average pressure vs. cumulative production information. With the heat-materials balance equation one will be able to estimate initial volume, pressure, and temperature. This information, in turn, may be used to predict the well performance. The methodology is similar to the Ramey/Whiting technique [18], but extended to include the effects of additional parameters and a comprehensive sensitivity analysis.

It cannot be overemphasized, though, that reservoir performance predictions can only be suggested with data from one well. Several holes, judiciously determined in conjunction with geological data, are necessary for confident performance predictions. Furthermore, although virtually immediate speculations can be offered for obviously deficient wells, 30year projections will not be possible unless a comprehensive well measurement program is undertaken. A three-month period per well is considered standard.

\section{c. Physical Modelling}

A literature survey made on models of geothermal reservoirs showed very few physical modelling studies. Most of the investigations published have been made on numerical models. The construction of physical models was undertaken as part of the Hawaii Geothermal Project to complement the numerical modelling portion of the program.

To insure similarity between the physical and mathematical models, a modified Rayleigh number is used. This dimensionless number is defined as follows:

$$
\operatorname{Ra}=\operatorname{Gr} \operatorname{Pr} \frac{k}{h^{2}}
$$

where $\mathrm{Gr}=$ the Grashof Number

$$
\begin{aligned}
& =\frac{\text { buoyant forces }}{v i \text { scous forces }} \\
& =\frac{\beta g \Delta \mathrm{Th}^{3}}{v^{2}}
\end{aligned}
$$


and $\mathrm{Pr}=$ the Prandt 1 Number

$$
\begin{aligned}
& =\frac{\text { momentum diffusivity }}{\text { thermal diffusivity }} \\
& =\frac{y}{a}
\end{aligned}
$$

and $B=$ coefficient of thermal expansion

$g=$ gravitational constant

$\Delta \mathrm{T}=$ temperature difference

$h=$ height of aquifer

$v=$ kinematic diffusivity

$a=$ thermal diffusivity

$k=$ intrinsic permeability

so, $\operatorname{Ra}=\frac{\beta \Delta \operatorname{Tghk}}{\alpha v}$

The Grashof number is important in problems involving natural convecting systems and establishes dynamic similarity between the model and theoretical situations. The Prandt 1 number appears in heat transfer applications and establishes similarity of temperature fields between two systems. The permeability term reflects the porous property of the island. Convection is initiated at a Rayleigh number of about 40 . As the Rayleigh number increases above 40, the temperature contours in the aquifer develop mushroom shapes.

The original physical modelling program planned for the construction of a large two-dimensional model of a portion of an island. This model was to be twenty cubic feet in volume and was to have the flexibility of expansion to sixty cubic feet. It was felt that the large model would eventually be pressurized to simulate the underground conditions expected on the island of Hawaii. Preliminary models were decided on, however, due to financial constraints and safety regulations on pressure vessels. The physical modelling program was therefore divided into three phases: a preliminary unpressurized model, a preliminary pressurized model, and a final pressurized mode1. The status as of December 31, 1975, can be summarized as follows: 


\begin{tabular}{|c|c|c|c|c|c|}
\hline \multirow[t]{2}{*}{ MODEL } & \multirow[t]{2}{*}{$\underline{\text { SIZE }}$} & \multirow[t]{2}{*}{ PRESSURE } & \multicolumn{2}{|c|}{ TEMPERATURE } & \multirow[t]{2}{*}{ STATUS } \\
\hline & & & MAX. & PROBES & \\
\hline Preliminary \#1 & $3 \mathrm{ft}^{3}$ & Atmospheric & $\overline{212^{\circ}} \mathrm{F}$ & 10 & $\begin{array}{l}\text { completing } \\
\text { experimenta } 1 \\
\text { runs }\end{array}$ \\
\hline Preliminary \#2 & $31 / 3 \mathrm{ft}^{3}$ & 200 psi & $382^{\circ} \mathrm{F}$ & 23 & $\begin{array}{l}\text { undergoing } \\
\text { tests }\end{array}$ \\
\hline Final & $30^{+} \mathrm{ft}^{3}$ & $300^{+} \mathrm{psi}$ & $500^{+} \circ \mathrm{F}$ & 23 & $\begin{array}{l}\text { design } \\
\text { contemplated }\end{array}$ \\
\hline
\end{tabular}

The preliminary models simulate one-half of a rectangular island aquifer. Figure 3.1-7A shows the full island aquifer. Since the aquifer is symmetric with respect to a vertical axis through the middle of the aquifer, only one-half of the aquifer is modelled as shown in Fig. 3.1-7B. A removable cover is used for simulating confined aquifers. The cover is removed for unconfined cases. Glass beads are used as the porous medium and up to four heater/controller units simulate the hot rock heat source. Temperature measurements are made using an array of resistance temperature detectors.

Early in the physical modelling program, several companies were contacted for information on heaters to simulate the energy source of the model and temperature measurement devices to obtain temperature profiles. The constraints of time and cost resulted in the selection of a Stan-trol heater/controller system for the heat source, and resistance temperature detectors (RTD's) feeding an Esterline Angus 24 point recorder to obtain the temperature profile. A schematic diagram of the preliminary pressurized model is shown in Fig. 3.1-8.

The key components in addition to the tank are as follows:

1) Esterline Angus 24 point recorder using ten $1 / 4 " D$ and thirteen 3/16"D resistance temperature detector (RTD) probes. The RTD's were selected because they are capable of withstanding high pressures, saline fluid conditions, and were ipmediately available at reasonable cost. It is possible that the size of the 'RTD's could somewhat disturb flow patterns for the preliminary models. 2) Stan-trol heater and controller sensor system capable of varying heater surface temperature between ambient and $1800^{\circ} \mathrm{F} .1800^{\circ} \mathrm{F}$ is about the temperature of liquid magma. The total heat release 


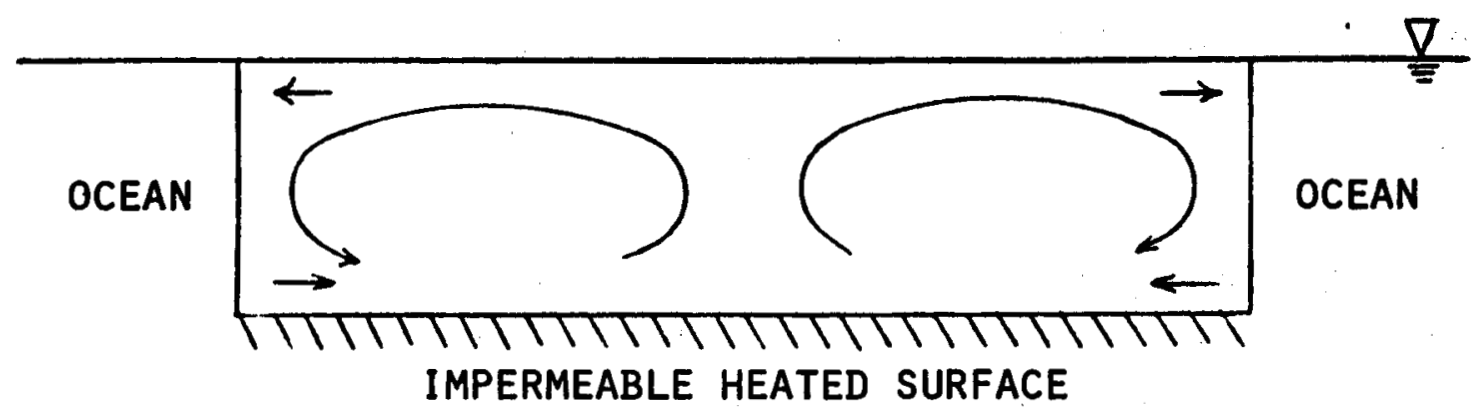

Figure 3.1-7a Model of Island Aquifer Heated from Below

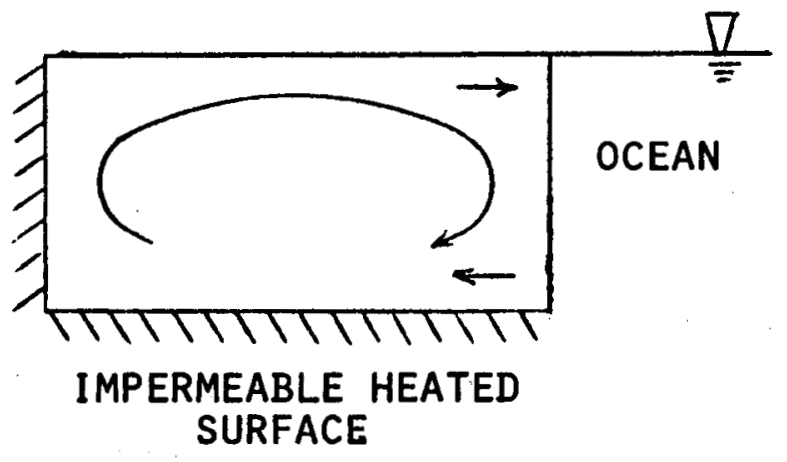

Figure 3.1-7b Model of One-half of Island Aquifer 


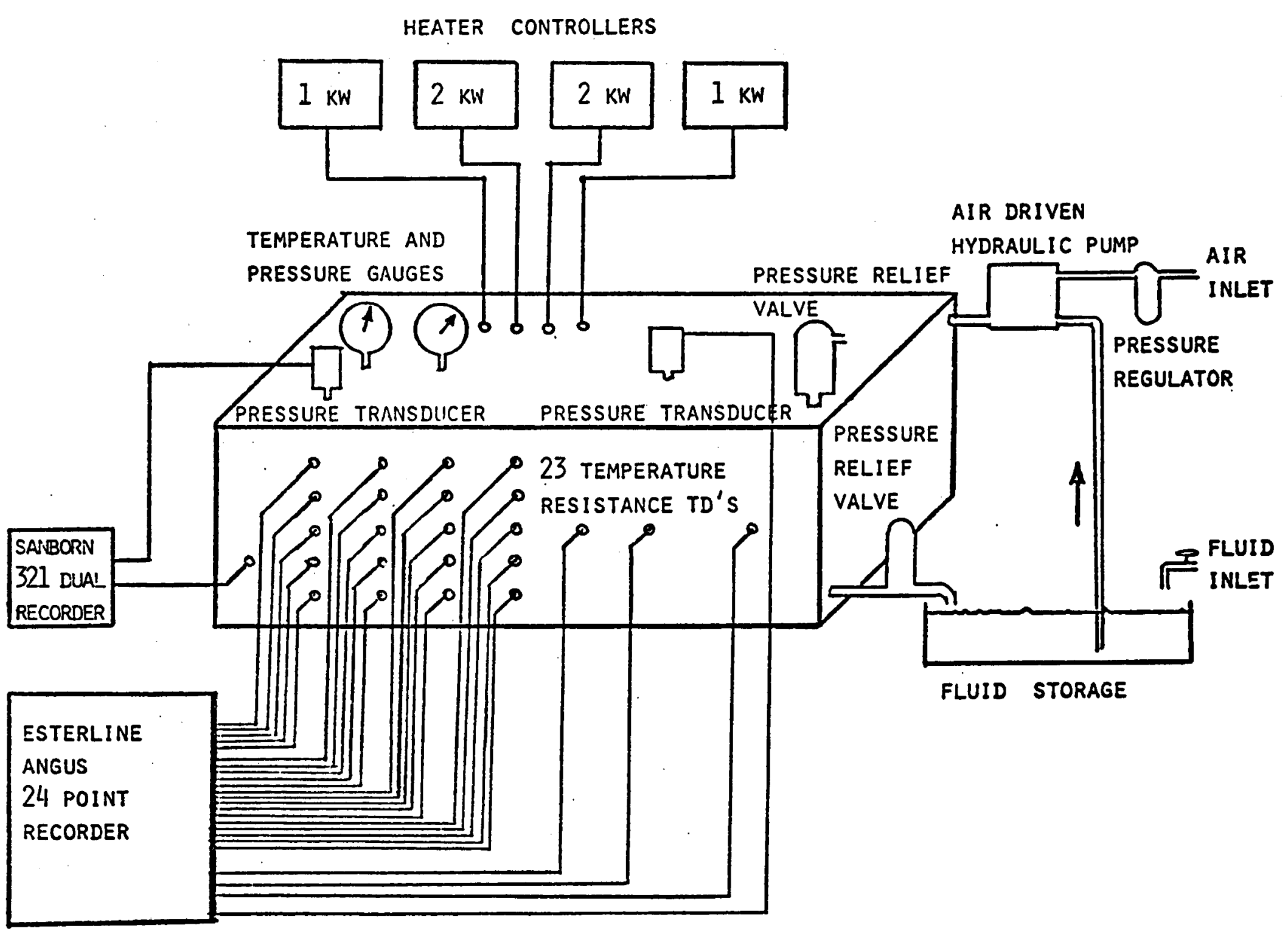

Figure 3.1-8 Schematic Diagram of Pressurized Geothermal Reservoir Physical Model 
capacity is 6 kilowatts: two $2 \mathrm{kw}$ and two $1 \mathrm{kw}$ heater controllers. The heaters can be formed to any shape desired.

3) Haskel air driven hydraulic pump to simulate compressed water conditions.

4) Sanborn dual channel recorder for continuous pressure (and temperature) measurements.

Several runs have been completed on the preliminary unpressurized model using either one or two heaters as a point source in confined and unconfined aquifers. The results from these tests are being analyzed and should be available in the near future. Some of the preliminary results will be presented in this report.

The point at which convection is noticed is at the critical Rayleigh number for the system. Theoretically, the critical Rayleigh number is near 40. Figures 3.1-9A and 3.1-9B show the temperature contours obtained at Rayleigh numbers of 22 and 75 respectively for a confined aquifer with a point heat source. The temperature contours shown in Fig. 3.1-9A are similar to those expected when conduction dominates. Figure 3.1-9B shows that convection has started and temperature contours are developing shapes resembling half mushrooms. Each contour drawn is for a dimensionless temperature $\theta=\frac{T-T_{s}}{T_{c}-T_{s}}$, where $T$ is the temperature of the isotherm, $T_{c}$ is the temperature of the heat source and $T_{S}$ is the ocean temperature.

The reason for the mushrooming of the temperature contours in the latter case is the convective pattern in the aquifer. The cold water from the ocean moves inland along the lower surface of the aquifer. As the water approaches the heat source, it is heated and starts to rise due to its lesser density. At the maximum heating point, directly above the heater, the hot water rises to the top of the aquifer. Since the aquifer is confined, the water moves along the caprock toward the ocean causing the half-mushroom shaped temperature contours.

A summary of work accomplished and planned can be found in Table 3.1-2. It is expected that all anticipated experimental runs will be completed during the first quarter of 1976.

The results of the tests from the physical model should be useful in the following ways: 


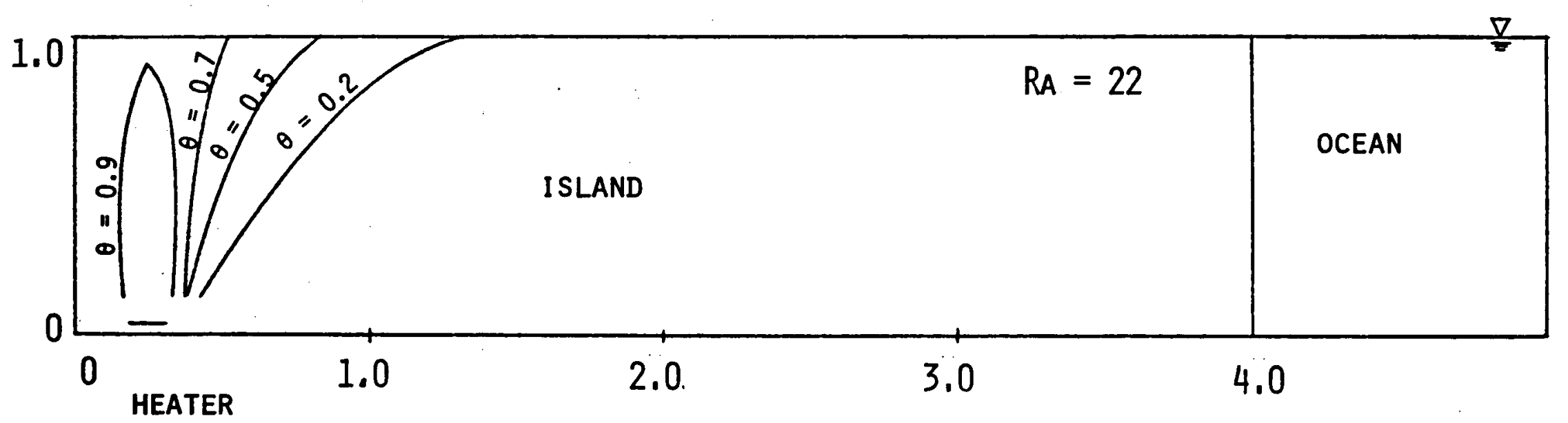

Figure 3.1-9a Temperature Contours in a Confined Island Aquifer at Ra $=22$

1
0
1

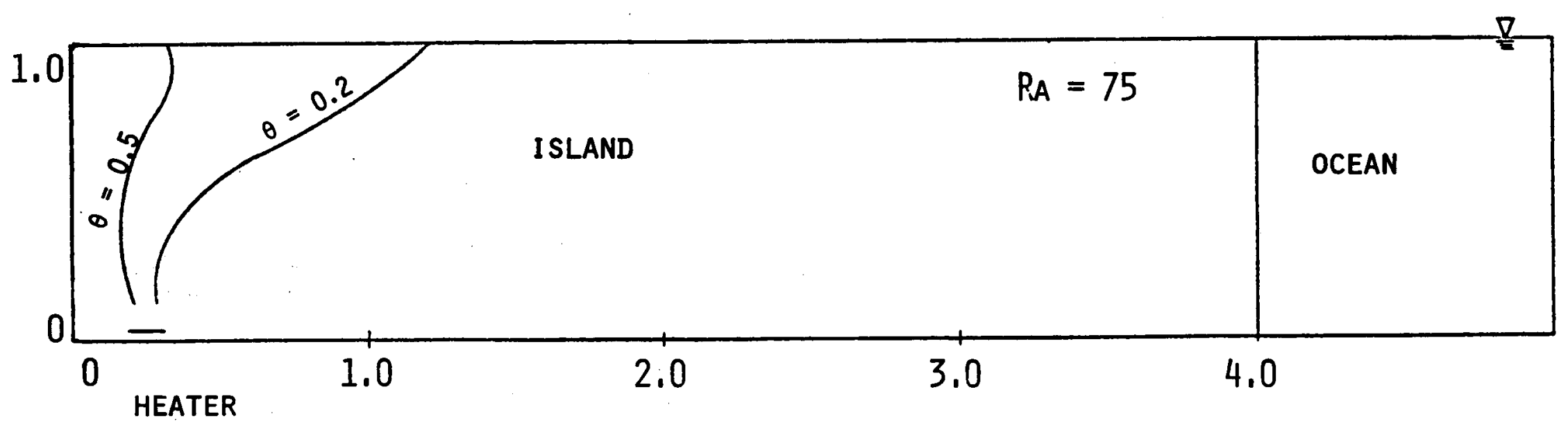

Figure 3.1-9B Temperature Contours in a Confined Island Aquifer at Ra $=75$ 
Table 3.1-2 PHYSICAL MODELLING LABORATORY PLAN

\begin{tabular}{|c|c|c|c|c|c|c|c|c|c|c|c|}
\hline \multirow{2}{*}{$\begin{array}{l}\text { Models Under } \\
\text { Investigation }\end{array}$} & \multicolumn{11}{|c|}{ Rayleigh Numbers } \\
\hline & 22 & 40 & 49 & 75 & 127 & 200 & 250 & 300 & 350 & 500 & 1000 \\
\hline Unpressurized Model: & & & & & & & & & & & \\
\hline 1) Confined Aquifer & & & & & & & & & & & \\
\hline Point Source & $x$ & 0 & $x$ & $x$ & $x$ & $x$ & $\mathrm{x}$ & $x$ & $x$ & & \\
\hline Exponential Source & 0 & 0 & & 0 & & 0 & & & 0 & & \\
\hline Horizontal Plate Source & 0 & 0 & & 0 & & 0 & & & 0 & & \\
\hline Vertical Plate Source & 0 & 0 & & 0 & & 0 & & & 0 & & \\
\hline 2) Unconfined Aquifer & & & & & & & & & & & \\
\hline $\begin{array}{l}\text { Point Source } \\
\text { Vertical Plate Source }\end{array}$ & 0 & 0 & & & & 0 & & & & & \\
\hline Pressurized Mode1: & & & & & & & & & & & \\
\hline 1) Confined Aquifer & & & & & & & & & & & \\
\hline Horizontal Plate Source & 0 & 0 & & & & 0 & & & 0 & 0 & 0 \\
\hline Vertical Plate Source & 0 & 0 & & & & 0 & & & 0 & 0 & 0 \\
\hline $\begin{array}{l}\text { 2) Unconfined Aquifer } \\
\text { Vertical Plate Source }\end{array}$ & 0 & 0 & & & & 0 & & & 0 & 0 & 0 \\
\hline
\end{tabular}

0 -- Not Complete

$X$-- Completed, but under anarysis as of $11 / 27 / 75$ 
1) A check can be made of fundamental information. For example, does convection initiate at a Rayleigh number of 40 ?

2) Data can be obtained to aid the various computer models in refining predictive capability.

3) The concept of geothermal reservoir self-sealing can be investigated.

4) Reinjection can be tested.

5) One of the classical points of contention, "Is a geothermal reservoir an open or closed system?" can be studied.

\section{c. Future Work}

1. Numerical Modelling of Geothermal Reservoirs

Effort will be devoted to the numerical solutions of free convection in unconfined geothermal island aquifers with recharge from the ocean and rainfal1. The interaction of production and withdrawal wells will also be examined. The effects of non-local thermodynamic equilibrium, the layer structure of the rock formation, and the irregular boundary of the reservoir will also be studied. Boundary layer analysis is being pursued for other problems of free and forced convection in geothermal reservoirs.

2. Well Test Analysis and Physical Modelling

a. Well Test Measurement

The well test training session scheduled for January 1976 should be valuable as a first exposure, although further on-the-job training will be necessary to insure competence. A means of facilitating the conversion of measurement data for convenient use with the computer program should be considered.

b. Well Analysis

A computer program to predict well performance is nearing completion. The program will ultimately be capable of handling geothermal reservoirs of all types: vapor or liquid-dominated, flashing within the reservoir, closed or open system and various salinities. The initial program will be tested with New Zealand measurement data and artificial systems. c. Physical Modelling

Tests on the unpressurized model are coming to a conclusion. Experimental runs for the preliminary pressurized model will follow. Design of the final pressurized model is being considered. The concept of self-sealing will be explored in the final pressurized model. 


\section{TASK 3.1 GEOTHERMAL RESERVOIR ENGINEERING}

D. References

1. Hawaii Geothermal Project, Engineering Program, Phase I Report, January 1975.

2. Cheng, P. \& K.H. Lau, "The Effects of Steady Withdrawal of Fluid in Confined Geothermal Reservoirs," Hawaii Geothermal Project, Technical Report No. 8, May 1975. Presented at the 2nd U.N. Symposium on Geothermal Resources, San Francisco, California, May 20-29, 1975.

3. Cheng, P. \& K.H. Lau, "Steady State Free Convection in an Unconfined Geothermal Reservoir," J. of Geophysical Research, V. 79, No. 29, 1974, pp. 4425-4431.

4. Cheng, P. \& W.J. Minkowycz, "Similarity Solutions for Free Convection About a Dike," Mawai i Geothermal Project, Engineering Program, Technical Report No. 10, October 1975.

5. Minkowycz, W.J. \& P. Cheng, "Free Convection About a Vertical Cylinder Embedded in a Porous Medium," Hawai i Geothermal Project, Technical Report No. 11, November 1975.

6. Cheng, P. \& I-Dee Chang, "Buoyancy Induced Flows in a Porous Medium Adjacent to Impermeable Horizontal Surfaces," Hawaii Geothermal Project, Engineering Program, Technical Report No. 12, December 1, 1975.

7 Hawaii Geothermal Project, Engineering Program, Quarterly Reports Nos. 1-5; Technical Reports Nos. 1-3; Technical Memorandum No. 2.

8 Takahashi, P., B. Chen, K. Mashima \& A. Seki, "State-of-the-Art of Geothermal Reservoir Engineering," American Society of Civil Engineering Journal, V. 101, No. 1, July 1975, pp. 111-126.

9 Takahashi, P. \& B. Chen, "Geothermal Reservoir Engineering," Geothermal Energy, V. 3, No. 10, October 1975.

10. Van Poollen, H.K., "Status of Drill-Stem Testing Techniques and Analysis," J. Pet. Tech., April 1961.

11. Mathews, C.S. \& D.G. Russe11, "Pressure Buildup and Flow Tests in Wells," SPE Monograph, V. 1, SPE, Dallas, 1967.

12. Mashima, K.I., "An Assessment of Techniques for Testing Geothermal Wells," Masters Thesis, University of Hawaif, May 1975.

13. Armstrong, E.L. \& E.A. Lundberg, Geothermal Resource Investigations Test WeII Mesa 6-1, Bureau of Reclamation, February 1973.

14. Hunt, A.M., "Measurement of Borehole Discharges, Downhole Temperatures and Pressures, and Surface Heat Flows at Wairakei," United Nations, Rome, 1961. 
15. Smith, J.H., "Collection and Transmission of Geothermal Fluids," Geothermal Energy, UNESCO, 1973.

16. Marshall, G.S. \& R.H. Henderson, "Recording Temperatures in Deep Boreholes," Engineering, October 1963.

17. Ramey, H.J., Jr., "Short-time Well Test Data Interpretation in the Presence of Skin Effect and Wellbore Storage," J. Pet. Tech., February 1968.

18. Whiting, R.L. \& H.J. Ramey, Jr., "Application of Materials Energy Balances to Geothermal Steam Production," presented at the Annual Fall Meeting, SPE, AIME, Houston, Texas, October 1967. 
TASK 3.6 OPTIMAL GEOTHERMAL PLANT DESIGN

Investigators: H. C. Chai, J. Chou and D. Kihara

A. Timetable

June 30,1975

1. Heat exchanger design--check out test set-up and extend analysis of heat exchanger specifications as input parameters are changed

2. Construct components and assemble experimental heat transfer loop

September 30, 1975 1. Establish general requirements, ground rules, and design criteria for a research-oriented plant for liquid-dominated fields

2. Construct and test vertical heat exchanger

December 31, 1975 1. Set up procedures for the design and selection of the components of regenerative binary fluid plants

2. Continue testing of vertical heat exchanger and write computer program for vertical heat exchanger

3. Complete conceptual design of a prototype research plant for assisting a mechanical engineering contractor to complete the final design

4. Binary-fluid cycle research--survey the availability of components to be used with each working fluid

June 30,1976

1. Lay out detailed flow diagrams of the plant based on a regenerative binary fluid system, with a vapor flashing system as the alternative

2. Analyze test data for vertical heat exchanger and begin testing of horizontal heat exchanger

December 31, 1976

1. Estimate capital costs of the plant, evaluate unit operating cost, and compare feasibilities of the two systems

2. Complete testing and analyze test data for horizontal heat exchanger 
B. Progress to Date

1. Conceptual Study of a Research-Oriented Plant

Based on geological and geophysical surveys, the geothermal resource in Hawai is probably heated intrusive seawater, although the probability that it is heated meteoric water cannot be neglected. The probability of finding an adequate reservoir is sufficiently high that advanced planning for a researchoriented power plant is warranted, but the decisions on the main features of the plant cannot be made until the resource is proven and reservoir characteristics learned. The purposes of a research-oriented plant would be to provide facilities for testing new plants of unconventional design and to experiment with the components of conventional vapor-flashing plants. Thus, the economic implication, environmental impact, and operational reliability of innovative plants can be accurately evaluated. As most of the known geothermal fields in this country are liquid-dominated, the results will be beneficial not only to the State of Hawaii, but to all of the United States. During the past period, a part of the effort was applied to the conceptual study of research-oriented plants.

Consideration has been given to the size of the experimental plant. It must be large enough to experience all the problems of a production plant. For the assessment of long-term capabilities of a new reservoir, the size must fit the optimal production rate from at least one well. On the other hand, an unnecessarily large plant might become wasteful. Studies show that the range of 5 to $10 \mathrm{Mw}$ is suitable.

The vapor-flashing system, which has been highly developed in New Zealand and Japan, has been proven to be reliable and economically viable. In order to become familiar with its development, the designs of this system and its components were reviewed last year [1].* The most critical component of a plant which extracts power directly from the vapor of the geothermal fluid is the prime mover, usually a low-pressure steam turbine. Further research on the prime mover could significantly improve the plant performance. The researchoriented plant, which may receive a mixture of vapor and liquid through a single pipe, should be designed so as to retain the flexibility for testing

*Task 3.6 References are 1isted on page 132. 
innovative prime movers, such as the helical rotary screw expander, which has already been initially tested at Lawrence Livermore Laboratory [2].

The binary fluid system is being studied intensively, and its success will depend largely on the development of efficient heat exchangers which can be kept free from scaling on the geothermal fluid side of the exchanger. The relationship among heat exchanger performance, power generation, fluid consumption, and other factors is currently being studied.

2. Temperature Distributions in Counterflow Isobutane-Water Heat Exchangers

The entire system of a binary fluid cycle plant is difficult to optimize because of its complexity. In such a case, one may try to optimize subsystems and then choose the optimum combination of these subsystems. The most critical component of a binary geothermal plant is the heat exchanger between water and isobutane. While commercial heat exchangers contain combinations of counterflow, parallel flow, and cross flow, counterflow heat exchangers will probably be used for extracting energy from geothermal fluids since the temperature distribution of a counterflow arrangement gives the highest final temperature which the isobutane can attain when it is heated by the hot fluid. An additional advantage of the counterflow arrangement is that less heating surface is required by this arrangement than by parallel flow and cross flow arrangements.

There are two difficulties in heat transfer problems involving superheated isobutane. One is the lack of precise data on its thermodynamic properties; another is the peculiarity of the constant-pressure specific heat of superheated isobutane vapor. To facilitate the interpolation and to increase the precision of calculations, the temperature-enthalpy relationships may be taken from a small-size chart as given in the ASHRAE Handbook [3] and replotted with much larger scales. Figure 3.6-1 is the temperature-enthalpy curve of the superheated vapor at $700 \mathrm{psia}$. The two points of inflection are at approximately 280 and $320^{\circ} \mathrm{F}$. The slope of the curve represents the constant-pressure specific heat. As shown, the specific heat of isobutane varies greatly with the temperature.

For a given mass ratio of water to isobutane, the enthalpy of liquid water in Btu per pound of isobutane can also be plotted in the same diagram. Since the specific heat of water is nearly constant, the temperature-enthalpy relationship is shown as a straight line, and its slope is dictated by the mass ratio of water to isobutane. Because of the large difference in the 
(2)
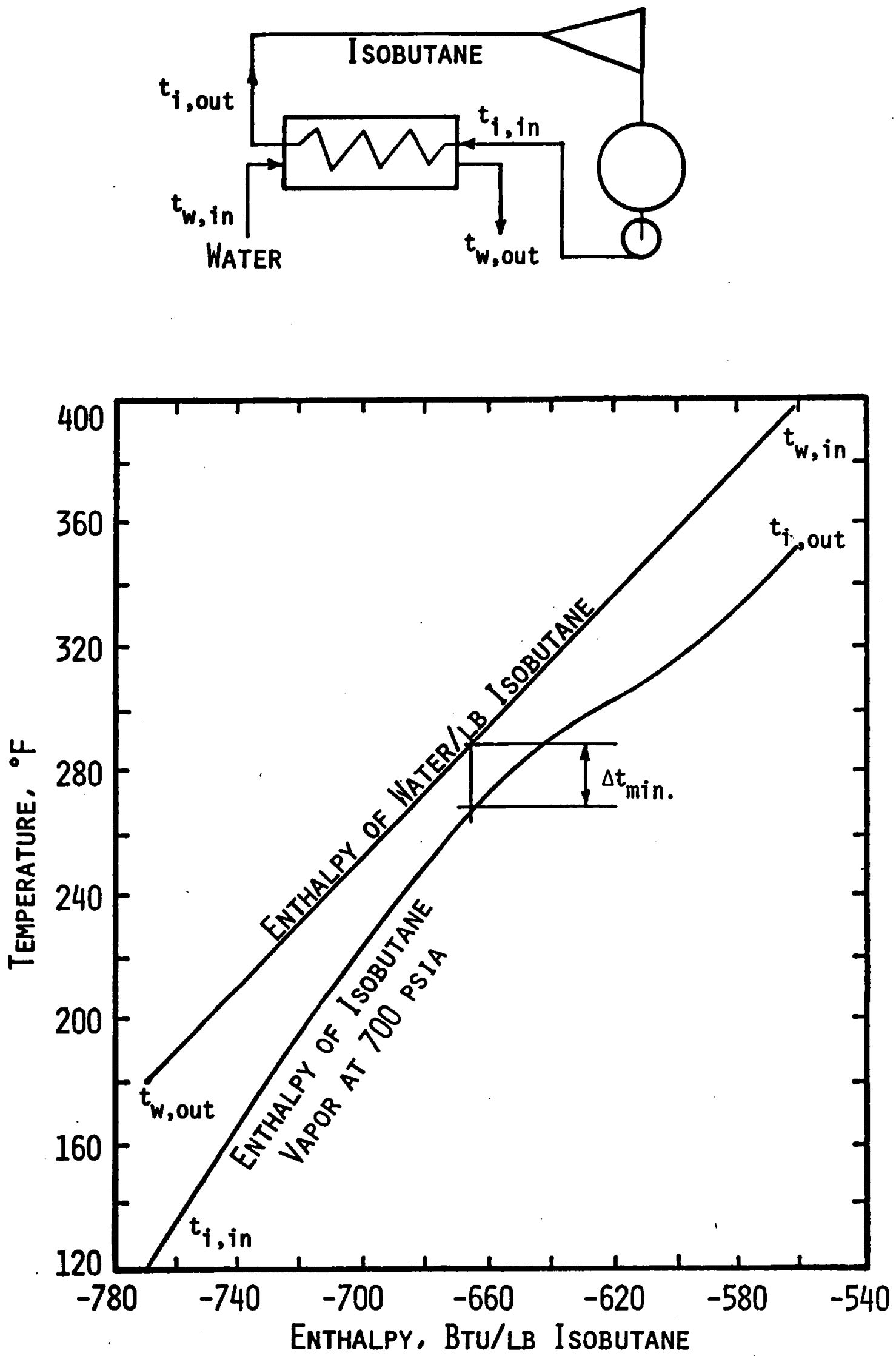

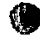

Figure 3,6-1 Temperature-Enthalpy Relationship of IsOBUTANE AND WATER IN HEAT EXCHANGER 
characteristics of the specific heats of the two fluids, the logarithmic mean overall temperature difference cannot be applied to the design of isobutanewater heat exchangers. If the overall unit conductance $U$ is fairly constant, a numerical step-by-step integration may be used to determine the required heat-transfer area $A$ per pound of isobutane,

$$
A=\frac{1}{U} \Sigma \frac{\Delta h}{\Delta t}
$$

where $\Delta h$ is the enthalpy change per pound of isobutane and $\Delta t$ is the mean temperature difference between the two fluids in the corresponding interval.

In the analysis of an isobutane cycle, the temperature of isobutane entering the heat exchanger is determined by the condensing temperature of the cycle. The inlet temperature of the hot geothermal fluid depends upon the reservoir and the method of bringing the fluid to the surface. If suitable pumps can be developed to force the fluid out through the well, the temperature of the fluid entering the heat exchanger may vary from 300 to $600^{\circ} \mathrm{F}$. With the two inlet temperatures, $t_{i, \text { in }}$ and $t_{w, i n}$, fixed, as shown in Fig. 3.6-1, different patterns of temperature distribution may be obtained by varying the minimum temperature difference between the two fluids and the slope of the straight line. As previously mentioned, the mass ratio of the two fluids prescribes the slope.

In the design of a power plant, an attempt is made to arrive at an optimum configuration based on certain desired objectives and imposed constraints. These objectives and constraints have yet to be defined for the power plant considered by the Hawaii Geothermal Project. However, it is possible to apply constraints frequently used by privately-owned utilities, that is, minimizing the cost of power production. For the purposes of discussion only, consider the problem of finding the value of the minimum temperature difference which minimizes the cost of power production for a given mass ratio. As the temperature difference is increased, the cost of the heat exchanger is decreased at the sacrifice of power output per pound of geothermal fluid. The drop in power output is attributed to the high heat content of the spent fluid and to the low thermal efficiency of the isobutane cycle. The area of heating surface and the power output were calculated by assuming that the following data apply: 
Geothermal fluid

Condensing temperature

Isobutane turbine efficiency

Pump efficiency

Isobutane pressure

Mass ratio of fluid to isobutane

Overall heat transfer coefficient
Saturated $400^{\circ} \mathrm{F}$ water

$120^{\circ} \mathrm{F}$

$85 \%$

$80 \%$

700 psia

1

$175 \mathrm{Btu} /(\mathrm{hr})\left(\mathrm{ft}^{2}\right)\left({ }^{\circ} \mathrm{F}\right)$

The results are:

$\frac{\text { Minimum } \Delta t}{5^{\circ} \mathrm{F}}$

10

20

30

40
Heating Surface

$0.072 \mathrm{ft}^{2} /(1 \mathrm{~b}$ water $/ \mathrm{hr})$

0.047

0.033

0.025

0.019
Power Production

$9.710^{3} \mathrm{kwh} / 10^{6} 1 \mathrm{~b}$ water

9.3

8.8

8.5

8.2

The cost of the heating surface is currently in the range of $\$ 5$ to $\$ 10$ per $\mathrm{ft}^{2}$. The annual fixed charge and operating cost is around $10 \%$ of the initial cost, but depends upon the estimates of equipment life, interest rate, and maintenance cost. The major cost items for power production are the well, power plant, and transmission. A detailed cost analysis is difficult, and the results are expected to be different from one case to another. A conservative estimate of the cost of the additional amount of power produced due to the efficient use of the heat exchanger is $1 \$$ per kwh. By taking $40^{\circ} \mathrm{F}$ minimum temperature difference as the reference point, the annual revenue from the additional power production and the annual cost of the heat exchanger were compared, as shown in Fig. 3.6-2. The annual cost of the heating surface is taken to be $\$ 1$ per $\mathrm{ft}^{2}$. It is interesting to note that based on these preliminary cost estimates, the optimum point of the minimum temperature difference is around $5^{\circ} \mathrm{F}$. At a higher estimate of the revenue or a lower estimate of the heat exchanger cost, the optimum value of the minimum temperature difference will be lower. Because of surface scaling on the geothermal fluid side, a conservative value of heat transfer coefficient was used for the calculation. A higher value of $U$ will also lower the optimum value of minimum temperature difference.

(2)

Calculations for a water inlet temperature of $600^{\circ} \mathrm{F}$ were also performed. As the temperature of isobutane increases, the optimum pressure of the Rankine 


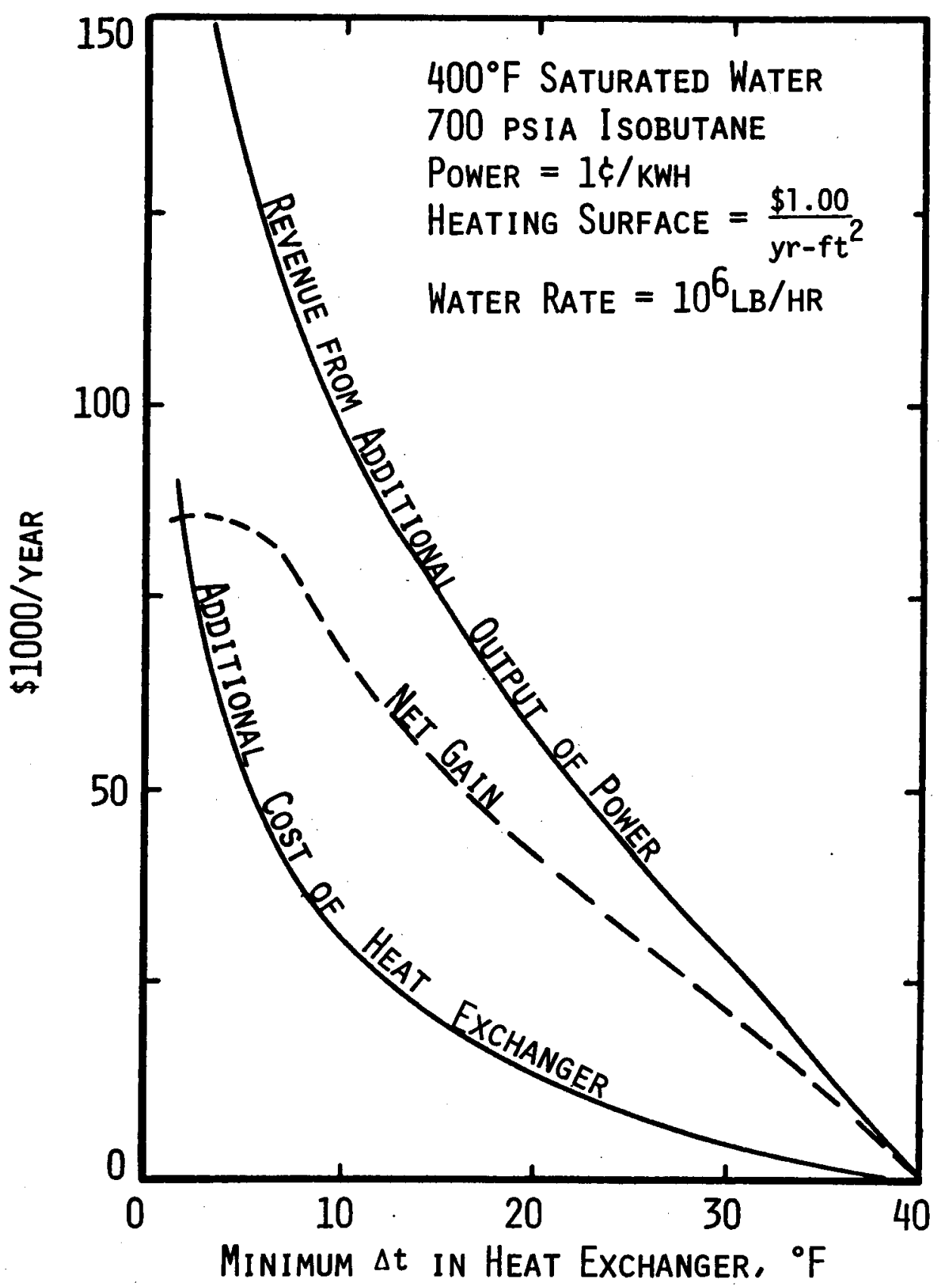

Figure 3.6-2 Pattern of Effects of Minimum Temperature Difference Between Water AND ISOBUTANE ON COSTS 
cycle also increases. For $600^{\circ} \mathrm{F}$ water, the optimum pressure of isobutane is 2,000 psia. All other assumptions are the same as aforementioned. The optimum value of the minimum temperature difference is again in the neighborhood of 5 to $10^{\circ} \mathrm{F}$.

Next, the effects of varying mass ratio of water flow to isobutane flow were evaluated for a fixed value of the minimum temperature difference. The location of the minimum temperature difference (Fig. 3.6-1) may vary with the mass ratio. At a given value of minimum temperature difference, its location moves downward as the slope of the water enthalpy line increases. At a small proportion of water mass to isobutane mass, the minimum temperature could occur at the exit of water. The advantage of lowering the exit temperature of water is to lower the amount of waste energy; however, the cycle efficiency drops as the exit temperature of isobutane is pushed down by tilting the enthalpy line of water. With the same assumptions used for determining the optimum value of minimum temperature difference for $400^{\circ} \mathrm{F}$ saturated water, the required area of heating surface and the power output were determined for $10^{\circ} \mathrm{F}$ minimum temperature difference at various mass ratios. The effect of mass ratio on the power output is surprisingly large, as shown by the following results:

\begin{tabular}{ccccc}
$\begin{array}{c}\text { Mass Ratio, } \\
\text { Ib } \mathrm{H}_{2} \mathrm{O} / \mathrm{lb} \\
\text { Isobutane }\end{array}$ & $\begin{array}{c}\text { Exit Temperature } \\
\text { of Water, }{ }^{\circ} \mathrm{F}\end{array}$ & $\begin{array}{c}\text { Heating Surface } \\
\text { ft } /(\mathrm{b} \text { Water } / \mathrm{hr})\end{array}$ & $\begin{array}{c}\text { Power Output, } \\
\mathrm{Mw} /\left(10^{6} 1 \mathrm{~b} \text { Water } / \mathrm{hr}\right)\end{array}$ \\
\cline { 1 - 2 } 0.70 & 142 & & 0.0970 & 10.7 \\
0.75 & 147 & & 0.0963 & 10.9 \\
0.80 & 155 & & 0.0955 & 10.8 \\
0.85 & 165 & & 0.0953 & 10.6 \\
0.90 & 172 & & 0.0952 & 10.3 \\
1.00 & 179 & 0.0940 & 9.3
\end{tabular}

The optimum mass ratio is 0.74 pounds of water per pound of isobutane. As expected, the variations of heating surface area with mass ratio are not too significant.

A similar evaluation was made for the case of water with an inlet temperature of $600^{\circ} \mathrm{F}$ and 2,000 psia throttle pressure. With $10^{\circ} \mathrm{F}$ minimum temperature difference, the mass ratio of 0.56 gives the highest power output. 
It is clear that the economy of the isobutane binary plant is dependent upon the proper selection of the minimum temperature difference in the heat exchanger and the ratio of the mass flow rates of the two fluids. Since the effects of the mass flow ratio and the minimum temperature difference upon the system performance are so great, heat balances must be carefully carried out for each situation in order to optimize the design of the system.

Up to this point, the discussion in this section has been on the temperature distribution of liquid water and isobutane in a counterflow heat exchanger. If the hot water flows to the surface without pumping, steam will flash out inside the well. For this case the heat exchanger may be divided into two sections. The first condenses the flashed steam, and the second subcools the liquid water. Figure 3.6-3 depicts the pattern of temperature distribution of 800 psia isobutane heated by $400^{\circ} \mathrm{F}$ wet saturated steam of 29.2 quality at a mass ratio of 0.43 pound of steam to one pound of isobutane. If the heat exchanger is well insulated, the following energy equations apply:

$$
\frac{1}{m}=\frac{x h_{f g}}{h_{6}-h_{5}}=\frac{h_{2}-h_{3}}{h_{5}-h_{4}}
$$

where $m$ represents pounds of wet saturated steam per pound isobutane, $x$ is the quality, $h_{f g}$ is the latent heat of vaporization, $h_{2}$ and $h_{3}$ are the specific enthalpies of liquid water, $h_{4}, h_{5}$, and $h_{6}$ are the specific enthalpies of isobutane at the respective points as shown in the diagram. At a given mass ratio, the length of 1 ine 1-2 and the slope of line 2-3 are fixed for a given state of the steam at the inlet of the heat exchanger. By moving these two lines crosswise, the two terminal temperature differences, $\Delta t_{1}$ and $\Delta t_{2}$ increase or decrease simultaneousiy. As the mass ratio changes, both the length of 1ine 1-2 and the slope of line 2-3 are subject to change so that one of the two terminal temperature differences may remain the same. Various combinations of $\Delta t_{1}$ and $\Delta t_{2}$ can be obtained by changing the mass ratio and by moving the point 1 at a given temperature level.

Efforts were made to determine the optimum temperature differences for the plants which use geothermal fluid in the form of liquid-vapor mixtures. From the point of high power output, the temperature of the fluid leaving the plant should be low, and the thermal efficiency of the cycle should be high. At a given pressure of isobutane in the heat exchanger, there is an 

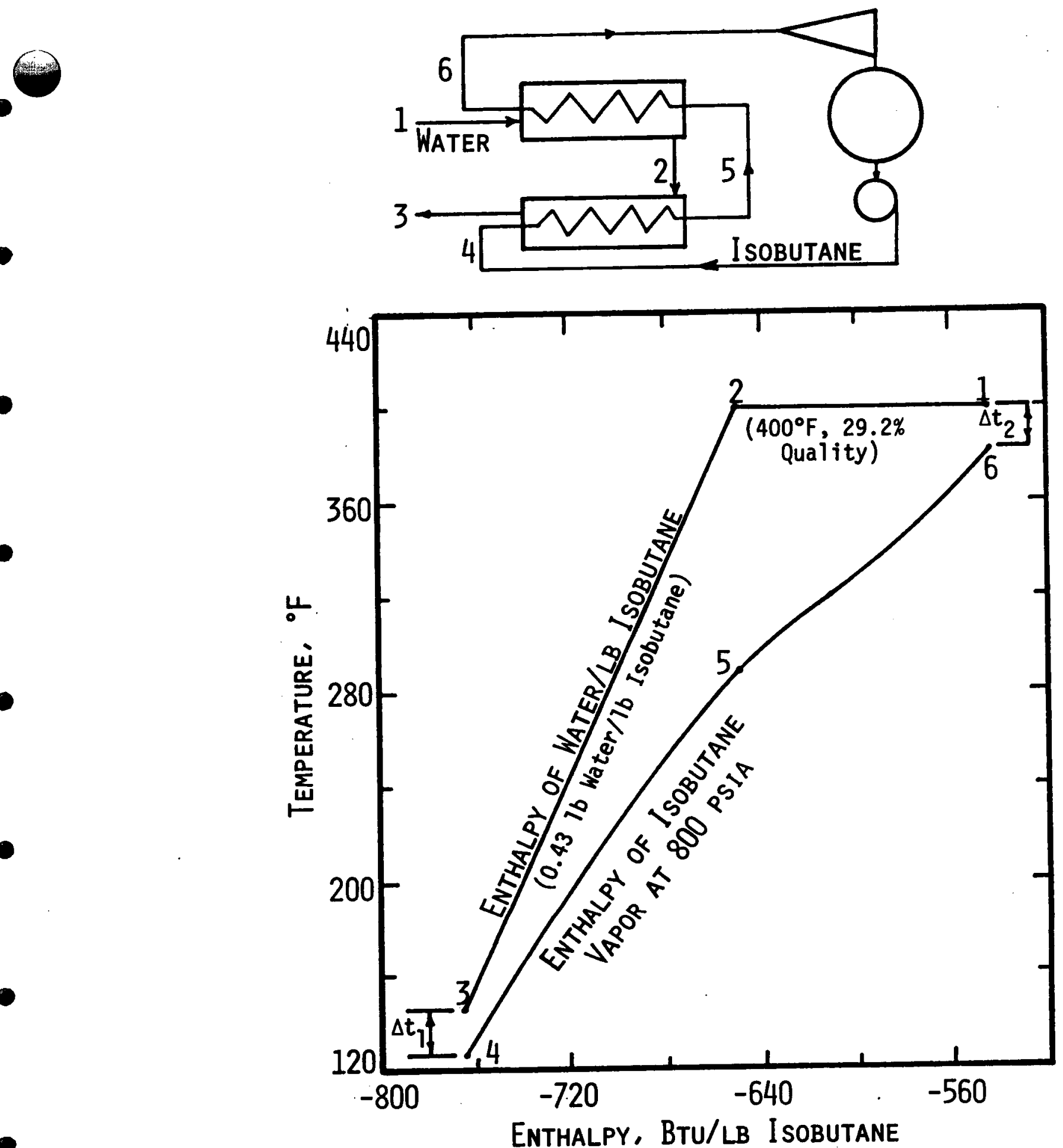

Figure 3,6-3 Temperature Distribution of Wet Saturated Steam and Isobutane in a Heat Exchanger 
optimum value of the exit temperature of isobutane for maximum efficiency. Effects of temperature distribution on the costs of the heat exchanger were found to be insignificant because of the relatively small size of heat exchanger required for transferring the heat from wet steam at a large temperature difference. As an example, calculations were performed for the following conditions:

$\begin{array}{ll}\text { Geothermal fluid } & \begin{array}{c}400^{\circ} \mathrm{F} \text { saturated steam, } \\ 29.2 \% \text { quality }\end{array} \\ \text { Isobutane pressure } & 800 \mathrm{psia} \\ \text { Condensing temperature } & 120^{\circ} \mathrm{F} \\ \text { Turbine efficiency } & 85 \% \\ \text { Pump efficiency } & 80 \% \\ \text { Heat transfer coefficient, } & 500 \mathrm{Btu} /(\mathrm{hr})\left(\mathrm{ft}^{2}\right)\left({ }^{\circ} \mathrm{F}\right) \\ \quad \text { condensing section } & 175 \mathrm{Btu} /(\mathrm{hr})\left(\mathrm{ft}^{2}\right)\left({ }^{\circ} \mathrm{F}\right) \\ \quad \text { liquid section } & \$ 1.00 / \mathrm{ft}^{2} \\ \text { Annual cost of heating surface } & 1 \% / \mathrm{kwh}^{2} \\ \text { Power cost } & \end{array}$

The trends of the annual gross revenue and the annual cost of heating surface are shown in Fig. 3.6-4. The optimum combination of the two temperature differences is around $\Delta t_{1}=10^{\circ} \mathrm{F}$ at the water exit and $\Delta t_{2}=20^{\circ} \mathrm{F}$ at the water inlet, where the mass ratio of water to isobutane is 0.43 . In another example, for steam at $312^{\circ} \mathrm{F}, 10.3 \%$ quality steam and 700 psia isobutane, the maximum power output occurs at $\Delta \mathrm{t}_{1}=10^{\circ} \mathrm{F}, \Delta \mathrm{t}_{2}=18^{\circ} \mathrm{F}$, and mass ratio $=0.48$. Obviously, work on heat balances in the developmental stage of a binary isobutane plant can help to insure high power production. For a given wellhead condition, the power output is affected by both the isobutane pressure and the temperature distribution in the heat exchanger.

3. Effects of Downhole Pump on Power Production

Pumping hot fluid out from a reservoir increases the production rate of a well, eliminates scale formation on the well surface, lessens the surface scaling in heat exchangers of a binary cycle plant, and preserves the available energy of the geothermal fluid. Several projects to develop downhole pumps are in progress. Although the future use of pumps depends upon the development of reliable pumps capable of handling hot geothermal fluids and the favorable economic analysis of a specific project, the effects of pumping on power production per unit mass of fluid can be estimated within a small uncertainty. 


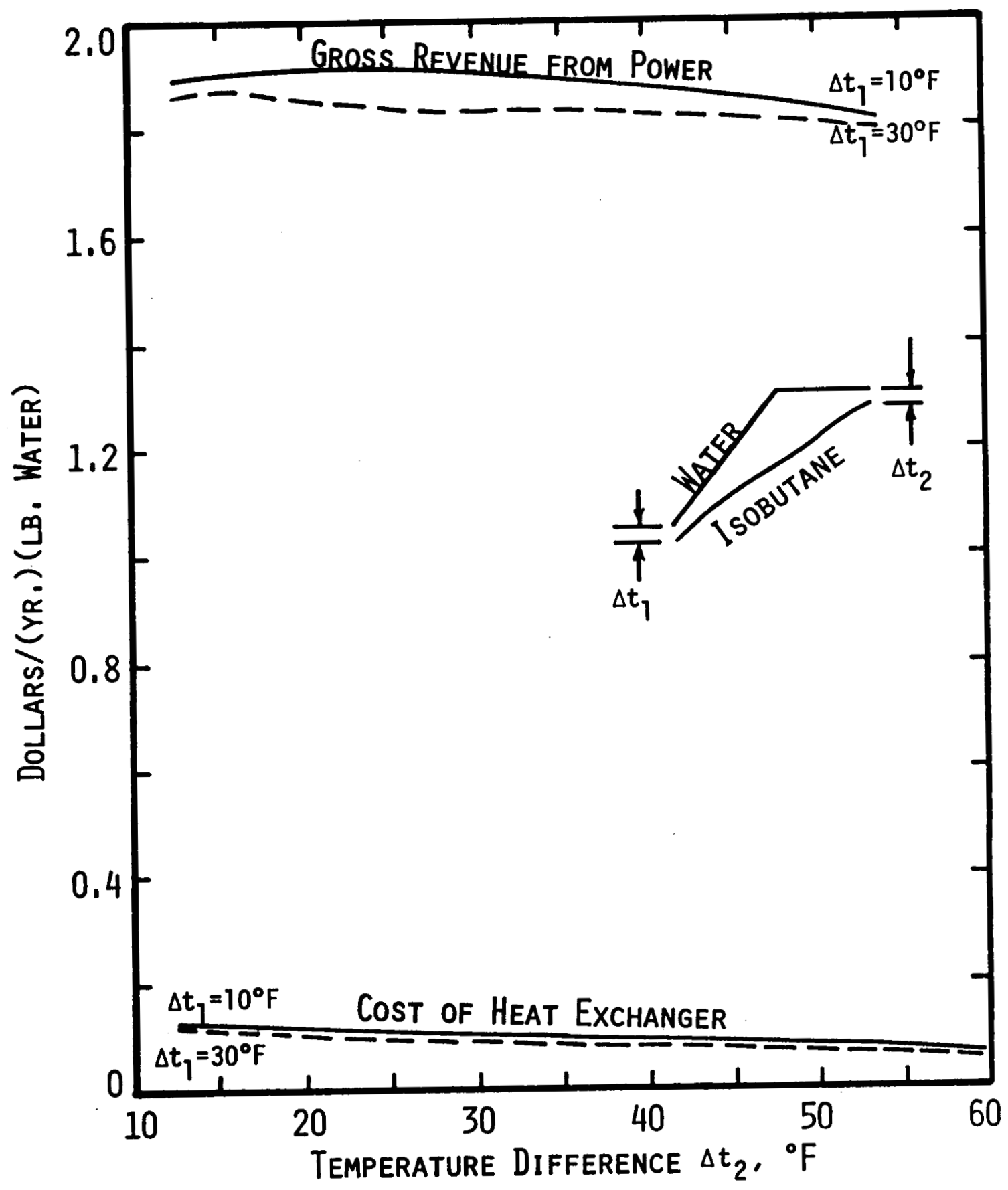

0

Figure 3,6-4 Effects of Temperature Distribution in a Wet-Steam Heat Exchanger on Costs 
The prevailing method of converting energy in geothermal fluid into power is the two-stage vapor flashing method, as illustrated in Fig. 3.6-5A. This type of plant first became operational in New Zealand and then in several other countries. The design and performance of these plants have been reported in many publications and summarized by Chou and Ahluwalia [1]. There are two other methods under serious study: the binary-fluid method with isobutane as the working fluid, and the total-flow-concept method.

To utilize the heat in the exhaust vapor from the isobutane turbine, the addition of a regenerative heat exchanger to the basic isobutane cycle has been suggested in a previous report [4]. The consequence is that the exit temperature of fluid in the main heat exchanger can be increased to such a degree that the waste heat in the effluent fluid may be used for industrial heating. Figure 3.6-5B shows another version of the modification in which a second concept was advanced by Austin, et al. at Lawrence Livermore Laboratory [5]. The idea is to expand the liquid and vapor of the wellhead fluid directly in the nozzle and impulse turbine (Fig. 3.6-5C) or in some suitable machine such as a helical rotary screw expander. A problem which has yet to be resolved is the scaling on the water side of the heating surface in a binary plant. The degree of success of the total flow concept depends upon the development of a reliable machine with higher thermal efficiency.

In a liquid-dominated reservoir, the hot geothermal fluid is in a compressed liquid state. If the hot fluid is driven out by natural forces through a well, the vapor pressure of the fluid drops due to the wall friction and the change of potential energy; thus the vapor flashes out while the temperature decreases. As a result of this transition, the available energy of the fluid decreases as it moves up. Both the flow rate and the change of available energy per unit mass of geothermal fluid are functions of vapor pressure drop. To maximize the power production, the optimum value of vapor pressure at wellhead must be determined in the early stages of plant design. For plants currently in operation, wellhead pressures are in the range of 50 to 100 psia. When reliable downhole pumps become available, the hot fluid can be pumped out without any vapor flashing. Thus, the fluid at wellhead may remain in the compressed liquid state so that its available energy can be preserved, and the flow rate is no longer restricted by the allowed drop of vapor pressure. 


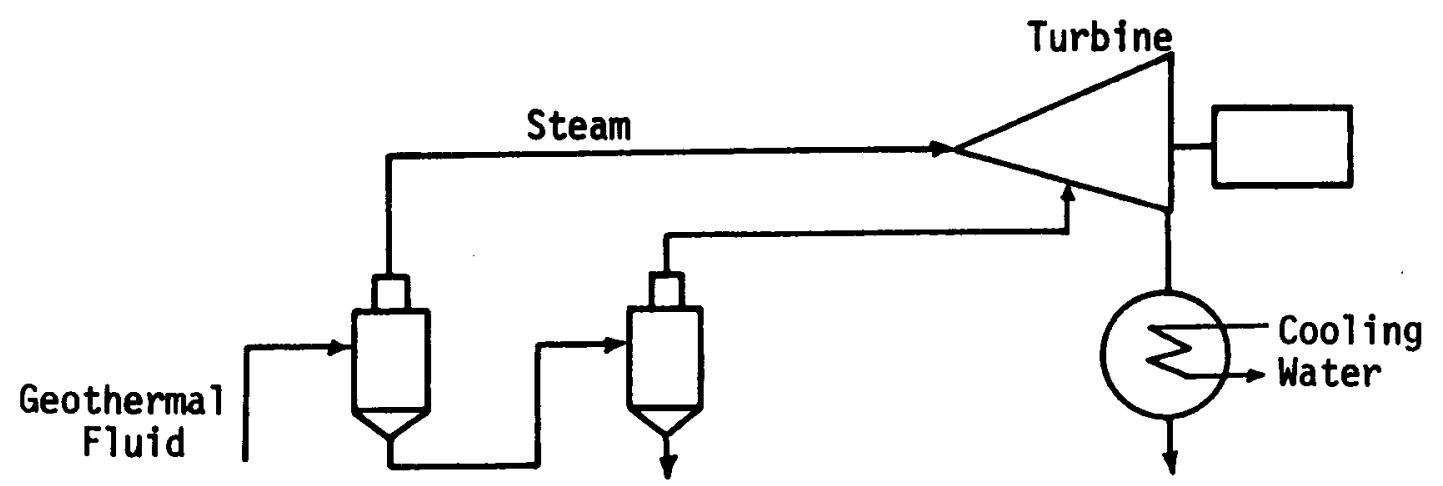

(A) Two-stage Vapor Flashing System

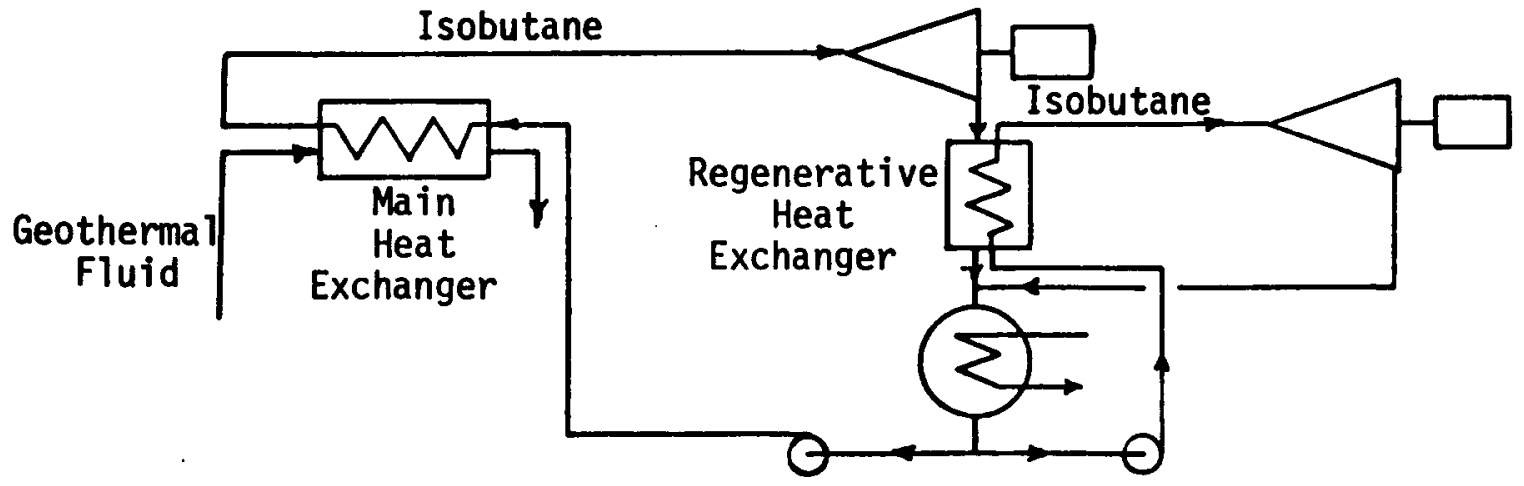

(B) Regenerative Binary System

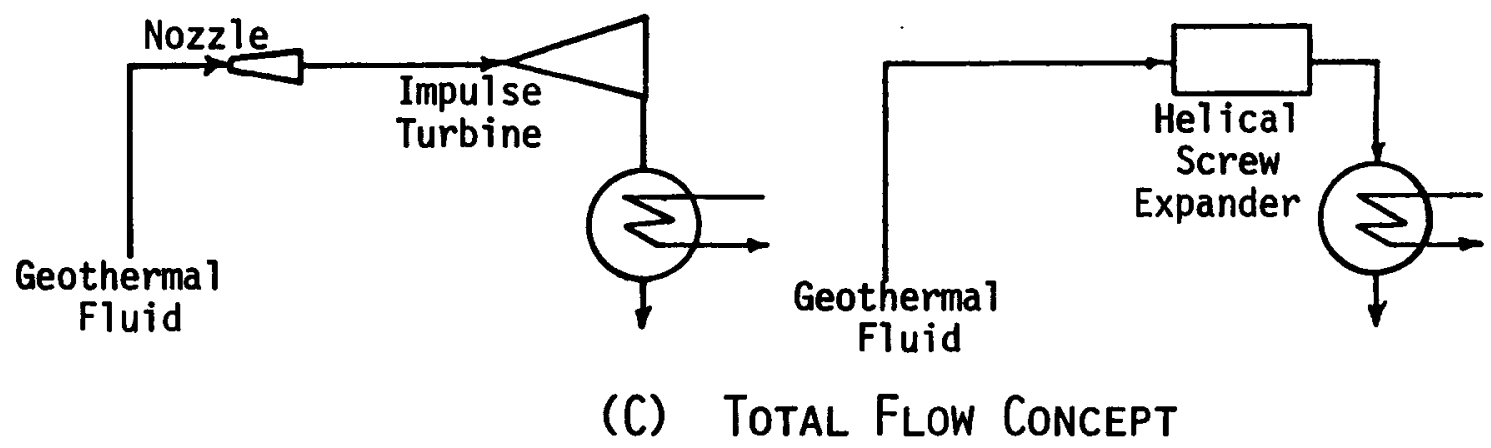

Figure 3,6-5 Methods of Converting Thermal Energy in Hot Geothermal Fluid into Useful Work 
In an actual situation, the heat content of the fluid in a reservoir is different from that at the wellhead due to the change of potential energy, the pump work, if any, and the heat loss from the well to its surroundings. However, by examining the magnitude of each term in an energy equation for a typical well; one may accept the assumption that the enthalpy of the fluid is approximately constant throughout the well. For simplicity, this assumption is used for the comparisons of power production per unit mass of geothermal fluid with or without a downhole pump in the we11. Other general assumptions on fluids are that the thermodynamic properties of geothermal fluid may be approximated by those of water, and that the pressure effects on the properties of liquid may be neglected.

Based on the information in a paper by Anderson [6], the turbine efficiencies of isobutane turbines are expected to be higher than those of steam turbines of the same ratings. For the analyses of system performances here, the efficiencies of isobutane and steam turbines are assumed to be $85 \%$ and $75 \%$, respectively. At present, manufacturers' experiences in isobutane turbines are very limited, so the cost of an experimental isobutane turbine may not be much lower than that for the steam turbine. All the performance calculations in this section are based on $120^{\circ} \mathrm{F}$ condensing temperature and 80\% pump efficiency.

The procedures used to calculate heat balances depend upon the preference of the engineer making the calculations. "For the heat balances of binary systems in this study, the first step was to select the isobutane pressure which has been optimized in terms of wellhead temperatures by trial heat balances as shown in Fig. 3.6-6. Next, the temperature distribution in the main heat exchanger was determined as outlined in the last section. As to the regenerative heat exchanger, the temperature difference at the end of the condensate inlet was assumed to be $10^{\circ} \mathrm{F}$. Under these assumptions, the work output in. kwh per 1000 pounds of geothermal fluid was calculated; the results are shown in Fig. 3.6-7. Without a downhole pump, the performance of the basic isobutane system is relatively poor. Addition of the pump can improve the performance significantly. Also, the formation of scale in the well and the heat exchanger is suppressed because the fluid is kept under pressure with the pump.

If the fluid temperature is less than $380^{\circ} \mathrm{F}$, the degree of superheat of the exhaust isobutane will be too low to justify the addition of a regenerative 


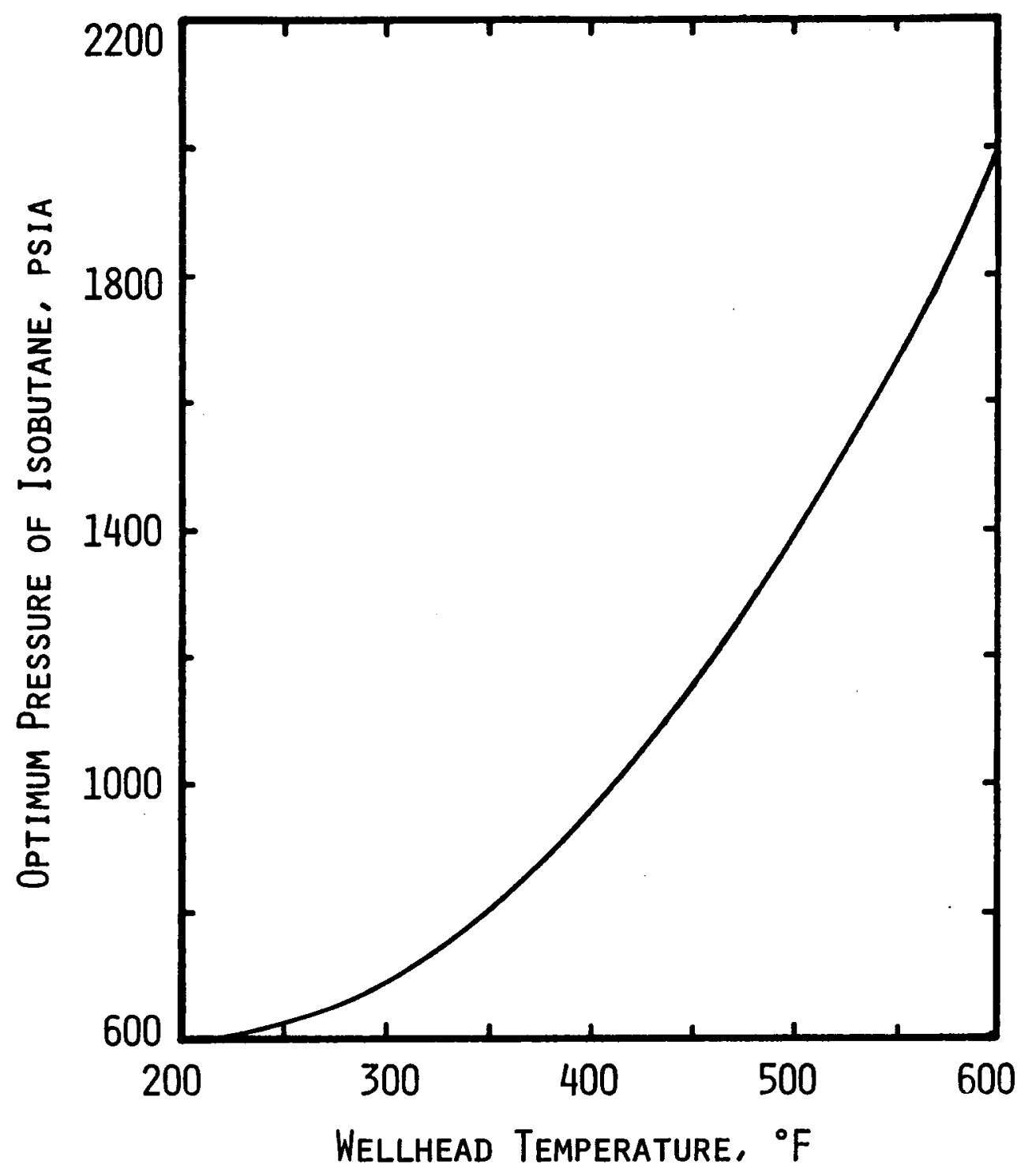

Figure 3.6-6 Optimum Pressure of Isobutane for Maximum Power OUtPut 


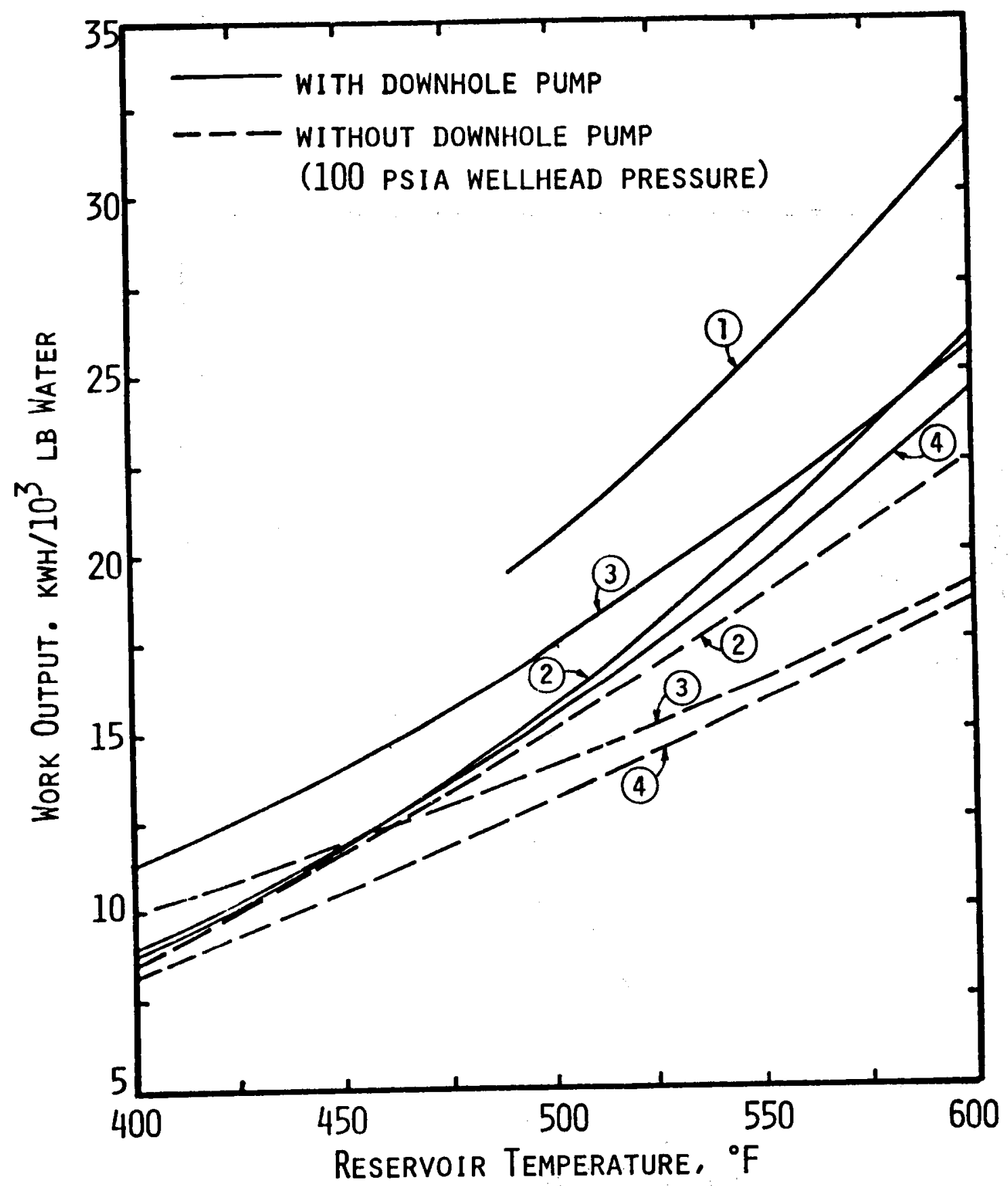

1 Regenerative Isobutane System

2 TWo-stage Vapor Flashing System

3 Basic I SOBUtANE SYSTEM

4 Total Flow Concept

Figure 3.6-7 Effects of Downhole Pump on Work Output 
heat exchanger to the binary system. When there is a demand for the lowtemperature heat in waste fluid, a regenerative isobutane system can function at a wellhead pressure around 200 psia without a downhole pump. In such a case, the work output per unit mass of fluid is almost equivalent to that by a two-stage vapor flashing system at 100 psia wellhead pressure. With fluid delivered by a downhole pump, the regenerative isobutane system yields the highest work output as illustrated by curve 1 in Fig. 3.6-7. This curve is terminated at $485^{\circ} \mathrm{F}$ reservoir temperature because the moisture content in the exhaust vapor of the second isobutane turbine exceeds the temperature limit of $12 \%$. If a suitable working fluid is selected for the second closed cycle to avoid the high moisture content in the exhaust vapor, curve 1 could be extended further down.

Figure 3.6-7 shows the comparisons of work output per unit mass of fluid at reservoir temperatures from 400 to $600^{\circ} \mathrm{F}$. The performances of total flow concepts are based on engine efficiency of $55 \%$, which is slightly above the maximum efficiency from the recent performance test of a helical screw expander at Lawrence Livermore Laboratory [5]. Through research, it is likely that the equivalent engine efficiency of the combination of nozzle and impulse turbine may greatly exceed 55\% [7]. In the performance calculations for a vapor flashing system, the temperature of vapor from the second cyclone separator is the average of the condensing temperature and the saturated temperature of fluid at wellhead. The performance of the vapor flashing system is not much improved by using a downhole pump.

4. Working Fluid Selection and Heat Exchanger Design

A parametric study was conducted of a vertical, counterflow, shell and tube heat exchanger designed for use in a $10 \mathrm{Mw}$ geothermal power plant which utilizes geothermal fluid at moderate temperatures [8]. The following conditions were used:

Geothermal fluid

Available cooling water

Efficiency of turbine-generator

Efficiency of pump

Working fluid velocity

Tube sheet
Saturated liquid water at $350^{\circ} \mathrm{F}$

$80^{\circ} \mathrm{F}$

$85 \%$

$75 \%$

$7 \mathrm{ft} / \mathrm{sec}$

1 inch diameter with tube pitch of 1.1 on a triangular arrangement 
Following a preliminary screening process, candidate working fluids were selected from two groups with similar chemical structures, isobutane as being representative of hydrocarbons, and Refrigerant- 114 from the halogenated hydrocarbons. Characteristics of the Rankine cycle and the primary heat exchanger were then determined for these two fluids.

Detailed in graphical form are the results showing how (a) the required water flow rate, (b) tube lengths, (c) number of tubes, and (d) pressure drops are affected by changes in working fluid, turbine inlet temperature, system pressure (subcritical and supercritical), and scale thickness.

In Fig. 3.6-8, for all turbine inlet pressures, the required working fluid flow rate decreased as turbine inlet temperature is increased. However, it is to be noted that the decrease is more pronounced for supercritical pressure: Figure 3.6-9 shows that a minimum water flow rate occurs at supercritical pressures for both fluids.

The minimum tube length occurs at a subcritical pressure and a turbine inlet temperature of approximately $300^{\circ} \mathrm{F}$, for both fluids. In the turbine inlet temperature range of $280-320^{\circ} \mathrm{F}$, the tube length curve for each fluid is almost flat, indicating only a slight variation of tube length with increasing turbine inlet temperature (see Fig. 3.6-10).

In terms of the amount of tube material or total heat transfer surface area required, for both fluids the subcritical pressure cycles require substantially less material (see Fig. 3.6-11). The smaller number of tubes due to lower working fluid flow rate and the shorter tube lengths account for the smaller amount of tube material.

The total she11-side pressure drop for the subcritical pressure case is approximately constant for both working fluids. However (from Fig. 3.6-12), the pressure drops for $\mathrm{R}-114$ are seen to be much larger than those for isobutane. At supercritical pressures, the total shell-side pressure drop for each fluid is lower than for subcritical pressures. The larger pressure drops for $\mathrm{R}-114$ are a result of higher density and flow rates.

To determine the effect of scale thickness on heat exchanger design and working fluid selection, a turbine inlet temperature of $280^{\circ} \mathrm{F}$ and a subcritical pressure were selected. The resulting tube lengths and shell-side pressure drops are shown in Fig. 3.6-13. 

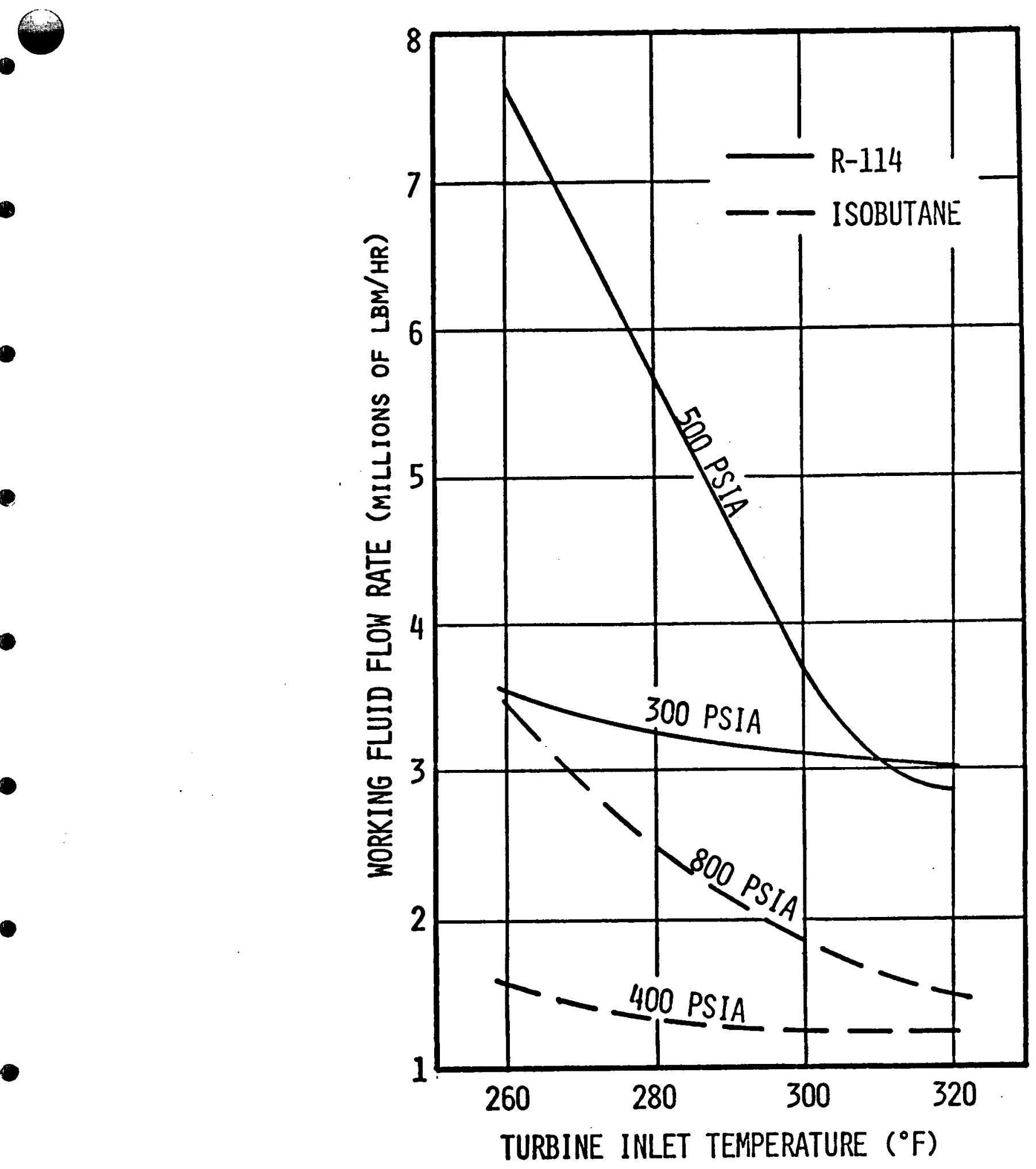

(3)

Figure 3.6-8 Influence of Turbine InLet Temperature and Pressure on Flow Rate of Working Fluid 


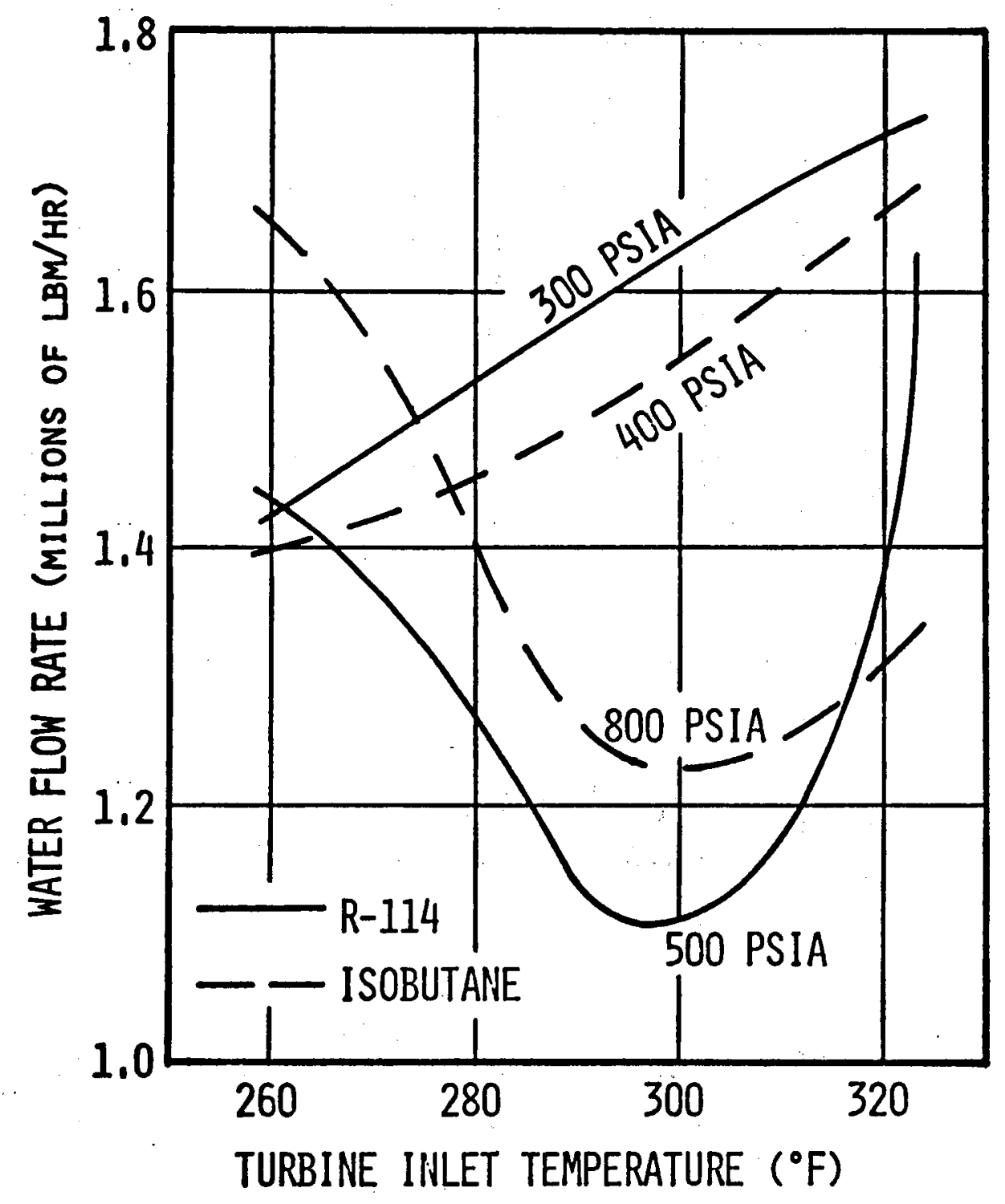

Figure 3.6-9 Influence of Working Fluid, Turbine Inlet Temperature and Pressure on flow Rate of Water 


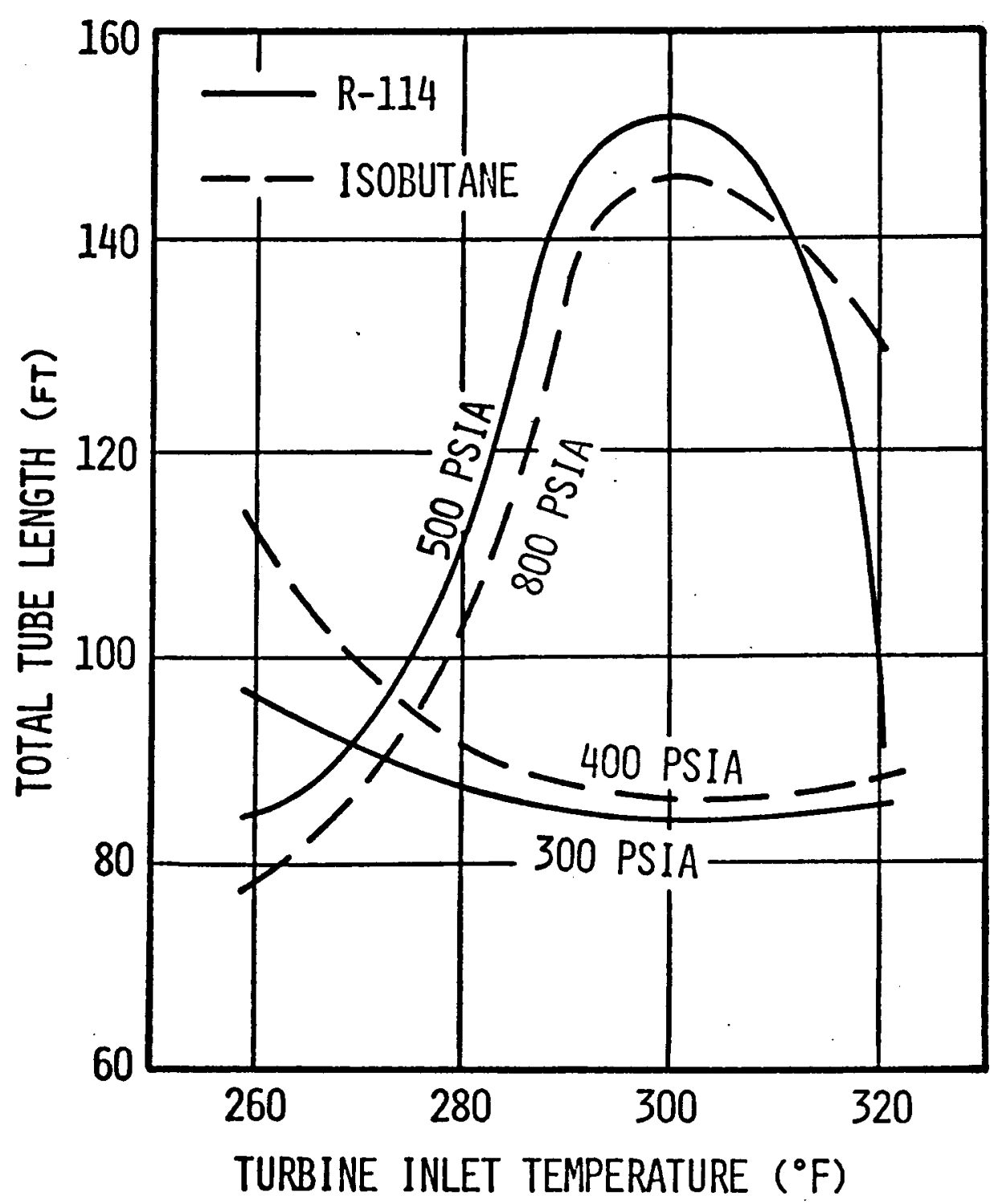

Figure 3.6-10 Influence of Horking Fluid, Turbine Inlet Temperature and Pressure on Total Tube Length 


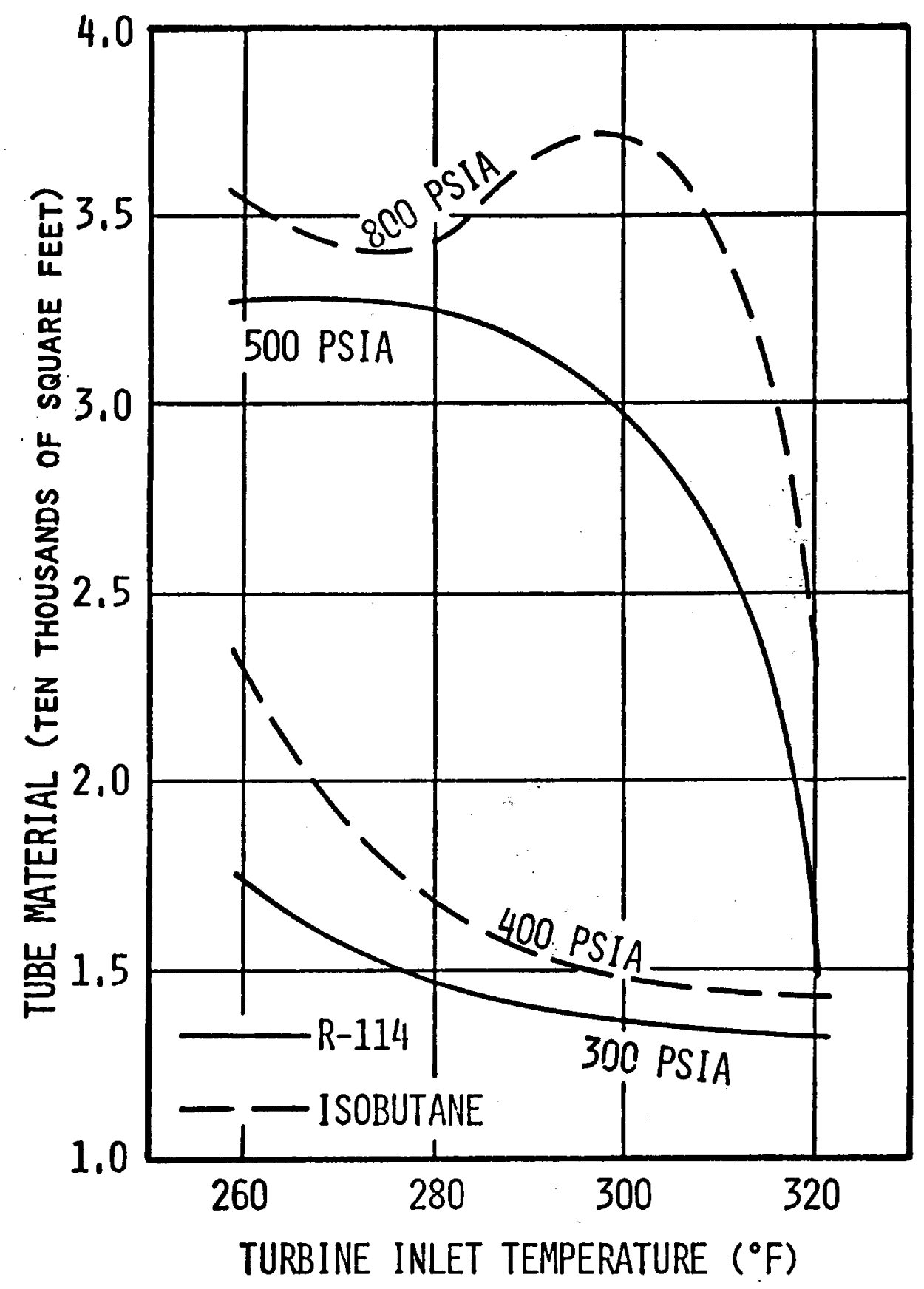

Figure 3.6-11 Influence of Horking Fluid, Turbine Inlet Temperature and Pressure on Tube Material Required 


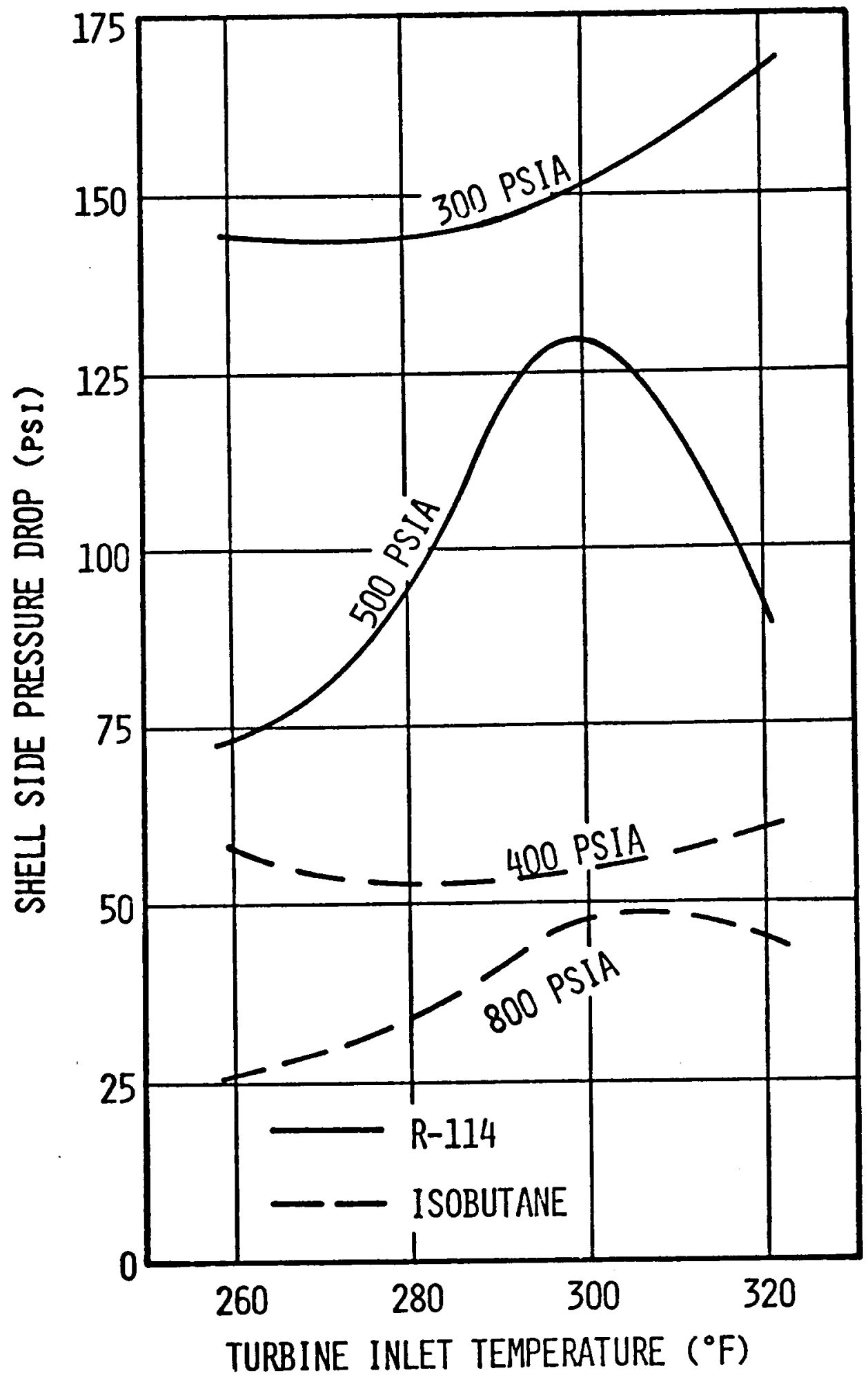

0

Figure 3,6-12 Influence of Working Fluid, Turbine Inlet Temperature and Pressure of Shell Side Pressure Drop 


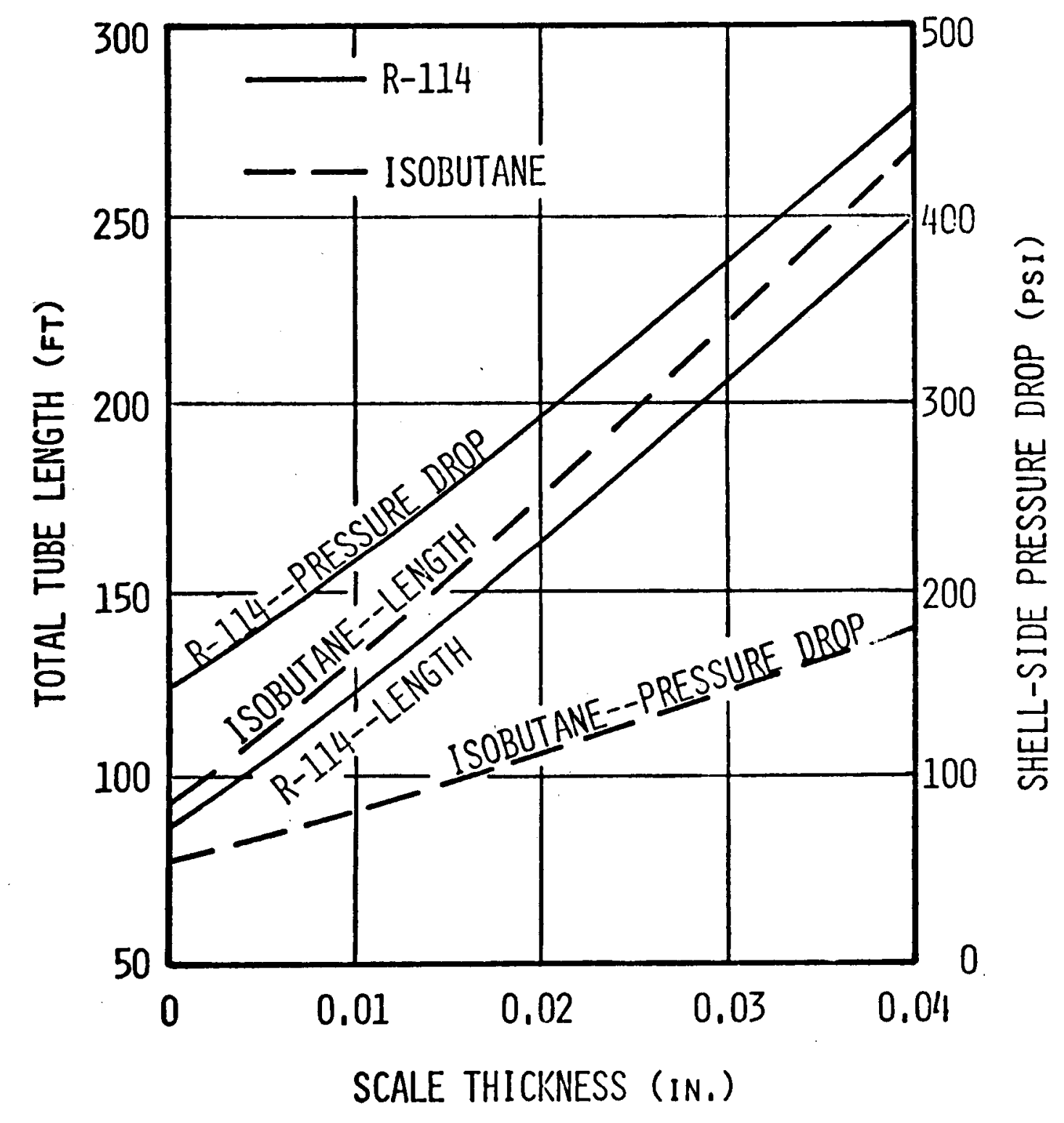

Figure 3.6-13 Influence of Scale Thickness un Total Tube Length and Shell Side Pressure Drop 
In general, this study showed that the minimum fluid flow rate for each working fluid occurred at a supercritical pressure. However, the tube lengths for these turbine inlet conditions were at a maximum. The tube lengths for the subcritical system pressures were substantially less but resulted in Targer pressure drops.

The addition of a regenerator to the organic fluid Rankine cycle increased the thermal efficiency of the cycle by decreasing the amount of heat transferred from the water. The turbine inlet conditions considered for the regenerative cycle were a turbine inlet temperature of $320^{\circ} \mathrm{F}$ and a turbine inlet pressure of 400 psia, using isobutane as the working fluid. These conditions result in highly superheated vapor at the turbine outlet and fairly short heat exchanger tube lengths.

Since the addition of a regenerator involves a second heat exchanger, the amount of tube surface area saved in the water-working fluid (primary) heat exchanger may be offset by the surface area required for the regenerator. The subcritical pressure system was chosen because of the shorter tube lengths and the highly superheated vapor at the turbine outlet.

The results of employing a shell-and-tube regenerator are shown in Table 3.6-1. Although the cycle efficiency increases by almost 25\% for the regenerative cycle, the total tube length of the primary heat exchanger is not significantly reduced. In fact, if the amount of tube material for the primary heat exchanger is considered, the non-regenerative case uses slightly less material owing to the smaller number of tubes required.

The tube length of the liquid-heating section shows the greatest decrease because of the higher mean temperatures of the water and of the isobutane. All the tube lengths decrease because the larger number of tubes required for the regenerative cycle decrease the heat transfer rate per tube.

The calculations for the regenerator assumed the vertical shell-and-tube configuration with the same average liquid isobutane velocity, inside tube diameter, tube wall thickness, and triangular tube arrangement as the primary heat exchanger. The isobutane vapor flowed in the channels while the isobutane liquid flowed in the tubes. The pitch ratio was increased to 1.4 because lower pitch ratios resulted in higher vapor pressure drops while higher pitch ratios resulted in longer tube lengths. Even at this pitch ratio, the vapor pressure drop is substantial because of the very low density of the isobutane at the condensing pressure. 
TABLE 3.6-1

THE EFFECT OF REGENERATION ON THE PRIMARY HEAT EXCHANGER CONDITIONS

\begin{tabular}{lcc}
\hline & $\begin{array}{c}\text { Without } \\
\text { Regeneration }\end{array}$ & $\begin{array}{c}\text { With } \\
\text { Regeneration }\end{array}$ \\
\hline Liquid-heating Section & 12.4 & 16.1 \\
Thermal efficiency (\%) & \\
Primary Heat Exchanger & 88.1 & 80.4 \\
Length ( $\mathrm{ft}$ ) & 443.6 & 505.9 \\
Number of tubes & 1.4 & 1.5 \\
Tube material (ft ${ }^{2} \times 10^{4}$ ) & 61.2 & 46.0 \\
Shel1-side pressure drop (psia) & \\
Regenerator & \\
Number of tubes & 149.4 \\
Tube length (ft) & 35.7 \\
Vapor pressure drop (psia) & 7.5 \\
Liquid pressure drop (psia) & \\
\hline
\end{tabular}


Although the required tube lengths are prohibitive for this type of heat exchanger, finned tubes or a compact heat exchanger could be used to increase the low vapor heat transfer coefficient and decrease the overall heat exchanger size.

\section{Experimental Test Loop for Heat Exchanger}

The design of an experimental test loop to study the heat transfer and pressure drop characteristics of Freon-11 on the outside surface of a tube bundle has been completed. The front elevation view of the loop is shown in Fig. 3.6-14. The loop is so designed that the following test parameters can be varied: heat input, fluid velocity through the bundle, inlet condition of fluid, pitch-to-diameter ratio of the heating rods, and orientation of test section. The valves are arranged in such a way that any section of the test loop can be removed for maintenance. Also, the volume and the location of the liquid receiver are such that all the Freon in the loop can be drained and stored. Initially, it was planned to insert the tube bundle in a Pyrex glass cylinder so that the flow patterns of the Freon could be observed, but this idea was dropped and stainless steel was used because of the low allowable stress of the Pyrex glass. Also, the size of the heater was reduced from the size previously reported (without changing the pitch-todiameter ratio), so that a smaller Freon pump could be used.

All the components of the loop have been received. Some of the major components received are as follows:

a. Pump for Refrigerant-11 service: $40 \mathrm{GPM}, 60$ feet total head

b. Constant voltage transformer: capacity of $13 \mathrm{KVA}$

c. Variable voltage transformers: capacities of 28.5 amperes and 30 amperes

d. Water chiller: 3-ton cooling capacity

e. Condenser: $15,000 \mathrm{Btu} / \mathrm{hr}$ capacity

f. Liquid Receiver: volume of 10 cubic feet

g. Six-channel digital indicator capable of reading temperature $0-400^{\circ} \mathrm{F}$ and flow rate $0-29 \mathrm{GPM}$, plus 4 open channels

h. Digital multi-meter (3-1/2 digits) 2 units, voltage: $0-500$ volts, current: $0-50$ amperes with shunt

i. Heaters (Incoloy heating rods): outside diameter of 0.315 inches, length of 24 inches, heating capacity of 30 watts/sq. inch 

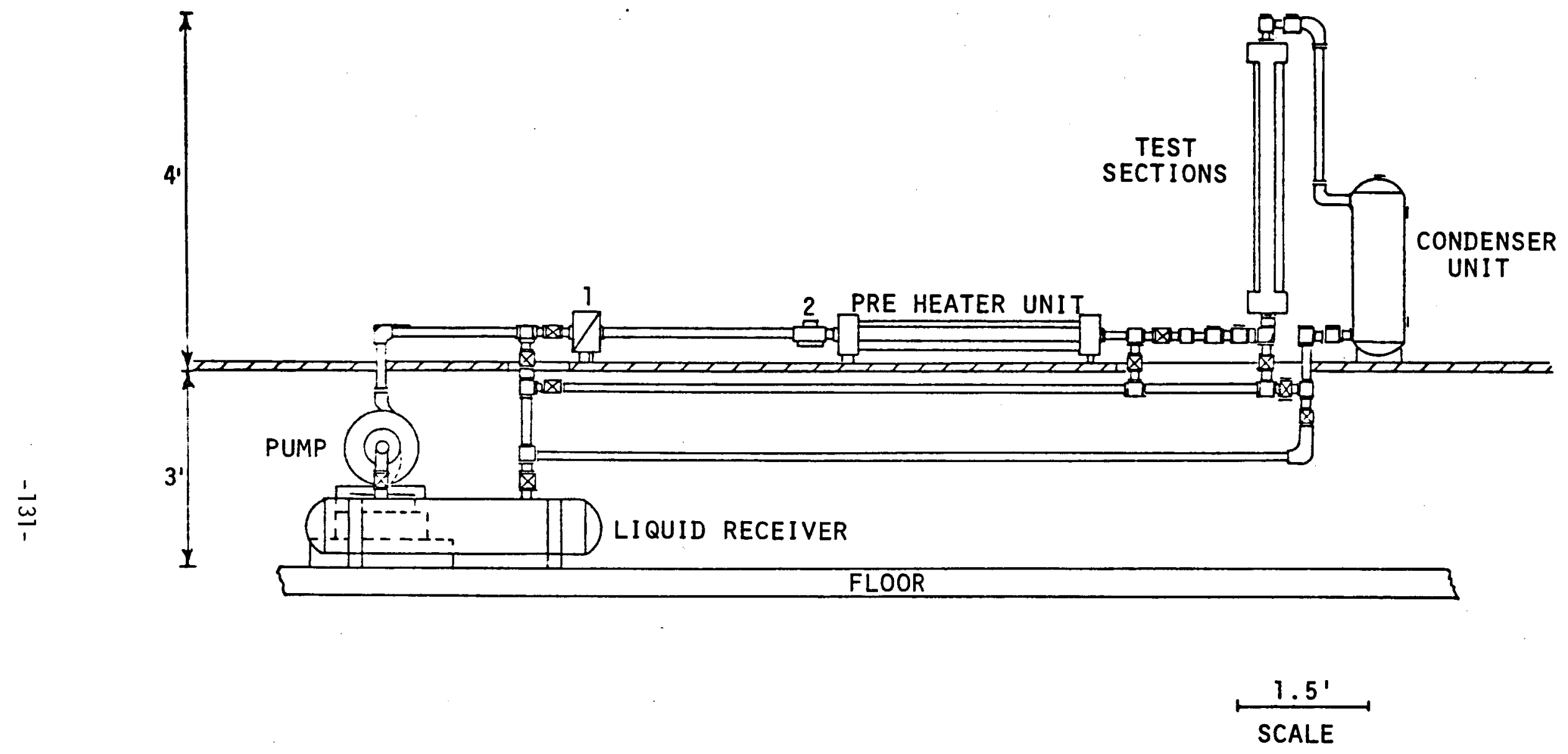
1 PRES REG
2 FLOW METER

『ALVE

D TEE

(b) FITTING ELBOW

Figure 3.6-14 Front Elevation View of Experimental Test Loop 
A11 the instruments except the direct measuring instrument for density or void fraction of two-phase flow have been procured. It appears that no reliable commercial instrument is presently available at a reasonable price. Therefore, the exit condition of the Freon will be computed from the heat input and by using a guarded heater to eliminate heat loss from the test section.

C. Future Work

During the next reporting period, the following will be undertaken:

1. Continue with the detailed design of a prototype research plant, laying out flow diagrams for the various options.

2. Complete assembly of the experimental test loop, collect and analyze test data for vertical heat exchanger.

TASK 3.6 OPTIMAL GEOTHERMAL PLANT DESIGN

\section{References}

1. Chou, J. \& R.K. Ahluwalia, "Characteristics of Vapor Flashing Geothermal Plants," Hawaii Geothermal Project, Engineering Program, Technical Report No. 6, November 1974.

2. Weiss, H., R. Steidel \& A. Lundberg, "Performance Test of a Lysholm Engine," UCRL-51861, Lawrence Livermore Laboratory, University of California, July 1975 .

3. ASHRAE, Handbook of Fundamentals, American Society of Heating, Refrigerating and Air Conditioning Engineers, Incorporated, New York, 1972, p. 629.

4. Chou, J., R.K. Ahluwalia \& E. Woo, "Regenerative Vapor Cycle with Isobutane as Working Fluid," Hawait Geothermal Project, Engineering Program, Technical Report No. 4, June 1974. Geothermics, V. 3, 1974, p. 93.

5. Austin, A.L., G.H. Higgins \& J.H. Howard, "The Total Flow Concept for Recovery of Energy from Geothermal Hot Brine Deposits," UCRL-51366, Lawrence Livermore Laboratory, University of California, April 1973.

6. Anderson, J.H., "The Vapor-Turbine Cycle for Geothermal Power Generation," Geothermal Energy, Stanford University Press, Chapter 8, 1973, p. 163.

7. Austin, A.L., "Prospects for Advances in Energy Conversion Technologies for Geotherma 1 Energy Development," UCRL-76532, Lawrence Livermore Laboratory, University of California, May 1975.

8. Kihara, D.H. \& P.S. Fukunaga, "Working Fluid Selection and Preliminary Heat Exchanger Design for a Rankine Cycle Geothermal Power Plant," presented at the 2nd U.N. Symposium on Geothermal Resources, San Francisco, Cal ifornia, May 20-29, 1975. 


\section{HAWAII GEOTHERMAL PROJECT \\ ENVIRONMENTAL-SOCIOECONOMIC PROGRAM \\ Robert M. Kamins}

SUMMARY

The objectives of the Environmental-Socioeconomic Program are:

(1) identifying the major impacts of geothermal development on the economy and society of Hawaii; (2) identifying potential legal, administrative and economic impediments to the development of geothermal resources in Hawaii; (3) identifying alternative public policies toward geothermal development in Hawai (as in defining ownership and setting regulation of the resource, in tax policies, subsidies, land use regulation); (4) ascertaining potential impacts of geothermal development on the environment, and establishing benchmarks prior to development by which to measure that impact.

As concurrent functions, the Program: (1) worked with officers of the State of Hawaii and with the landowner to obtain a right-of-entry permit for the drilling on the Island of Hawaii planned by the Project in 1975; (2) has maintained liaison with agencies of the State and County governments particularly concerned with the Project, namely the Department of the Attorney General, the State Department of Land \& Natural Resources, the State Department of Planning \& Economic Development and the Hawai County Department of Research \& DeveTopment.

Work has progressed on the following three tasks which were funded among the larger number originally proposed:

Task 4.1 Environmental

Task 4.2 Legal and Regulatory

Task 4.4 Economics

\section{TASK 4.1 ENVIRONMENTAL}

The exploratory drill site is located on a 4-acre parcel in the Puna district of Hawai, approximately 3 miles east of Pahoa and about 3 miles in from the coast. (See the attached figure) Along the road to the coast lies one of the major papaya-growing areas in the State. Aside from the papaya groves and a few homes on the subdivisions which abound on the map 


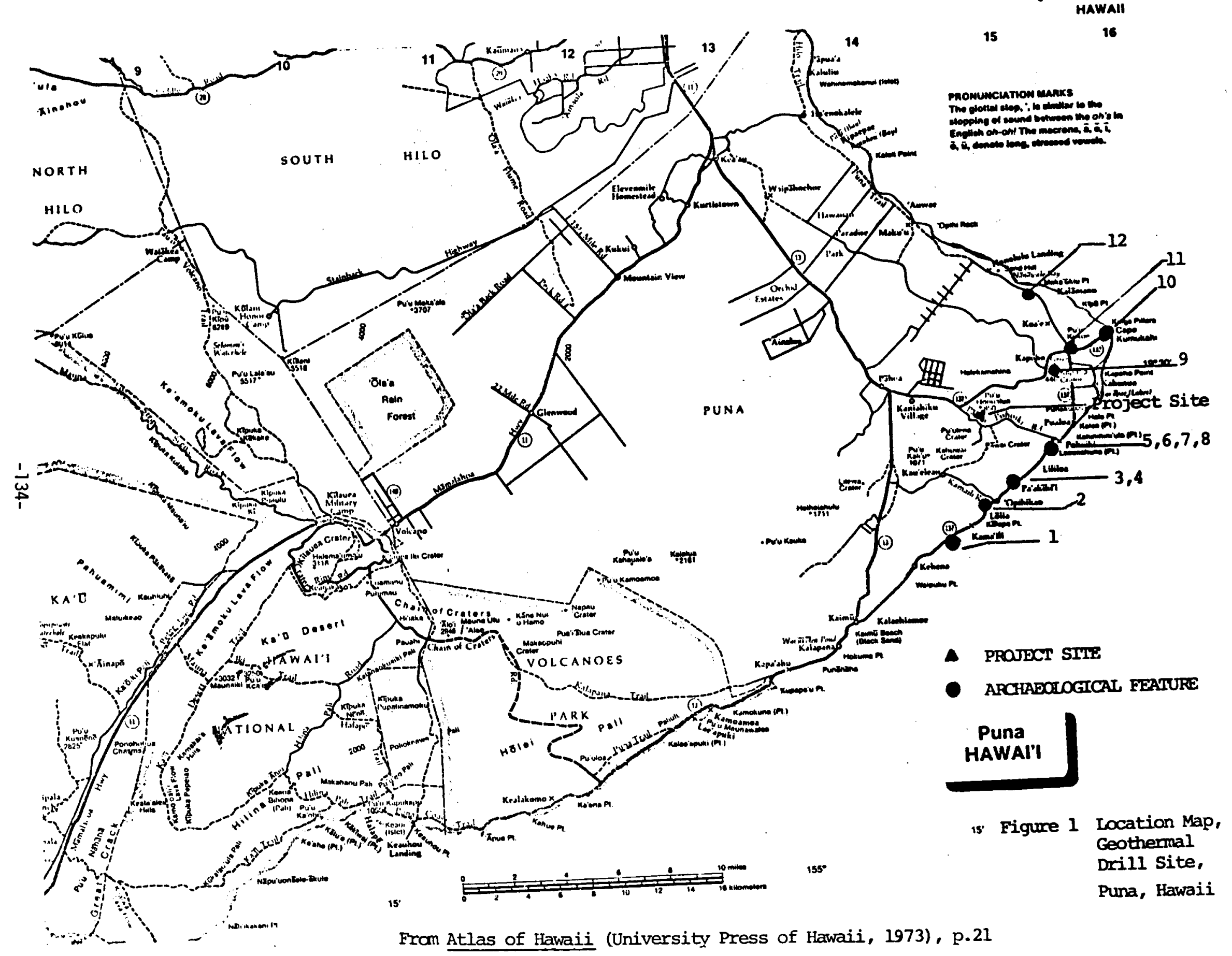


of Puna, there is yet relatively little economic development of this rift zone area. A major task of the environmental-socioeconomic program was to determine the impact of a geothermal drilling program. Because this is an exploratory we11, a formal environmental impact statement is not required; nevertheless it was understood from the beginning that a benchmark study would be made from which to determine subsequent changes in the environment which may be attributable to geothermal exploration and production.

Between June and December 1975, the primary baseline studies were completed. These covered the archeology of the area, flora, ground water and air. No important archeological sites were found within three miles of the drill site. If any such site had previously existed, they were covered by flows from the 1955 eruption of the Kilauea volcano which broke through the earth's crust approximately one-quarter mile from the drill site. By sampling, an inventory of major floral species and their density was prepared. It showed 32 species, none of them of current economic value, except as ground cover. Measurement was made for mercury, arsenic and selanium in the soil as well as in the vegetation.

The ground water was sampled in six wells and at one thermal stream entering the ocean approximately 3 miles by air from the drill site. They were checked for temperature, $\mathrm{pH}, \mathrm{Na}, \mathrm{K}, \mathrm{Ca}, \mathrm{Mg}, \mathrm{Cl}, \mathrm{HCO}_{3}, \mathrm{SO}_{4}, \mathrm{SiO}_{2}, \mathrm{NO}_{2}$, $\mathrm{NO}_{3}$, and $\mathrm{P}$. Microbiological analysis was made to record levels of coliform and fecal coliform microorganisms.

The air was sampled, and compared with samples from Hilo and the Sulphur Bank area of the Volcano National Park. Mercury was measured in all samples, since it is hypothesized that the level of element may be most affected by geothermal drilling, as has been reported in other geothermal sites.

Testing continues as the drilling goes on, to see if any of the critical factors affecting the water supply, the air, soil and plants change.

\section{TASK 4.2 LEGAL AND REGULATORY}

A. Legal Regime for Geothermal Resources and Policy for their Development The 1974 session of the Hawai $i$ legislature enacted a measure, Act 241, which defines geothermal resources as mineral, and therefore subject to 
reservations by the government of Hawaii going back to the original division of 1 ands by the King in the mid-19th century. However, our research of the land grants for the Puna district of the Island of Hawaii, site of the exploratory drilling, revealed that 419 of the land grants in the district do not have the explicit mineral reservation while 222 have the reservation. Since the grants carrying the reservation tend to be larger than those which do not, approximately $65 \%$ of the total land area in the district is owned under conditions which reserve mineral rights, now inclusive of geothermal rights, to the government, leaving $35 \%$ without such reservation. This finding is incorporated in an expanded revision of a report originally made by the Hawaii Geothermal Project in February 1974, entitled "Legal and Public Policy Setting for Geothermal Resource Development in Hawaii." The report draws upon the experience of California, and the statutes and regulations concerning geothermal development of the Western mainland states, to indicate the alternatives that are open to Hawaij in establishing a legal regime for geothermal development and a policy towards that deve lopment.

The contents of this report are already being used by the office of the Attorney General, the Department of Land \& Natural Resources, and the Department of Planning and Economic Development in preparing draft policy statements and draft bills to implement that policy, to be presented to the forthcoming 1976 Hawaij State Legislature. Alternative geothermal policies were analyzed in two papers. The first, prepared jointly with Dr. Eugene M. Grabbe of the Department of Planning and Economic Development, is entitled "State Policy Considerations for Geothermal Development in Hawaii." The second, a paper presented to the 2nd U.N. Symposium on geothermal resource development in San Francisco in May 1975, was entitled "Geothermal Development Policy for an Isolated State: The Case of Hawaij."

B. Regulation of Geothermal Production

Since Hawai i is without experience in regulating the production of either oil or minerals, the project brought in David N. Anderson, Geothermal Officer of the California Department of Conservation, as consultant to advise the State on the manner and scope of regulations which Hawai $i$ would need in the event that geothermal resources were used to generate electricity or for other commercial purposes. Mr. Anderson was later retained as 
consultant by the Department of Land and Natural Resources. He drafted a set of regulations, based on the experience of California, but with Hawaij's different circumstances in mind.

In the last months of 1975, the Department of Land and Natural Resources, utilizing the Anderson draft, prepared regulations which would govern geothermal development. The Hawaii Geothermal Project worked with the Department in defining these regulations so that they may be more effective.

C. Obtaining Use of Private Land as Site for Exploratory We11

The Hawaii Geothermal Project contacted the private owners of land identified as being the best site for exploratory drilling to ascertain their availability for this purpose. One site was already subdivided as a residential housing area and the developers were not willing to grant access for drilling. However, the immediately adjacent site, currently not in economic use, was made available and we worked with the legal officer of the University of Hawaii and the Department of the Attorney General to prepare, and then obtain agreement on, a right-of-entry permit. This permit makes the land necessary for this drilling available at the nominal payment of a dollar, and provides that in the event a commercially usable geothermal source is discovered that the conditions for exploiting the geothermal resource will be negotiated by the land owner with the State of Hawai i, if the State requires the use of the resource.

\section{TASK 4.4 ECONOMICS}

In Phase I of the Hawaii Geothermal Project, we had adopted a recently completed input-output model for the County of Hawaii to identify existing industries on the Big Island which used relatively large amounts of electricity per dollar of value added in production. These industries are potential growth elements in the island economy, if geothermal development makes electric power more abundant and cheaper. At the close of the year, we were discussing these findings with the Department of Research and Development of the County of Hawaii, to see how they fitted with their projections of economic growth to ascertain what new industries had an interest in locating on Hawai and to consider how geothermal power may affect their decisions. 
The GEOCOST computer program for geothermal cost analysis (Battelle Pacific Northwest Laboratories, 1975) was examined and found to be potentially applicable to analysis of geothermal production in Hawaij. Geothermal resource characteristics of Hawaij's first reservoir, to be obtained from the exploratory well now being drilled, were identified as preliminary to applying the GEOCOST program to the resource locally, so as to estimate the cost of producing electricity on the Island of Hawaii from geothermal resources, once these characteristics are known. From this computer program it may be possible to define, in these limits, the potential supply curve for geothermally generated electricity in Hawaii.

Our survey from the literature of geothermal resource utilization around the world (The Worldwide Electric and Nonelectric Geothermal Industry) indicates the diversity of uses of the resource and the importance of nonelectric applications, in space heating and cooling, industry, agriculture and balneology-tourism. By our estimate, approximately half of the dollar value generated by geothermal use throughout the world comes from the latter application, particularly in the spas of Japan and Europe. This information is useful in stimulating ideas for multiple-use employment of geothermal resources in Hawaii. 
HAWAII GEOTHERMAL PROJECT

DRILLING PROGRAM

Gordon A. Macdonald

TASK 5.0 MANAGEMENT AND SUPPORT

Introduction

In accordance with "Hawai i Geothermal Project - Phase II, Revision to Proposal AER7500285-000", pp. 5-1 to 5-13, selection of a site for exploratory drilling was restricted to the east rift zone of Kilauea Volcano, in the Puna District of the Island of Hawaii. The site selection and operations committee consisted of:

Agatin T. Abbott, Chairman, Co-Principal Investigator and Director of Exploratory Drilling, University of Hawaii

Pow-foong Fan - Geochemistry, University of Hawai $i$

Augustine S. Furumoto - Geophysics, University of Hawai

Gordon A. Macdonald - Geology, University of Hawaii

Donald W. Peterson - Geology, U.S. Geological Survey

Robert I. Tilling - Geochemistry, U.S. Geological Survey

Charles Zablocki - Geophysics, U.S. Geological Survey

The Cormittee considered at length all of the geophysical, geological, hydrological, thermal, and geochemical evidence, and concluded that the most favorable site is on the Pahoa self-potential anomaly (Fig. 8, p. 2-27, Reference 1). This was in accord with the recommendation of $A$. S. Furumoto, the Co-Principal Investigator for the Geophysics Program, as stated on page 2-52 of Reference 1. Furumoto later revised his opinion to favor the Opihikao anomaly (Figure 9, p. 2-28 of Reference 1), but the rest of the Committee was unanimous in favoring the Pahoa anomaly, on the basis of the self-potential field and evidence other than geophysical. Geochemical evidence, and water temperatures in existing wells particularly favor the Pahoa site, especially when the hydrology of the area is taken into consideration.

Because it was impossible to get permission from land owners to drill at Site 1 on the Pahoa anomaly (Figure 5-3 of Reference 1), the drilling site was shifted northeastward to the only slightly less favorable Site 2 (Figure 5-3 of Reference 1), where permission to drill was granted by the Kapoho Land and Development Co. The site is just under 600 feet altitude, approximately 200 feet north of the Pohoiki Bay Road, 0.6 mile southwest of the prehistoric cone of Puu Honuaula, and 0.23 mile south of the first vents 
of the 1955 eruption. A. T. Abbott placed a stake in the ground at the site early in May, 1975.

Shortly after the site was selected, Dr. Abbott was forced by $i 11$ health to withdraw from active participation in the project, though remaining in an advisory capacity, and Principal Investigator Dean John $W$. Shupe requested G. A. Macdonald to take over Dr. Abbott's duties. It was expected that the takeover would be temporary, until Abbott was able to resume the work; but on July 31 Dr. Abbott died, and Macdonaid's assignment became permanent. Macdonald was selected because of his long (36 years) experience in Hawaiian geology and ground-water hydrology, and because he was on sabbatical leave and hence temporarily free of teaching duties.

Specifications for the drill hole were drawn up by Abbott, and invitations to bid on the job were sent out to 28 drilling companies, in addition to general advertising, in early June. Nevertheless, there was only a single bidder, Water Resources International, Inc., of Honolulu. The company is the only one in Hawaij with drilling equipment large enough to handle the job. Several companies in conterminous united States replied that it would not be worth their while to ship a drilling rig to Hawai to dritl a single hole, and hence they did not bid.

Drill ing Management

Since no one at the University of Hawaii had any extensive recent experience with deep-hole drilling, particularly in a geothermal environment, it was decided to hire a drilling management firm. During the summer Kingston, Reynolds, Thom, and Allardice, Ltd., of Auckland, New Zealand, was selected to handle the technicalities of the drilling, the scientific aspects remaining under Macdonald. KRTA has had extensive experience in the New Zealand geothermal fields, and also in the Philippines, Chile, and Central America. Warwick J. Tracey was named the company's representative on the job, and the general drilling program was set up directly by $R$. Kingston.

\section{Reference}

1. "Hawai Geothermal Project - Phase II, Revision to Proposal AER7500285-000". 
TASK 5.1 DRILLING

\section{Drilling Program}

On the basis of discussion with the representatives of the drilling company, and the Co-Principal Investigators of the Hawaii Geothermal Project, utilizing Hawaian drilling experience and knowledge of Hawaiian geology and hydrology, as well as experience in geothermal drilling in other parts of the world, Mr. Kingston drew up the drilling program. The following casing program was decided upon, with minor alterations in the size of casing permitted according to the availability of materials:

$\begin{array}{ll}\text { Conductor pipe }-30 \text {-inch } & \text { to } 12 \text { feet } \\ \text { Surface casing }-20 \text {-inch } & \text { to } 400 \text { feet } \\ \text { Anchor casing }-133 / 8 \text {-inch } & \text { to } 1000 \text { feet } \\ \text { Production casing }-95 / 8-i n c h & \text { to } 2500 \text { feet } \\ \text { Liner }-75 / 8 \text {-inch } & \text { to } 6000 \text { feet or to } \\ & \text { termination depth. }\end{array}$

Because of the labor situation, the driller planned to work 10 days around the clock, followed by a 4-day shut-down period, except when drilling conditions required continuous operations.

Due to the very high permeability of many Hawaiian stratigraphic units, return circulation of drilling mud carrying cuttings back to the surface is very difficult to achieve. Every effort is being made to get returns, using various additives in the mud, such as cellophane chips and cottonseed hulls.

Because continuous coring would be prohibitively expensive, it was decided to core only when it is necessary to withdraw the tools from the hole to change the drilling bit, with additional coring whenever the University geologist considers that it is indicated, either by cuttings in the return fluid or by a radical change in the drilling rate. Below sea level the drilling rate will be watched closely for any possible indication of a thick tuff or hyaloclastite mass interbedded with the laval flows.

Down-hole testing during drilling will consist of water sampling and temperature measurements at various depths, and geophysical logging. It is planned to utilize the 4-day shut-down periods for temperature measurements, a temperature log being run as short a time as possible before the resumption on drilling to allow the maximum amount of time for the hole to recover from the effects of injection of cold drilling fluid. 



\section{APPENDIX I}

Summary of Drilling Progress

Drilling from December 10 to December 23, 1975

The drilling contract was approved by ERDA and the State of Hawaij in late November. The drilling site had been prepared in late September, using funds made available by the Hawai ian Electric Co., and mobilization of drilling equipment started in early 0ctober, on the responsibility of the drilling company. The drilling site was dedicated on November 22. By early December mobilization was essentially complete.

Drilling commenced on December 10, using a Spencer-Harris model 7000 drilling rig, and a $97 / 8$-inch tri-cone rock bit. On that day drilling was for $91 / 2$ hours only, while the remaining "bugs" were gotten out of the equipment, and only 2 feet of hole was made. Drilling was exceedingly hard, in dense fresh basalt lava-flow rock. The slowness of the drilling was due partly to the hardness of the rock, and partly to the fact that only limited weight could be put on the bit, because of a tendency for the hole to deviate from the vertical if a greater pressure was applied.

Drilling went onto a 24-hour basis on December 11. From 7:30 a.m. on that day to $8 \mathrm{a} . \mathrm{m}$. On December 12 the hole was drilled an additional 21 feet. Drilling continued mostly in very hard basalt, with limited weight on the bit. Complete return circulation of drilling fluid was attained for the first 10 feet below the cellar floor (22 feet below ground surface). At 11 feet circulation was lost on entering a thin zone of aa clinker, but was regained by increasing the density of the drilling mud. Circulation continued until the hole entered another zone of aa clinker at 17 feet, then was lost completely again. On December 16 approximately 50 bags of Gelflake, mica flakes, and cotton-seed hulls were dumped down the hole, and partial return of circulation was attained. This condition continued until the hole reached a depth of 393 feet, on December 18. The depths at noon on successive days (below the rotary table) were as follows:

$$
\begin{array}{cr}
\text { December } & 13-59 \text { feet } \\
\text { " } & 14-114 \text { feet } \\
" & 15-189 \text { feet } \\
" & 16-209 \text { feet } \\
" \quad 17-304 \text { feet } \\
" \quad 18-393 \text { feet }
\end{array}
$$


Throughout the entire depth the rock was medium to dark gray basalt lava, largely aa, with alternating dense zones and clinkery zones a few feet in thickness.

At noon on December 16 the bottom of the hole was 209 feet below the rotary table (192 feet below ground surface). That depth was reached at about 9 a.m., when drilling was stopped and the tools started coming out of the hole to change drilling bits. The bit was completely worn out, with hardly any sign of teeth left. The bit was replaced with a carbide-tipped bit with journal bearings. The slow drilling during this period was due in part to the hardness of the rock, but also to a large degree to the small amount of weight that could be put on the bit.

On December 18, with the hole at a depth of 393 feet, the driller commenced opening out the hole to a diameter of 26 inches, in preparation for setting the 20-inch casing. The work commenced using a $151 / 2-i n c h$ hole opener, to be followed by 20-inch and 26-inch openers. The hole-opening process continued until the end of drilling at $8 \mathrm{a} . \mathrm{m}$. On December 23 , when operations were shut down for the holiday season, to resume on January 5 , 1976.

Drilling from January 1 to January 15,1976

By the end of the holiday shut-down period anchors for the guy lines to the drilling mast had been set, the electric logging equipment had been delivered, and valves had been installed in the mud lines so that drilling mud can now be mixed without stopping the drilling. Delivery of the valves had been delayed by the airline strike.

Work resumed at $8 \mathrm{a} . \mathrm{m}$. on January 5 , as scheduled. Mixing new mud and general preparations took until 4:30 p.m., when drilling was resumed, using a $97 / 8$-inch bit. At the time of the pre-Christmas shutdown the bottom of the $97 / 8$-inch hole was at 390 feet BRT, and at 8 a.m. on January 6 the hole had reached 456 feet--the terminal depth before the 20-inch casing is set (at 400 feet).

Because the hole was in an appropriate condition, and the tools had to be withdrawn, it was decided to take a core. Coring started at 456 feet. At 458.6 feet the bit entered a small cavity in the rock and jammed. Because it was believed that good core recovery had been achieved to that point, it was decided to terminate the core run, and the tools were 
withdrawn. The core consisted of 27 inches of hard fresh dense to moderately vesicular medium gray basalt with scattered phenoscrysts of olivine and feldspar mostly less than $1 \mathrm{~mm}$ across, similar to many of the tholeiitic basalt lavas of Kilauea Volcano. Core recovery was 86 percent, and coring time for the 2.6-foot run was approximately 4 hours (not including the time used in going into and coming out of the hole, which was approximately 6 hours).

Opening of the hole to $151 / 2$ inches was resumed at approximately 10 p.m., at a depth of 300 feet (where the opening had ended before the holiday shutdown). By noon on January 7 only 3 feet of new opening had been made, in very hard rock. At noon on January 8 the $151 / 2$-inch hole had reached 347 feet, and by 4 p.m. on January 9 it had reached 401 feet. Opening of the hole to 20 inches started at $10 \mathrm{p} . \mathrm{m}$. on January 9 , and continued until January 15. At 11 a.m. on January 15 the 20-inch hole had reached 401 feet, and operations were shut down until January 19.

Drilling from January 19 to February 8, 1976

After the four-day shut-down period, hole opening was resumed on January 19. At 10:30 a.m. on January 28 the 26-inch hole reached 407 feet below the rotary table. The rest of January 28 and January 29 was used in reaming the hole. On the morning of January 30 the contractor began running the 20-inch casing into the hole, but it stuck at 100 feet BRT. The casing was withdrawn, and a reaming shoe was welded onto it. Running casing was resumed, using the reaming shoe, and the casing reached 400 feet successfully.

On January 31 cementing of the casing was begun, pumping the cement down inside the casing. A total of 87 tons of cement was used--300 percent more than the calculated amount necessary to completely fill the annulus between the casing and the country rock. The cement rose in the annulus, but did not reach the surface. At the end of the night shift operations were shut down for two days.

Work resumed at $8 \mathrm{a} . \mathrm{m}$. on February 3. Probing showed that the cement had risen in the annulus to 54.5 feet BRT (at the same very permeable zone in which circulation had been lost during the original drilling). Additional cement was tremied into the annulus to fill it to the level of the cellar floor. Drilling was then resumed, using the $97 / 8$-inch carbide-tipped rock bit. 
Drilling progress was much faster after the 400 -foot surface casing was set and the blow-out preventors installed. This has been partly because of softer rock, but also partly because it was possible to put more weight on the bit owing to the longer string of drilling tools. At 1 p.m. on February 7 the $97 / 8$-inch hole reached 1,057 feet BRT. During the interval between 450 and 1,057 feet the drilling rate ranged from 4 feet to 45 feet per hour, and averaged more than 150 feet per day.

Loss of drilling fluid continued high, and large amounts of loss materials, principally Gelflake and cotton-seed hulls, were used in an effort to reduce the loss and to establish circulation. The effort was largely successful, and return circulation existed, albeit intermittently, throughout the period. Through most of the interval cutting samples were obtained every 10 feet. The cuttings were almost entirely of vesicular basalt pahoehoe, though a little denser material and a few bits of red cinder are present in some samples. Tiny bits of moderately coarse-grained gabbro are probably from one or more inclusions in the basalt, and are common in flows exposed on the surface in the nearby area. The section penetrated consists largely of thin-bedded pahoehoe lava flows. Occasional drops of the drilling tools of a few inches were caused by small open spaces--tubes, inter-flow spaces, or blisters--in the pahoehoe. Such cavities would also account for the occasional abrupt losses, amounting to as much as 2,000 gallons, of drilling fluid.

At 1,057 feet driliing of new hole stopped, and the hole was cleaned out in preparation for taking a core. Running the core barrel into the hole started on the morning of February 7 , but the bit encountered an obstruction at 937 feet. A rock fragment from its wall apparently had tumbled into the hole, blocking it. To take the core, it would have been necessary to reenter the hole with the $97 / 8$-inch rock bit and clean out the hole, then go back in with the core bit. However, there would have remained the possibility of further caving of the hole, possibly sticking either the rock bit or the core bit. It was therefore decided to start opening the hole to 20 inches down to 1,000 feet to take the next casing string, and delay taking the core until after the casing is in place and cemented, eliminating the possibility of further caving from that portion 
of the hole. Hole opening to $151 / 2$ inches started on the evening of February 7 and continued through February 8 . This will be followed by opening to 20 inches to take the casing.

Between 1,000 and 1,057 feet drilling was very rough, and on pulling the tools out of the hole it was found that the bit had started to lose teeth. It will be necessary to replace it on resumption of drilling the $97 / 8$-inch hole. This carbide-tipped rock bit has been used to drill the $97 / 8$-inch hole from 209 feet to 1,057 feet--a total run of nearly 850 feet, as compared with approximately 200 feet for the ordinary rock bit.

When the casing is in place, it is planned to clean out the pilot hole and make a core run before regular drilling is resumed. 

0

0

默

0 